\title{
Pedro Rodrigues Genta
}

\section{Validação da medida da pressão crítica de fechamento da faringe durante $o$ sono induzido}

Tese apresentada à Faculdade de M edicina da Universidade de São Paulo para obtenção do título de Doutor em Ciências

Programa de: Pneumologia Orientador: Prof.Dr. Geraldo Lorenzi Filho

São Paulo 


\title{
Dados Internacionais de Catalogação na Publicação (CIP)
}

\author{
Preparada pela Biblioteca da
}

Faculdade de Medicina da Universidade de São Paulo

Genta, Pedro Rodrigues

Validação da medida da pressão crítica de fechamento da faringe durante o sono induzido / Pedro Rodrigues Genta. -- São Paulo, 2010.

Tese(doutorado)--Faculdade de Medicina da Universidade de São Paulo. Programa de Pneumologia.

Orientador: Geraldo Lorenzi Filho.

Descritores: 1.Apnéia do sono tipo obstrutiva/fisiopatologia 2.Pressão crítica de fechamento da faringe 3.Faringe/efeitos de drogas 4.Faringe/fisiopatologia 5.Faringe/anatomia \& histologia 6.Midazolam 7.Sedação consciente 8.Tomografia computadorizada por raios $\mathrm{X}$

USP/FM/DBD-520/10 


\section{Dedicatória}

Ao meu Pai, Dr. Edison Norbert Genta, quem me despertou para esta profissão e para a curiosidade científica. Com quem tive o prazer de trabalhar durante a iniciação científica no laboratório de Nutrição Humana e Doenças Metabólicas chefiado pelo Prof. Aurélio Borelli e até hoje no Grupo de Apoio Clínico. Minha admiração pelo seu caráter. M eu muito obrigado por todos os ensinamentos na M edicina e na Vida.

À minha Mãe Marly Rodrigues Genta. Sua dedicação, humildade e espiritualidade serão sempre para mim exemplo e inspiração. Muito obrigado pelo apoio incondicional durante todos esses anos.

À Maria Luiza, minha esposa e melhor amiga, mãe dos três frutos mais bonitos de minha vida. Obrigado pela compreensão e incentivo em todos os momentos.

Aos queridos Felipe, Luiza e Julia. Apesar de não recompensar os momentos de ausência, dedico este trabalho a vocês. 


\section{Agradecimentos}

Ao Prof. Dr. Geraldo Lorenzi Filho, quem me atraiu para a Medicina do Sono. Sua liderança é fruto da simplicidade com que trata a todos e da demonstração do prazer que tem em ensinar. Obrigado pelo convívio e pela oportunidade, apoio e incentivo no desenvolvimento deste projeto.

Ao Prof.Dr. Francisco Vargas, quem promoveu grandes conquistas à Disciplina de Pneumologia, entre as quais uma Pós-Graduação de excelência. Sou muito grato à confiança em mim depositada desde a Residência M édica.

Aos Prof.Dr. Mário Terra Filho e Prof.Dr.Rogério de Souza, pela oportunidade participar, como aluno, do programa de Pós-Graduação em Pneumologia, o qual tem se destacado pelo alto nível de seus resultados.

À enfermeira Naury de Jesus Danzi, sempre disponível, se empenhou em solucionar os obstáculos.

Ao Dr. Marcelo Gervilla Gregório, pelo auxílio no protocolo de indução do sono. 
Às Dra. Eloisa Gebrim e Dra. Ula Passos, pela contribuição indispensável na aquisição e interpretação das imagens de tomografia.

À Dra. Amanda Lopes, pelo auxílio nas medidas cefalométricas.

Ao Engenheiro Henrique Takachi Moriya e ao seu aluno de graduação Marcelo Cirelli, pelo auxílio no desenvolvimento do software de análise dos dados de fluxo e pressão.

Ao Danny Eckert, fisiologista do laboratório do sono do Brigham and Women's Hospital, pela amizade, disponibilidade, acolhimento e incentivo.

Ao Prof.Dr.Atul Malhotra, diretor do laboratório do sono do Brigham and Women's Hospital, pela oportunidade incondicional de estudar a técnica de determinação da colapsabilidade da faringe.

Aos técnicos de polissonografia Fabio Kleber Hilario e Ana Cristina Muriel, muito obrigado pelo apoio.

Aos pós-graduandos e colegas do laboratório do sono do InCor pela paciência e colaboração. 
Aos voluntários que participaram deste protocolo, pacientes na expressão máxima da palavra. Empolgados em poder contribuir, verdadeiros co-autores deste estudo. 
Esta tese está de acordo com as seguintes normas:

Referências: adaptado de International Committee of Medical Journals Editors (Vancouver)

Universidade de São Paulo. Faculdade de M edicina. Serviço de Biblioteca e

Documentação. Guia de apresentação de dissertações, teses e monografias.

Elaborado por Anneliese Carneiro da Cunha, M aria Julia de A. L. Freddi, Maria F. Crestana, Marinalva de Souza Aragão, Suely Campos Cardoso, Valéria Vilhena.

2a ed. São Paulo: Serviço de Biblioteca e Documentação; 2005. 


\section{Sumário}

Lista de abreviaturas

Listas de tabelas

Lista de figuras

Resumo

Summary

1 Introdução Pág. 1

1.1 Apnéia obstrutiva do sono Pág. 2

1.2 Epidemiologia. Pág. 5

1.2.1 Etnia Pág. 6

1.3 Tratamento Pág. 8

1.4 Fisiopatologia...............................................................................Pág. 8

1.4.1 Anatomia das vias aéreas superiores Pág. 9

1.4.2 Avaliação radiológica. .Pág. 13

1.4.3 Obesidade Pág. 13 
1.4.5 Instabilidade ventilatória Pág. 17

1.4.6 Diferença entre sexos. Pág. 19

1.4.7 Idade Pág. 20

1.5 Pressão crítica de fechamento (Pcrit). .Pág. 20

1.5.1 Pcrit e anatomia da via aérea superior. Pág. 29

1.6 Indução do sono. Pág. 29

1.6.1 Midazolam. Pág. 30

2 Racional do estudo Pág. 31

3 Objetivos. .Pág. 33

4 Métodos. Pág. 35

4.1 Sujeitos. ..Pág. 36

4.2 Avaliações. Pág. 36

4.2.1 Avaliação tomográfica das vias aéreas superiores .Pág. 37

4.2.2 Polissonografia Pág. 40

4.2.3 Indução do sono Pág. 41

4.2.4 Determinação Pcrit. Pág. 41 
4.3 Cálculo amostral. .Pág. 46

4.4 Análise estatística. Pág. 46

5. Resultados. Pág. 48

6. Discussão Pág. 68

6.1 População estudada Pág. 69

6.2 Protocolo de sedação e determinação da Pcrit sob sedação. Pág. 70

6.3 Método de determinação da Pcrit. Pág. 72

6.4 Validação da Pcrit após indução do sono com midazolam Pág. 73

6.5 Efeitos da sedação na arquitetura do sono. Pág. 74

6.6 Significado fisiológico da Pcrit. Pág. 75

6.7 Anatomia das vias aéreas superiores e Pcrit. Pág. 77

6.8 Limitações. Pág. 79

6.9 Considerações Finais. Pág. 79

7. Conclusão .Pág. 81

8. Anexos. Pág. 83

8.1 Anexo A - Termo de consentimento livre e esclarecido. Pág. 84 
8.2 Anexo B - Escala de sonolência de Epworth ..........................................Pág. 92

9. Referências.....................................................................................Pág. 93 


\section{Lista de abreviaturas}

AOS

CPAP

EM G

H-ENP

IAH

IMC

MPH

NSBa

$\mathrm{PaCO}_{2}$

Pcrit

PSG

REM

RNM

Sat $\mathrm{O}_{2}$

SNA

SNB

VAS

$V_{\mathbf{i}} \max$
Apnéia obstrutiva do sono

Pressão positiva contínua nas vias aéreas

Eletromiografia

Distância do hióide ao plano mandibular

Índice de apnéia e hipopinéia

Índice de massa corpórea

Distância do hióide ao plano mandibular

Ângulo da base do crânio

Pressão parcial de dióxido de carbono arterial

Pressão crítica de fechamento da faringe

Polissonografia

"Rapid eye movement"

Ressonância nuclear magnética

Saturação de oxihemoglobina

Posição da maxila

Posição da mandíbula

Vias aéreas superiores

Pico de fluxo inspiratório 


\section{Lista de Tabelas}

Tabela 1 - Características clínicas e antropométricas.........................................Pág. 49

Tabela 2 - Polissonografia basal......................................................................ág. 50

Tabela 3 - Arquitetura do sono durante os estudos de Pcrit com sono natural e induzido Pág. 52

Tabela 4 - Pressão de manutenção de CPAP. Pág. 52

Tabela 5 - Características dos sujeitos conforme a predominância dos eventos respiratórios (hipopnéia vs.apnéia). Pág. 54

Tabela 6 - Coeficientes de correlação de Pearson entre IAH, Pcrit no sono natural e induzido e variáveis antropométricas e polissonográficas......Pág. 56

Tabela 7 - Coeficientes de correlação de Pearson entre IAH, Pcrit no sono natural e induzido e variáveis tomográficas. Pág. 61

Tabela 8 - Análise de regressão linear múltipla das variáveis associadas à variabilidade do IAH Pág. 67 


\section{Lista de figuras}

Figura la - Registro de polissonografia de um paciente apresentando apnéias

obstrutivas.

Pág. 3

Figura $\mathbf{1 b}$ - Registro de polissonografia de um paciente apresentando

hipopnéias

Pág. 4

Figura 2 - Prevalência de AOS por idade

.Pág. 6

Figura 3 - Anatomia das vias aéreas superiores

Pág. 10

Figura 4 - Interação entre estrutura óssea e partes moles.

Pág. 12

Figura 5 - Vetores de força dos músculos dilatadores da faringe.

Figura 6 - Representação da ativação neuromuscular do genioglosso.

Pág. 16

Figura 7 - Caracterização do" loop gain"

Pág. 18

Figura 8 - M odelo do resistor de Starling. ..Pág. 21

Figura 9 - Representação da limitação ao fluxo aéreo.

Pág. 23

Figura 10 - Comportamento da curva fluxo vs. pressão na vigência de limitação de fluxo e colapso parcial da faringe. Pág. 24 
Figura 11 - Pressão crítica de fechamento entre indivíduos normais, roncadores, portadores de hipopnéias e apnéias.

Figura 12 - Interação entre anatomia e resposta neuromuscular. .Pág. 28

Figura 13 - Desenho experimental. Pág. 37

Figura 14 a - Variáveis tomográficas em corte sagital. .Pág. 39

Figura 14b - Variáveis tomográficas em corte axial. Pág. 40

Figura 15 - Representação do equipamento utilizado na determinação da Pcrit. .Pág. 42

Figura 16 - Detalhe de uma redução de pressão da máscara e surgimento de padrão de limitação de fluxo. Pág. 43

Figura 17 - Seqüência de reduções da pressão da máscara e registro concomitante do fluxo aéreo Pág. 44

Figura 18 - Dispersão dos dados de fluxo inspiratório máximo e pressão da máscara de um exame para determinação da Pcrit e reta de regressão linear Pág. 45

Figura 19a - Hipnograma de um paciente submetido à determinação da Pcrit após indução do sono .Pág. 51 
Figura 19b - Hipnograma de um paciente submetido à determinação da

Pcrit após durante o sono natural à noite

Pág. 51

Figura 20 - Gráfico de Bland-Altman.

Pág. 53

Figura 21a - Correlação entre IAH e Pcrit (sono natural). ..Pág. 57

Figura 21b - Correlação entre IAH e Pcrit (sono induzido). Pág. 57

Figura 22 - Correlação entre IAH $\mathrm{Hup}_{\text {e }}$ Pcrit Pág. 58

Figura 23 -Correlação entre saturação mínima de oxigênio e Pcrit Pág. 58

Figura 24 -Correlação entre tempo médio de apnéia e Pcrit. Pág. 59

Figura 25 -Correlação entre IAH e circunferência abdominal Pág. 59

Figura 26 -Correlação entre IAH e comprimento de língua. Pág. 62

Figura 27 -Correlação entre IAH e distância M PH Pág. 62

Figura 28 -Correlação entre IAH e distância H-ENP. .Pág. 63

Figura 29 -Correlação entre IAH e comprimento de via aérea. .Pág. 63

Figura 30 -Correlação entre IAH e ângulo NSBa .Pág. 64

Figura 31 -Correlação entre Pcrit e distância M PH. ..Pág. 64

Figura 32 -Correlação entre Pcrit e ângulo NSBa. Pág. 65 
Figura 33 -Correlação entre Pcrit e área da velofaringe.......................................Pág. 65

Figura 34 -Correlação entre Pcrit (sono natural) e distância H-ENP.......................Pág. 66

Figura 35 -Correlação entre Pcrit (sono natural) e comprimento da via aérea......Pág. 66

Figura 36 -Correlação entre Pcrit (sono natural) e parede lateral da faringe... .....Pág. 67 


\section{Resumo}

Genta PR. Validação da medida da pressão crítica de fechamento da faringe durante o sono induzido [tese]. São Paulo: Faculdade de Medicina, Universidade de São Paulo; 2010.

Introdução: A pressão crítica de fechamento da faringe (PCrit) é a pressão nasal em que há colapso da faringe. Conceitualmente a Pcrit reflete a contribuição anatômica na gênese da apnéia obstrutiva do sono (AOS). No entanto, a relação entre a PCrit e a anatomia das vias aéreas superiores (VAS) tem sido pouco estudada. A PCrit determinada durante 0 sono requer pesquisadores experientes durante a noite. A indução do sono com midazolam é usada na prática clínica para a realização de procedimentos ambulatoriais e poderia ser uma alternativa mais conveniente para se determinar a Pcrit. Porém, o midazolam pode provocar sedação além de simples indução do sono, reduzir a atividade muscular das VAS e aumentar a colapsabilidade quando comparado com o sono normal. Objetivos: 1. validar a determinação da PCrit durante 0 dia após a indução do sono com midazolam; 2. comparar a arquitetura do sono induzido com baixa dose de midazolam com o sono natural; 3. correlacionar a PCrit com a anatomia das VAS. Métodos: Homens com graus variados de sintomas sugestivos de AOS foram submetidos a polissonografia completa noturna, determinação da PCrit durante o sono natural e após a indução do sono com midazolam bem como tomografia computadorizada de cabeça e pescoço para 
avaliação das VAS. Resultados: Foram estudados 15 sujeitos com idade (médiatDP) de $54 \pm 10$ anos, índice de massa corporal de $29,9 \pm 3,9 \mathrm{~kg} / \mathrm{m}^{2}$ e índice de apnéiahipopnéia (IAH) de $38 \pm 22$ (variação: 8-66 eventos/h). A indução do sono foi obtida em todos os sujeitos, utilizando doses mínimas de midazolam (mediana [intervalo interquartil]) $(2,4[2,0-4,4] \mathrm{mg})$. A PCrit durante o sono natural e induzido foram semelhantes $\left(-0,82 \pm 3,44\right.$ e $\left.-0,97 \pm 3,21 \mathrm{cmH}_{2} \mathrm{O}, \mathrm{P}=0,663\right)$ e se associaram (coeficiente de correlação intraclasse=0,92 (IC 95\% 0,78-0,97 P $\varangle$,001). A distribuição das fases do sono durante sono natural e induzido foi similar, com excessão da fase $1(10,5 \pm 5,1 \%$ vs. $20,6 \pm 8,1$, respectivamente; $P=0,001$ ). A Pcrit determinada durante 0 sono natural e induzido se correlacionaram com o IAH $(r=0,592, P=0,020$ e $r=0,576, P=0,025$, respectivamente). Além disso tanto a Pcrit determinada por sono natural e induzido se correlacionaram com diversas variáveis tomográficas de VAS, incluindo a posição do osso hióide, ângulo da base do crânio e as áreas seccionais da velofaringe e hipofaringe ( $r$ variando de 0,577 a $0,686, P \varangle 0,05$ ). A regressão linear múltipla revelou que o IAH foi independentemente associado com a Pcrit durante sono induzido, circunferência da cintura e idade $\left(r^{2}=0,785, P=0,001\right)$. Conclusão: A PCrit determinada durante 0 dia com indução do sono é semelhante à determinada durante o sono natural e é um método alternativo promissor para determinar a PCrit. 0 sono induzido por doses baixas de midazolan promove um sono similar ao sono natural. A Pcrit determinada tanto durante o sono natural e induzido correlaciona-se com várias características anatômicas das VAS. 
Descritores: 1. Apnéia do sono tipo obstrutiva/fisiopatologia; 2. Pressão crítica de fechamento da faringe; 3. Faringe/efeitos de drogas; 4. Faringe/fisiopatologia 5. Faringe/anatomia \& histologia; 6. Midazolam; 7. Sedação consciente; 8. Tomografia computadorizada por raios $X$ 


\section{Summary}

Genta PR. Validation of the pharyngeal critical closing pressure during induced sleep. [thesis]. São Paulo:"Faculdade de M edicina, Universidade de São Paulo"; 2010.

Introduction: The pharyngeal critical closing pressure (Pcrit) is the nasal pressure at which the airway collapses. Pcrit is thought to reflect the anatomical contribution to the genesis of obstructive sleep apnea (OSA). However, the relationship between Pcrit and upper airway anatomy has been poorly investigated. Pcrit determined during sleep requires experienced investigators at night. Sleep induction with midazolam is frequently used in clinical practice during ambulatory procedure and could be a more convenient alternative to assess Pcrit. On the other hand, midazolam could induce sedation rather than sleep, decrease upper airway muscle activity and increase collapsibility compared with natural sleep. Objectives: 1. validate Pcrit determination during the day after sleep induction with midazolam; 2. compare the sleep architecture of induced sleep after low doses of midazolam with natural sleep; 3.correlate Pcrit with upper airway anatomy. Methods: Men with different severity of OSA symptoms underwent baseline full polysomnography, Pcrit determination during natural sleep and after sleep induction with midazolam and head and neck computed tomography. RESULTS: Fifteen men aged (mean \pm SD) $54 \pm 10 y$, body mass index $=29.9 \pm 3.9 \mathrm{Kg} / \mathrm{m}^{2}$ and apnea hypopnea index $=38 \pm 22$, range: 8-66 events/h were studied. Sleep induction was obtained with minimum doses of midazolam (median[interquartile range] (2.4 [2.0-4.4] 
mg). Sleep phase distribution during natural and induced sleep was similar, except for stage 1 (10.5 $\pm 5.1 \%$ vs. $20.6 \pm 8.1$, respectively; $P=0.001)$. Natural and induced sleep Pcrit were similar $\left(-0.82 \pm 3.44\right.$ and $\left.-0.97 \pm 3.21 \mathrm{cmH}_{2} \mathrm{O}, \mathrm{P}=0.663\right)$ and closely associated (intraclass correlation coefficient $=0.92(95 \% \mathrm{Cl} 0.78-0.97, \mathrm{P} \varangle 0.001)$. Natural and sleep induced Pcrit correlated with AHI ( $r=0.592, P=0.020 ; r=0.576, P=0.025$, respectively). Pcrit determined both during natural and induced sleep were significantly associated with several tomographic variables, including hyoid position, cranial base angle and cross sectional areas of the velopharynx and hypopharynx ( $r$ range: 0.577 to 0.686 , $\mathrm{P} \varangle$.05). Multiple linear regression revealed that $\mathrm{AHI}$ was independently associated with induced sleep Pcrit, waist circumference and age $\left(r^{2}=0.785, \mathrm{P}=0.001\right)$. Conclusion: Pcrit determined during the day with sleep induction is similar to natural sleep and is a promising alternative method to determine Pcrit. Sleep induction with small doses of midazolam promoted sleep similar to natural sleep. Pcrit determined both during natural and induced sleep correlates with several anatomical characteristics of the upper airway.

Descriptors: 1. Sleep apnea, obstructive/physiopathology; 2. Pharyngeal critical closing pressure; 3. Pharynx/drug effects; 4. Pharynx/physiopatology; 5. Pharynx/anatomy \& histology; 6. Midazolam; 7. Conscious sedation; 8. X-ray computed tomography 


\section{Introdução}


Este estudo abrange a validação de um novo método de avaliação da colapsabilidade das vias aéreas superiores, propriedade importante envolvida na fisiopatologia da apnéia obstrutiva do sono (AOS). Os tópicos abaixo fornecem informações relevantes para o trabalho apresentado.

\subsection{Apnéia obstrutiva do sono}

A AOS é caracterizada pela obstrução recorrente, parcial ou completa, das vias aéreas superiores durante 0 sono. ${ }^{1} \mathrm{~A}$ AOS é comum entre os adultos e está associada a sintomas diurnos que interferem na qualidade de vida. Além disso, a AOS leva ao comprometimento de qualidade de vida do(a) parceiro(a). ${ }^{2}$ Os sintomas mais comuns são ronco, sonolência excessiva diurna, cansaço, noctúria. A AOS também pode causar progressão de aterosclerose e aumento da morbidade e mortalidade por doença cardiovascular. ${ }^{3,4}$ Estudos epidemiológicos recentes mostraram que a AOS grave está associada a aumento de mortalidade. ${ }^{5,6}$

A polissonografia é o exame, padrão ouro, para o diagnóstico da AOS e consiste do registro simultâneo de variáveis eletroencefalográficas, de tônus muscular e movimentação ocular para estadiamento do sono e de variáveis respiratórias como oximetria de pulso, movimentação torácica e abdominal e cânula de pressão (para registro do fluxo aéreo) para avaliação dos eventos respiratórios. ${ }^{1}$ A obstrução completa (apnéia) é caracterizada na polissonografia como ausência de fluxo aéreo 
pelo sinal da cânula de pressão e concomitante movimentação torácica e abdominal (Figura 1a). A obstrução parcial (hipopnéia) é caracterizada na polissonografia como redução parcial do fluxo aéreo pelo sinal da cânula de pressão (Figura 1b).

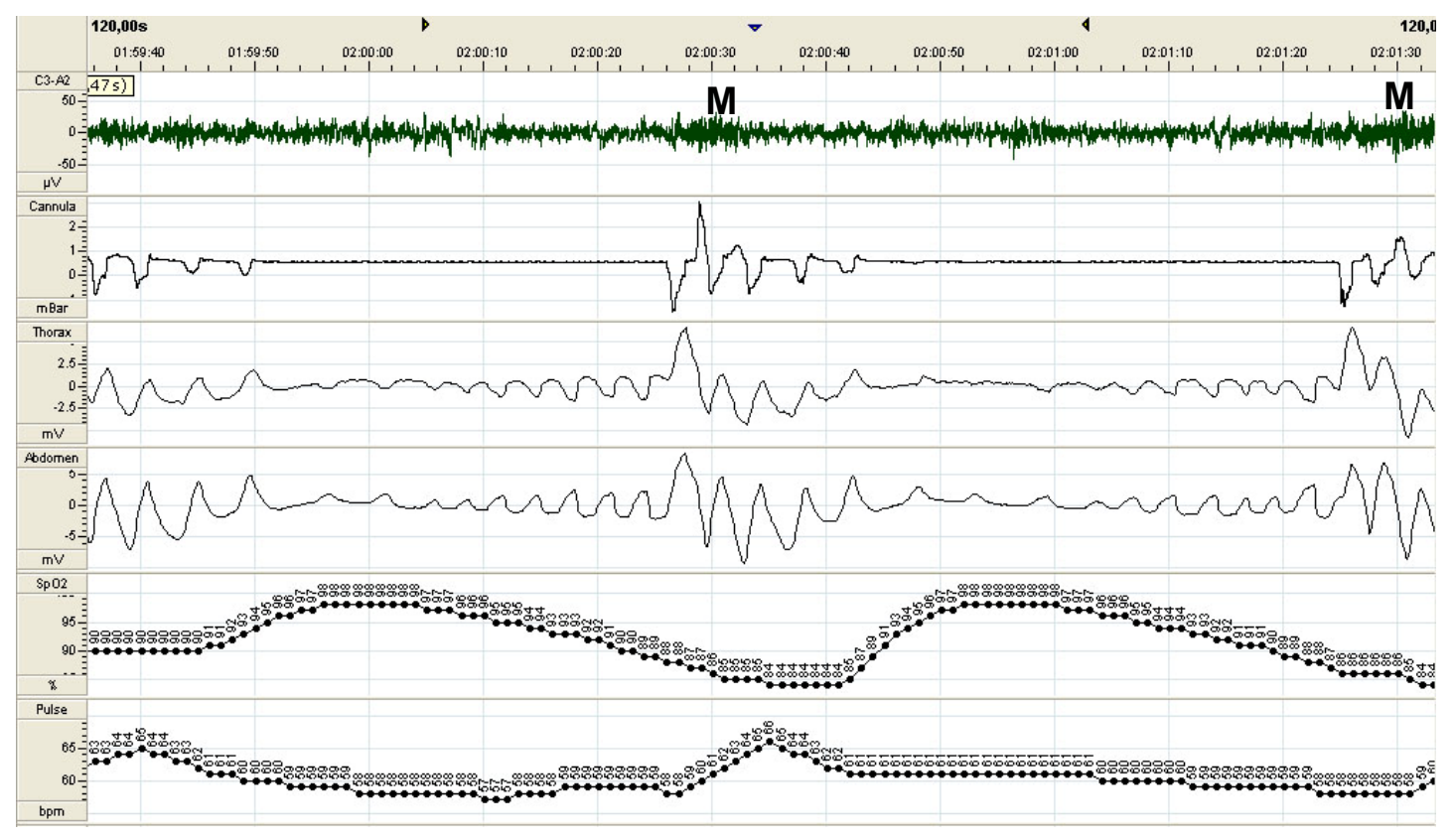

FONTE: Laboratório do sono, InCor

Figura 1a - Registro de 120 segundos de polissonografia de um paciente apresentando apnéia obstrutivas. Observe as interrupções do fluxo aéreo, mas com persistência de esforço respiratório (canais das cintas de movimentação torácica e abdominal), terminando com um microdespertar (M). Há queda da saturação da oxihemoglobina (Sp02), a qual tipicamente está atrasada em relação ao início da apnéia. Este fenômeno se deve à reserva pulmonar de oxigênio, que é reduzida no decorrer da apnéia. 


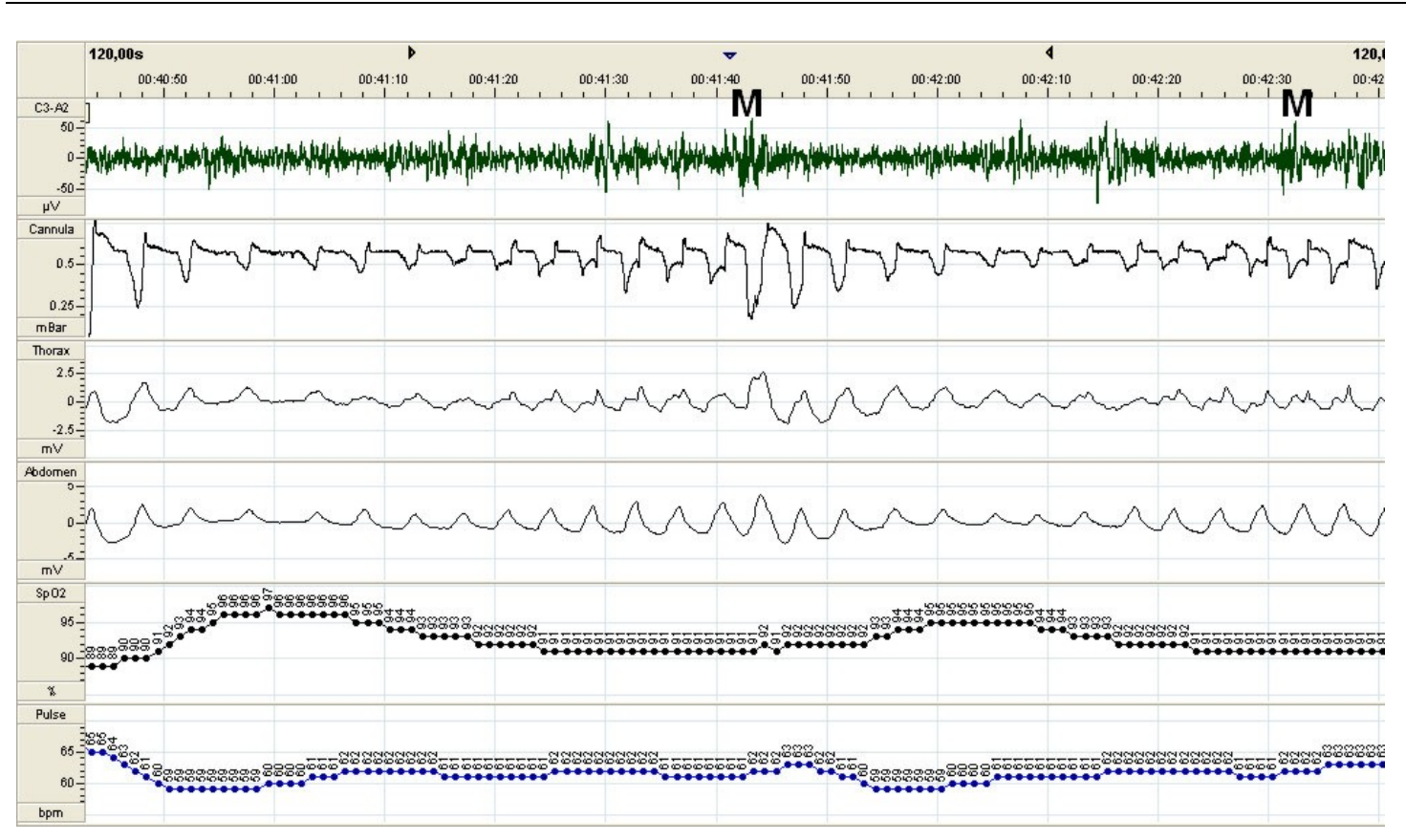

FONTE: Laboratório do sono, InCor

Figura $\mathbf{1 b}$ - Registro de 120 segundos de polissonografia de paciente apresentando uma hipopnéia. Observe as reduções do fluxo aéreo e a persistência de esforço respiratório, queda da saturação da oxihemoglobina (SpO2), terminando com um microdespertar (M).

Definição das abreviaturas: C3-A2, eletroencefalografia; Cannula, fluxo respiratório por sensor de pressão nasal; Thorax / Abdomen, cintas para monitorização de movimentação torácica e abdominal; Sp02, oximetria de pulso; Pulse, freqüência cardíaca derivada do oxímetro de pulso.

A classificação de gravidade da AOS é determinada pelo índice de apnéia e hipopnéia (IAH) que consiste da soma do número de apnéias e hipopnéias dividida pelo número de horas de sono ( $n^{0}$. eventos de apnéias +hipopnéias / horas de sono) obtidos 
durante a polissonografia. O IAH é considerado normal até 5 eventos/h. De 5-15, 15-30 e >30 eventos/h, classifica-se como apnéia do sono leve, moderada e grave, respectivamente. ${ }^{7}$

\subsection{Epidemiologia}

A AOS é um distúrbio com alta prevalência entre indivíduos adultos e está relacionada a diversas conseqüências. Um estudo epidemiológico realizado recentemente na cidade de São Paulo encontrou AOS em 24,8\% dos homens e 9,6\% das mulheres adultas quando se utilizou IAH • 15 eventos/h para a definição de AOS. $^{8} \mathrm{Em}$ 1993, Young e colaboradores estimaram a prevalência de AOS na população adulta norte-americana em $9 \%$ dos homens e $4 \%$ das mulheres quando utilizado o mesmo $\mathrm{IAH}^{9}{ }^{9}$ As diferenças entre os 2 estudos se devem provavelmente a utilização de sensores respiratórios mais sensíveis (cânula de pressão) e a inclusão de indivíduos idosos no estudo brasileiro. De fato, a prevalência da AOS aumenta progressivamente nos adultos até ao redor dos 65 anos (Figura 2). ${ }^{10} 0$ aumento da prevalência de obesidade nos últimos anos ${ }^{11,12}$ pode também contribuir para um aumento da prevalência da doença ao longo do tempo. 


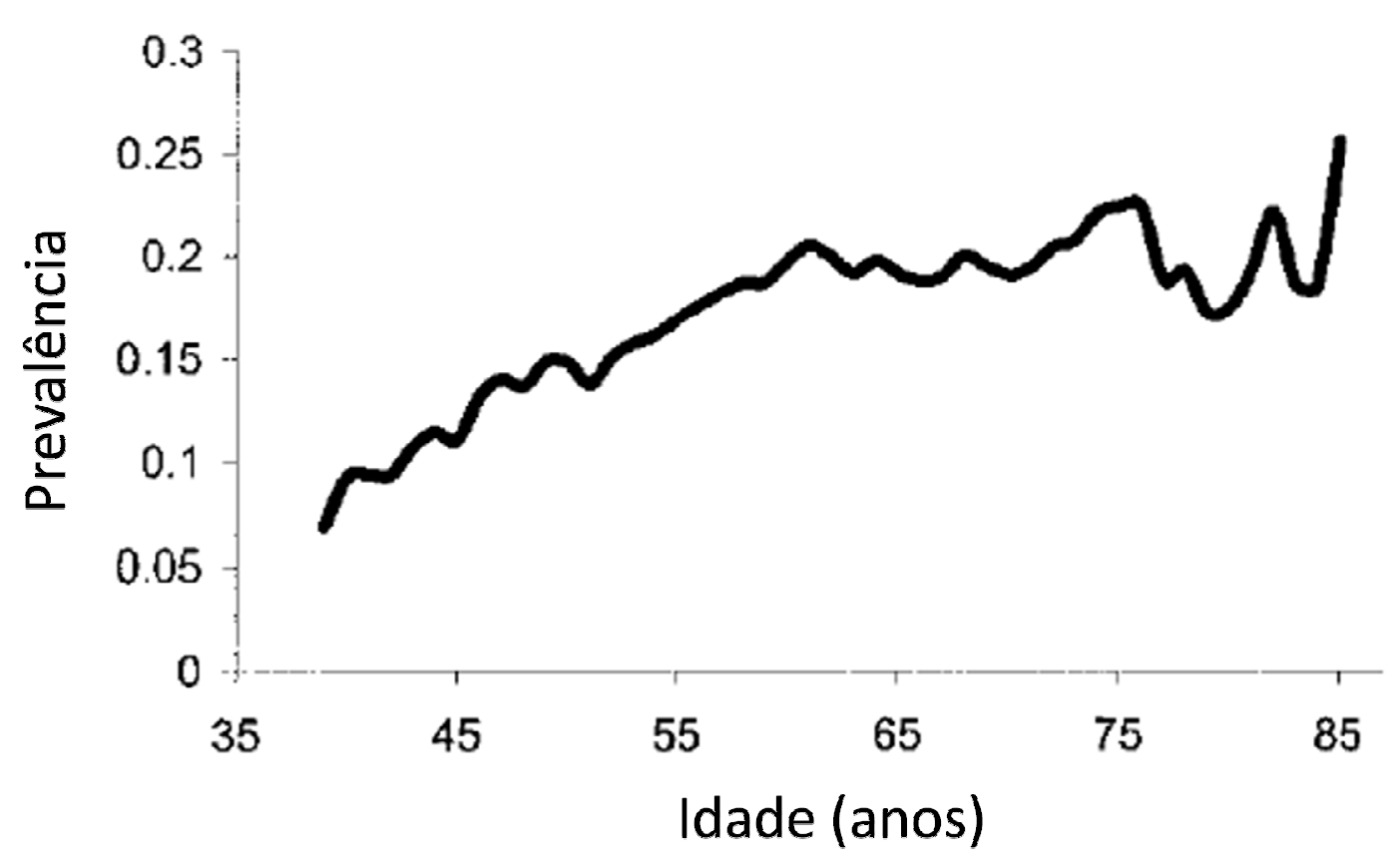

FONTE: Arch Intern M ed 2002;162:893-900.

Figura 2- Prevalência de AOS por idade no Sleep Heart Health Study. Observe 0 aumento de prevalência até cerca de 65 anos.

\subsubsection{Etnia}

Alguns grupos étnicos podem apresentar maior risco para AOS. Por exemplo, americanos da raça Negra apresentaram maior risco para AOS do que Caucasianos. ${ }^{13}$ Estudos recentes sugeriram maior gravidade da AOS em Asiáticos quando comparados com Caucasianos de mesmo índice de massa corpórea (IMC). ${ }^{14,15}$ Visto por outro lado, observou-se que os Asiáticos eram mais magros que os Caucasianos com AOS de mesma gravidade. ${ }^{14,15}$ Analisados em conjunto, esses dados sugerem que os Asiáticos 
são predispostos a desenvolver AOS. Diferenças na anatomia crânio-facial têm sido propostas para justificar AOS entre Asiáticos com IM C menor quando comparados com Caucasianos. ${ }^{14,15}$ Por outro lado, a baixa prevalência de obesidade em países Asiáticos, apesar de prevalências elevadas de doenças cardiovasculares poderia estar relacionada a diferenças na composição corporal entre as raças. ${ }^{16}$ Estes fatos levaram a Organização Mundial da Saúde a propor recentemente um IMC igual ou maior a 25 $\mathrm{Kg} / \mathrm{m}^{2}$ para definir obesidade na população Asiática, diferente da definição de $30 \mathrm{Kg} / \mathrm{m}^{2}$ para os demais grupos étnicos. ${ }^{17}$ Este mesmo mecanismo poderia explicar em parte a ocorrência de AOS em Asiáticos com menor IMC que Caucasianos. Em um estudo recente, comparamos as características antropométricas de descendentes de Japoneses e Brancos do sexo masculino encaminhados para polissonografia. ${ }^{18}$ Neste estudo, os Japoneses tinham menor IMC que os Brancos quando pareados pela gravidade da AOS. Em uma análise de regressão linear múltipla, a etnia Japonesa e o IMC foram associados independentemente a AOS. No entanto, quando foram consideradas as diferentes definições de obesidade entre descendentes de Japoneses e Brancos, a etnia Japonesa deixou de ser relacionada à AOS. Estudos epidemiológicos em países Asiáticos demonstraram prevalência de AOS muito similares à descrita entre Americanos de meia-idade, ${ }^{9,19,20}$ o que sugere que os Asiáticos não estejam mais predispostos do que Caucasianos à AOS. 


\subsection{Tratamento}

O tratamento da AOS melhora a qualidade de vida do paciente e parceiro (a) e reduz complicações cardiovasculares. ${ }^{2,3} \mathrm{O}$ tratamento envolve inicialmente a perda de peso naqueles indivíduos com sobrepeso ou obesidade. ${ }^{21}$ Dispositivos intra-orais para 0 avanço mandibular têm sido amplamente utilizados, tendo maior benefício na AOS leve a moderada. ${ }^{22}$ Diversas técnicas cirúrgicas também foram propostas para o tratamento desta doença. ${ }^{23}$ Mais recentemente, a terapia miofuncional, que envolve exercícios orofaríngeos, foi descrita para o tratamento de pacientes com AOS leve a moderada. ${ }^{24}$

O dispositivo de pressão positiva contínua nas vias aéreas (CPAP) é o tratamento de escolha para AOS grave. ${ }^{25}$ A utilização de CPAP reduz os níveis pressóricos de indivíduos hipertensos portadores de $\mathrm{AOS}^{26}{ }^{26}$ melhora a fração de ejeção do ventrículo esquerdo em pacientes com insuficiência cardíaca congestiva e $\mathrm{AOS}^{27}$ e reduz a mortalidade cardiovascular. ${ }^{3}$

\subsection{Fisiopatologia}

As razões para o colapso das vias aéreas superiores durante o sono em pacientes com AOS são múltiplas e não totalmente compreendidas. 0 colapso das vias aéreas superiores depende das características anatômicas, da instabilidade ventilatória durante o sono e do controle neuromuscular do calibre da via aérea superior. ${ }^{28}$ 


\subsubsection{Anatomia das vias aéreas superiores}

A faringe é uma estrutura complexa composta de mais de 20 músculos e participa de diversas funções como fonação, deglutição e respiração. ${ }^{29}$ (Figura 3) Nos seres humanos, a faringe é mais alongada do que a de outros mamíferos, o que deve se relacionar ao desenvolvimento da fonação. 0 osso hióide exerce função importante na estabilidade da faringe, pois nele se inserem alguns músculos dilatadores da faringe. Como conseqüência do alongamento da faringe, o osso hióide perdeu a conexão com 0 processo estilóide que é encontrada em outros mamíferos. ${ }^{30} \mathrm{~A}$ mobilidade e falta de conexão esquelética do osso hióide aumentou a colapsabilidade da faringe no ser humano. 


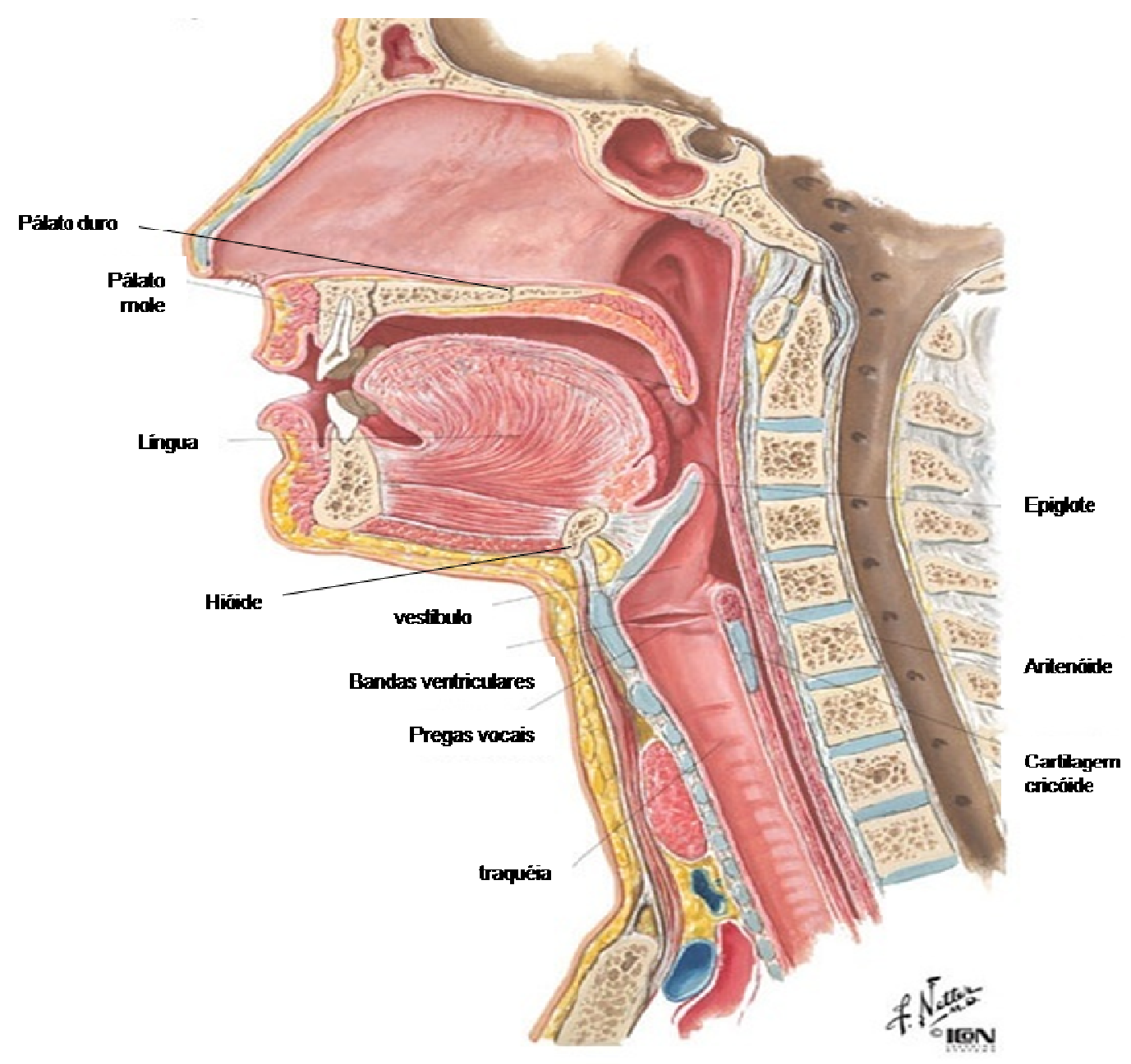

FONTE: GI M otility online 2006 doi: 10.1038/gimo25

Figura 3 - Anatomia das vias aérea superiores. Observe a região da faringe em que não há sustentação óssea ou cartilaginosa e, portanto, susceptível a colapso: velo-faringe, a partir da origem do pálato mole até a sua extremidade inferior; oro-faringe, da extremidade inferior do pálato mole até a epiglote. 
As características anatômicas das vias aéreas superiores desempenham um papel central na gênese da AOS. Alterações anatômicas como hipertrofia tonsilar, retrognatia e redução do comprimento do corpo da mandíbula foram associadas à AOS. ${ }^{31-36} \mathrm{~A}$ circunferência cervical aumentada está relacionada à distribuição central de gordura. ${ }^{37,38} \mathrm{Na}$ região cervical, o ganho de peso está associado à deposição de gordura na língua e ao redor das vias aéreas superiores, além de aumento das paredes laterais da faringe. 0 aumento de partes moles pode reduzir 0 diâmetro da via aérea e aumentar o risco de colapso. ${ }^{39,40} \mathrm{~A}$ interação da anatomia crânio-facial e partes moles da via aérea superior é importante na gênese da AOS. Quando há estrutura óssea estreita (ex. retrognatia), o aumento de partes moles causado pelo ganho de peso eleva o risco de desenvolvimento de AOS. Caso haja estrutura crânio-facial ampla, 0 aumento de partes moles apresenta risco menor. ${ }^{41}$ (Figura 4) 


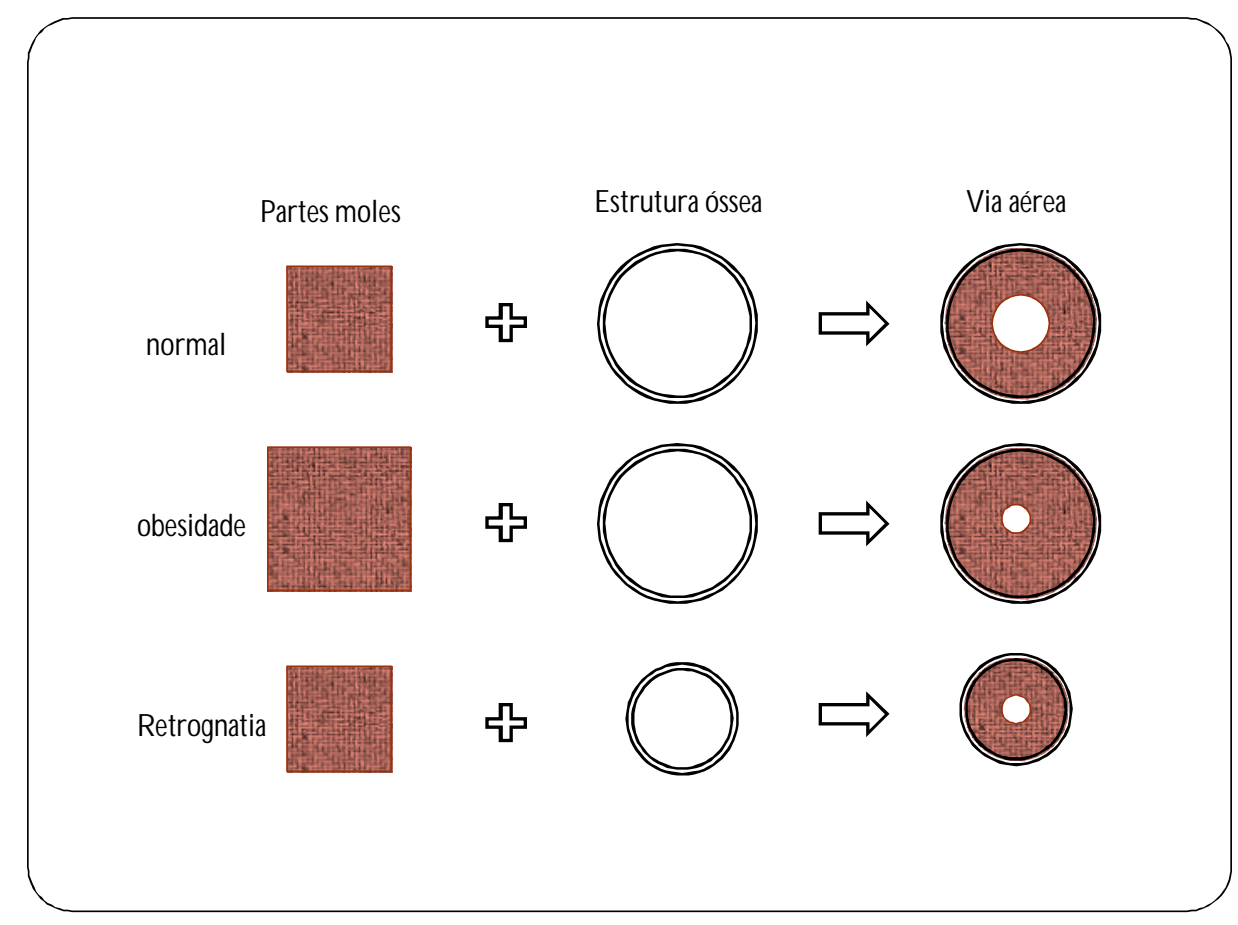

FONTE: Am J Respir Crit Care Med 2002; 165: 260-5

Figura 4 - Interação entre estrutura óssea e partes moles. Pacientes com peso normal podem desenvolver AOS por restrição crânio-facial (ex. retrognatia). Pacientes obesos tipicamente apresentam aumento das partes moles. Ambas as situações se apresentam com redução do diâmetro da via aérea.

Contribuindo para o aumento de partes moles da via aérea superior, foi descrito o deslocamento de líquido dos membros inferiores em direção à região cervical durante 0 decúbito. 0 deslocamento de líquido para a região cervical está associado ao aumento da circunferência cervical, a maior resistência das vias aéreas superiores (VAS) e à gravidade da $\mathrm{AOS}^{42-44}$ 


\subsubsection{Avaliação radiológica}

A avaliação radiológica da cabeça e pescoço permite estudar a anatomia da via aérea superior e sua contribuição na fisiopatologia da AOS. 0 método mais utilizado é a cefalometria lateral, extensamente utilizado na área de odontologia e cirurgia bucomaxilo-facial. Trata-se de uma radiografia lateral crânio-facial em posição padronizada que permite a determinação de ângulos e medidas baseadas em pontos de referência anatômicos. Várias alterações têm sido descritas quando são comparados portadores de AOS e indivíduos normais. As características mais comumente relatadas são: retroposição da mandíbula, distância do hióide ao plano mandibular aumentada, comprimento e ângulo da base do crânio reduzidos, comprimento da via aérea aumentado, comprimento e espessura do palato mole aumentados, redução da luz da via aérea (espaço posterior da faringe). ${ }^{45}$

A tomografia computadorizada traz as vantagens de melhor definição de partes moles, a possibilidade de avaliação tridimensional e medida de áreas em diferentes níveis e permite a reconstrução sagital para que as medidas cefalométricas clássicas sejam determinadas. ${ }^{45}$

\subsubsection{Obesidade}

A obesidade se relaciona à AOS por outras vias além da deposição de gordura ao redor da via aérea. Durante o sono, o indivíduo obeso tem redução significativa dos volumes pulmonares pelo volume abdominal aumentado e pelo decúbito. A parede 
faríngea sofre influência da tração da traquéia através de estruturas mediastinais, resultando em aumento da luz da faringe por tensão de suas paredes laterais. A redução dos volumes pulmonares diminui a tração da traquéia que ocorre durante a negativação da pressão intratorácica e descenço do diafragma, levando a um aumento da espessura da parede faríngea e estreitamento da via aérea. ${ }^{46}$ Por outro lado, 0 aumento experimental do volume pulmonar promovido através da negativação da pressão dentro de uma câmara similar a um pulmão de aço reduz a colapsabilidade da via aérea, provavelmente através do aumento da tração traqueal. ${ }^{47}$

\subsubsection{Fatores neuromusculares}

Os diversos músculos dilatadores da faringe e seus vetores de ação são representados na Figura 5. Os dilatadores da faringe são ativados de forma tônica (contínua) e fásica (intermitente) durante o ciclo respiratório. A ação desses músculos estabiliza a via aérea e se contrapõe à tendência ao colapso da faringe durante a inspiração, quando é gerada pressão negativa intra-torácica. A pressão negativa na faringe também estimula fibras proprioceptivas, aumentando a atividade dos dilatadores da faringe. ${ }^{48}$ (Figura 6). Alterações deste mecanismo protetor parecem estar envolvidas na patogênese da AOS. A atividade do genioglosso e do tensor palatino, por exemplo, é maior em portadores de AOS durante a vigília do que em indivíduos normais e é reduzida após a aplicação de pressão positiva. ${ }^{49}$ Esta 
hiperatividade muscular pode representar uma compensação ao menor diâmetro da faringe nos portadores de AOS. A atividade tônica e fásica dos dilatadores da faringe se reduzem progressivamente desde a transição do sono, estágios 1,2 e 3 e REM ("rapid eye movement") propiciando ao colapso. ${ }^{50}$ Pode haver ainda lesão muscular e nervosa provocada pela oclusão e reabertura repetida da faringe, o que prejudicaria a ativação reflexa dos dilatadores da faringe durante a inspiração e durante a apnéia. ${ }^{51}$

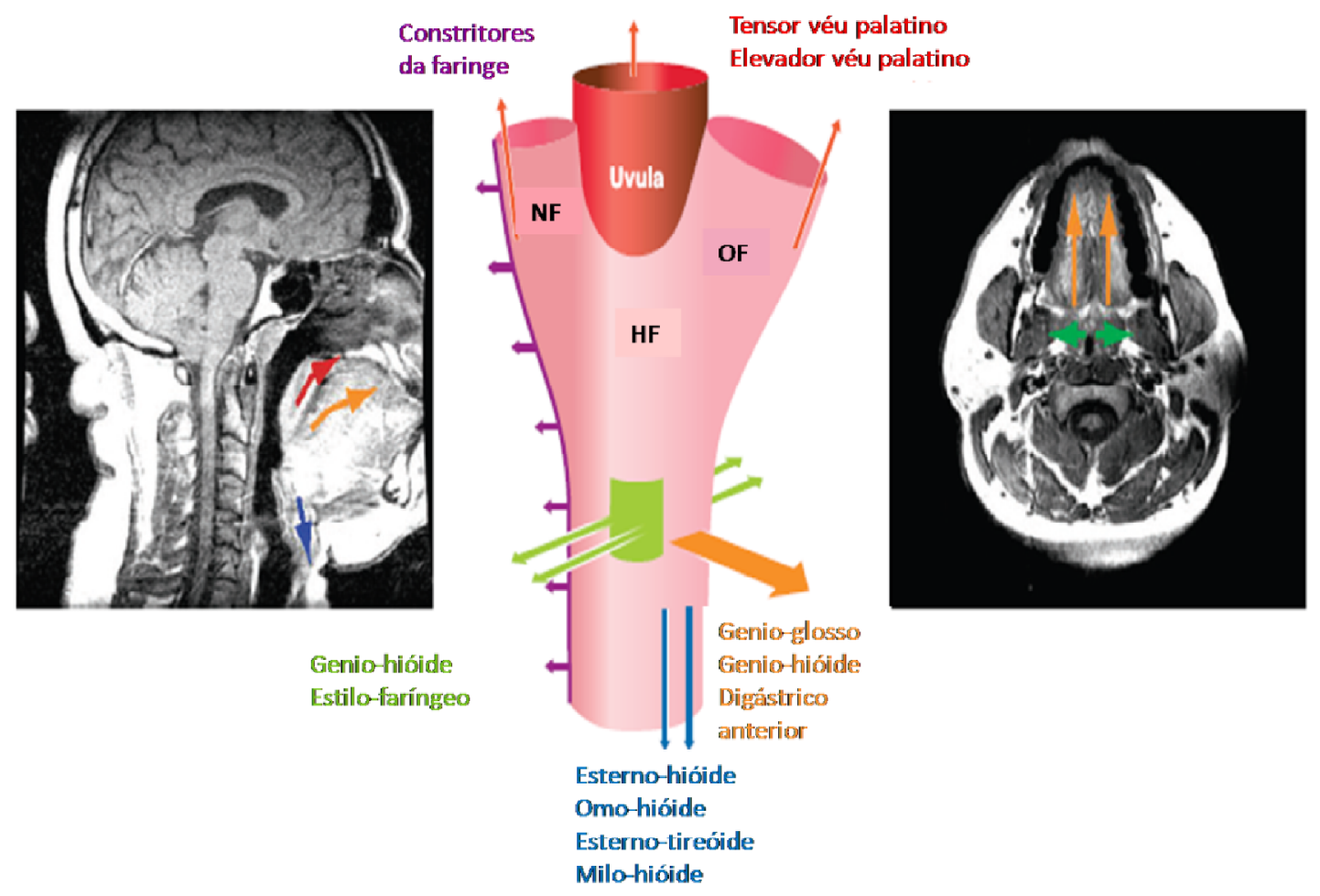

FONTE: Physiol Rev 2010; 90:47-112

Figura 5 - Vetores de força dos músculos dilatadores da faringe. As imagens de ressonância nuclear magnética (RNM) são de um indivíduo com AOS acordado. A via aérea é estreita mas patente devido à atividade dos músculos dilatadores da faringe. As setas demonstram os vetores de força no diagrama da faringe e nas imagens de RNM. 
Há necessidade de dilatação em todas as direções pois a faringe é colapsável em todas as tangentes de força. 0 genio-glosso é o principal músculo da língua e considerado 0 principal dilatador da faringe.

Definição das abreviaturas: NF, nasofaringe; HF, hipofaringe; OF, orofaringe

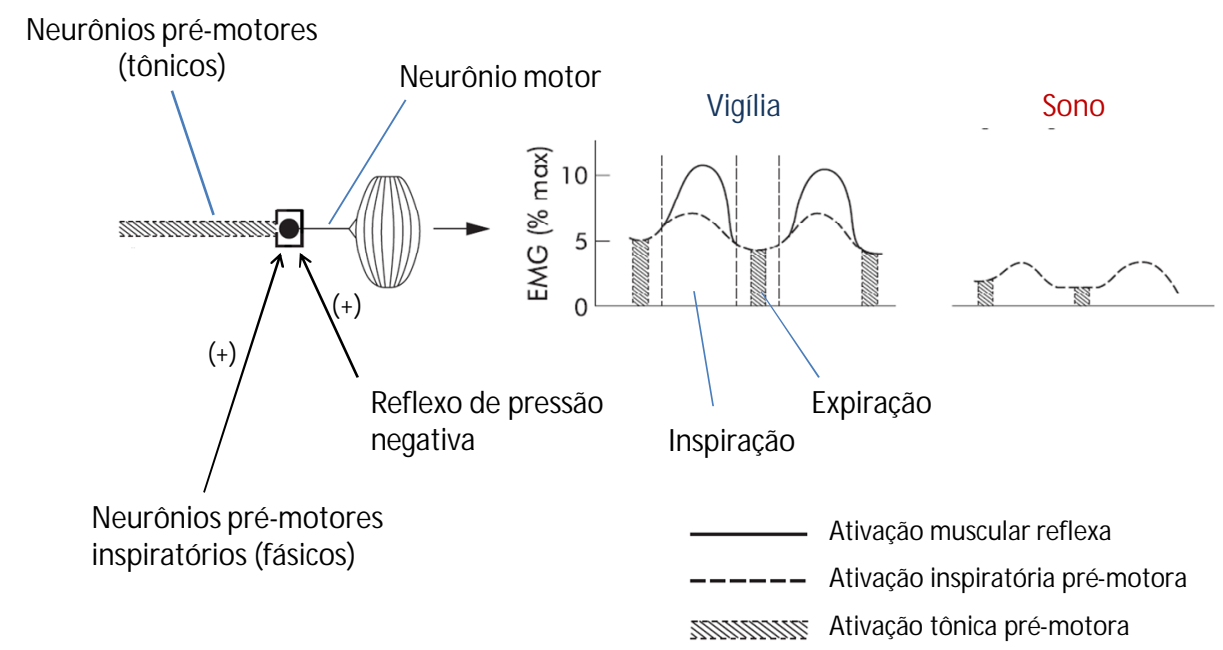

FONTE: Thorax 2004; 59:159-163

Figura 6 - Representação da ativação neuromuscular do genioglosso. Observe as três principais aferências ao neurônio motor (hipoglosso): neurônios pré-motores inspiratórios (fásicos), neurônios pré-motores tônicos, reflexo proprioceptivo de pressão negativa. Durante o sono há perda da aferência pré-motora tônica e da ativação muscular reflexa (proprioceptiva), levando a diminuição da atividade eletromiográfica e conseqüente risco de colapso da faringe.

Definição da abreviatura: EM G, atividade eletromiográfica. 


\subsubsection{Instabilidade ventilatória}

O controle da ventilação durante o sono é dependente dos quimioreceptores centrais e periféricos. A estabilidade do sistema respiratório durante o sono depende do ganho do sistema de controle. 0 "loop gain" mede a tendência de instabilidade do sistema de controle e avalia a resposta ventilatória em relação a um distúrbio na ventilação, por exemplo, uma apnéia (loop gain=resposta ventilatória/distúrbio na ventilação). 0 "loop-gain" menor que 1 gera instabilidade na ventilação pois a resposta ventilatória é exagerada em relação ao distúrbio inicial (Figura 7 A). "Loop-gain" maior ou igual a 1 promove estabilidade na ventilação (Figura 7 B). ${ }^{52}$

O limiar de apnéia durante o sono é definido pela $\mathrm{PaCO}_{2}$ abaixo da qual há desenvolvimento de apnéia central e é considerado um marcador de instabilidade respiratória. Oscilações da ventilação podem provocar redução da $\mathrm{PaCO}_{2}$ abaixo do limiar de apnéia e portanto provocar uma apnéia de origem central. Ocorre que durante uma apnéia central há redução do tônus da musculatura dilatadora da faringe..$^{53}$ Desta forma, uma apnéia central pode terminar como uma apnéia obstrutiva (apnéia mista). 0 despertar associado à apnéia obstrutiva por outro lado provoca 0 reestabelecimento da ventilação. Dependendo do "loop gain", ou seja, da estabilidade do sistema de controle, uma nova apnéia central pode ocorrer caso a $\mathrm{PaCO}_{2}$ atinja 0 limiar de apnéia. 

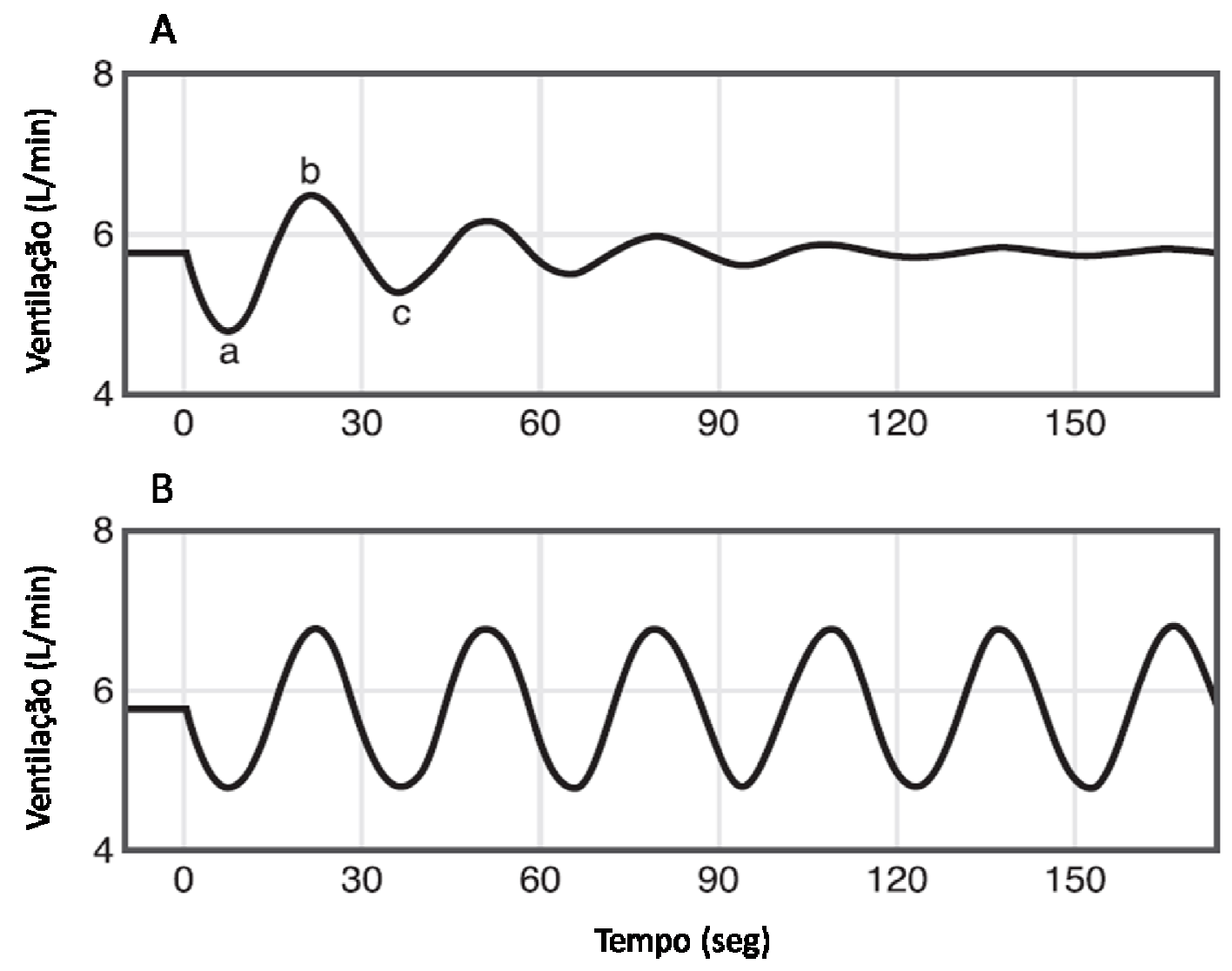

FONTE: Respir Physiol Neurobiol 2008; 162: 144-151.

Figura 7 - Caracterização do "loop gain" (razão entre resposta ventilatória e distúrbio ventilatório). Na figura $A$, "loop gain" é igual a 0,7. 0 distúrbio ventilatório é representado no ponto (a) como uma redução transitória da ventilação. Este distúrbio promove uma hiperventilação (b) que é $70 \%$ em magnitude do distúrbio inicial. A resposta subseqüente (c) também é $70 \%$ do ponto (b). Assim, o sistema oscila mas atinge a ventilação basal depois de algum tempo. Na figura B, "loop gain" é maior ou igual a 1. A resposta ventilatória é maior ou igual ao distúrbio que a gerou. Assim a ventilação que era estável oscila após uma redução transitória da ventilação sem retornar ao basal e, portanto, o sistema é altamente instável. 


\subsection{6- Diferença entre sexos}

Conforme já mencionado, estudos epidemiológicos mostraram que a prevalência de AOS entre mulheres é cerca de metade da dos homens. No entanto, há aumento de prevalência da AOS entre mulheres após a menopausa. ${ }^{54}$ Os mecanismos envolvidos na diferença de prevalência entre os gêneros não são totalmente compreendidos. Estudos recentes mostraram que a colapsabilidade da via aérea dos homens é significativamente maior do que a das mulheres, apontando para diferenças anatômicas. ${ }^{55,56}$ De fato, o comprimento da via aérea entre homens é maior do que entre mulheres, o que poderia explicar em parte 0 aumento da colapsabilidade da via aérea entre os homens. ${ }^{57}$ Por outro lado, o comprimento da via aérea é maior em mulheres pós-menopausa quando comparado com mulheres pré-menopausa. ${ }^{58}$ Influência hormonal na deposição central de gordura poderia também explicar parcialmente 0 aumento de gordura no pescoço e via aérea superior encontrada entre os homens ${ }^{59,60}$ Além disso, a instabilidade respiratória mais comum entre os homens poderia também parcialmente explicar a maior prevalência de AOS entre homens. De fato, o limiar de apnéia é mais baixo entre mulheres, fazendo com que oscilações ventilatórias e da $\mathrm{PaCO}_{2}$ mais dificilmente promovam apnéias entre as mulheres. ${ }^{61}$ 


\subsubsection{Idade}

Conforme demonstrado na Figura 2, existe aumento da prevalência da AOS com a idade, atingindo uma estabilização após 65 anos. A contribuição anatômica para a AOS piora com a idade e parece estar relacionada à deposição de gordura ao redor da faringe.$^{58}$ Além disso, o reflexo desencadeado pela pressão negativa na faringe parece deteriorar com a idade. ${ }^{62}$

\subsection{Pressão crítica de fechamento (Pcrit)}

Os fatores que influenciam o calibre da faringe humana durante 0 sono são similares àqueles que determinam o calibre de qualquer tubo colapsável. Exemplos biológicos incluem o colapso das vias aéreas intratorácicas durante expiração forçada, 0 colapso de capilares pulmonares no ápice pulmonar e o colapso das narinas durante uma inspiração forçada.

Um modelo de resistor de Starling, que consiste num tubo colapsável (faringe) dentro de uma caixa selada, interposto por dois segmentos rígidos (nariz e laringe) foi desenvolvido para explicar a relação entre pressão e fluxo da via aérea superior. ${ }^{63,64}$ (Figura 8) 


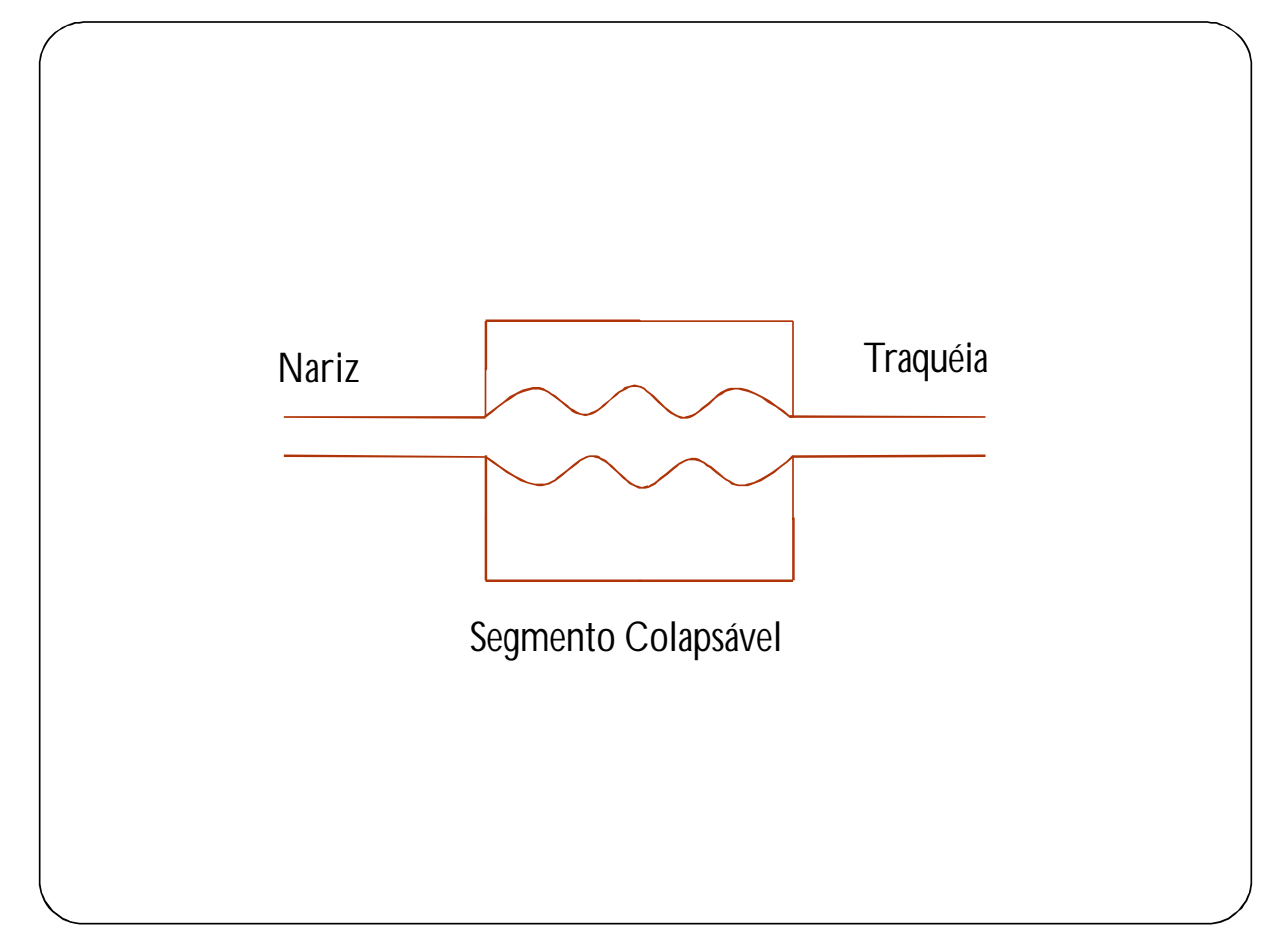

FONTE: Am Rev Respir Dis 1991; 143: 1300-1303

Figura 8 - Modelo do resistor de Starling consistindo de um segmento colapsável dentro de uma caixa selada (faringe) interposto por extremidades rígidas, à montante (nariz) e à jusante (traquéia). Ao redor da faringe, dentro da caixa selada, há estruturas ósseas e tecidos moles que geram pressão tecidual.

A pressão dentro da caixa e fora do tubo colapsável (tecidos e ossos ao redor da faringe) é constante e consiste na pressão tecidual (desde que não haja atividade muscular dilatadora da faringe). Quando a pressão dentro da faringe é menor que a pressão tecidual, há colapso. Caso a pressão dentro da faringe seja maior que a pressão tecidual há abertura da faringe. Desta forma, a pressão tecidual é igual a pressão crítica 
de fechamento da faringe (Pcrit). A Pcrit é definida como a pressão nasal em que 0 colapso da faringe ocorre. 0 gradiente de pressão durante a passagem de ar pelo sistema é definido pela pressão à montante (pressão nasal) - Pcrit e permanece independente da pressão à jusante (pressão traqueal). Este gradiente está relacionado à resistência ao fluxo de ar à montante gerado por estruturas anatômicas (nariz, septo nasal, conchas nasais). Assim, quando se reduz a pressão nasal, o gradiente diminui e limitação ao fluxo de ar se desenvolve. Na condição de limitação de fluxo, a pressão nasal é maior que a pressão traqueal, mas a pressão traqueal é igual à Pcrit. Desta forma, a limitação de fluxo persistirá até que a pressão nasal se iguale à Pcrit. ${ }^{63,65}$ (Figura 9) 
A

B
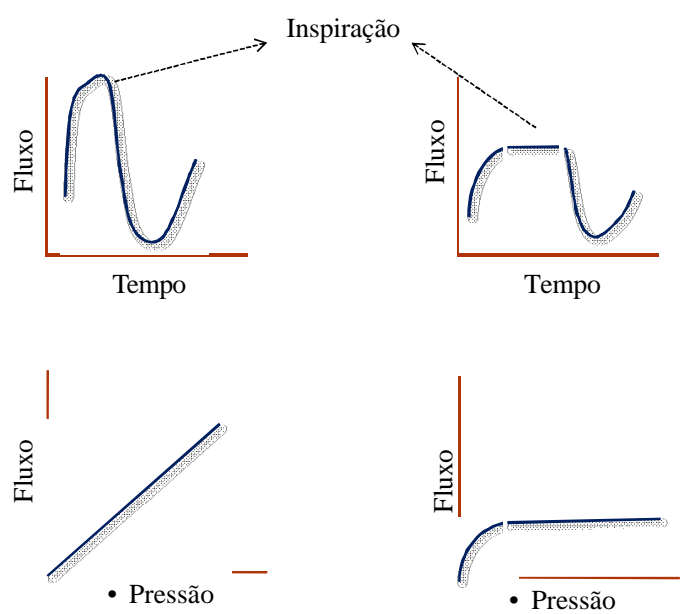

FONTE: Am J Respir crit Care Med 1994; 150: 475-480.

Figura 9 - Representação das curvas de fluxo aéreo, sem (A) e com (B) limitação, em um segmento colapsável. A limitação ao fluxo aéreo pode ser reconhecida pelo achatamento do fluxo inspiratório. Nesta condição (B), o fluxo aéreo aumenta até determinado ponto e depois permanece constante, independente do aumento da pressão traqueal.

Na vigência de limitação de fluxo, a faringe está em colapso parcial e o fluxo inspiratório máximo varia linearmente em função do gradiente (pressão nasal - Pcrit). (Figura 10) Assim, o fluxo inspiratório máximo é independente do aumento da pressão traqueal gerada durante a inspiração. 


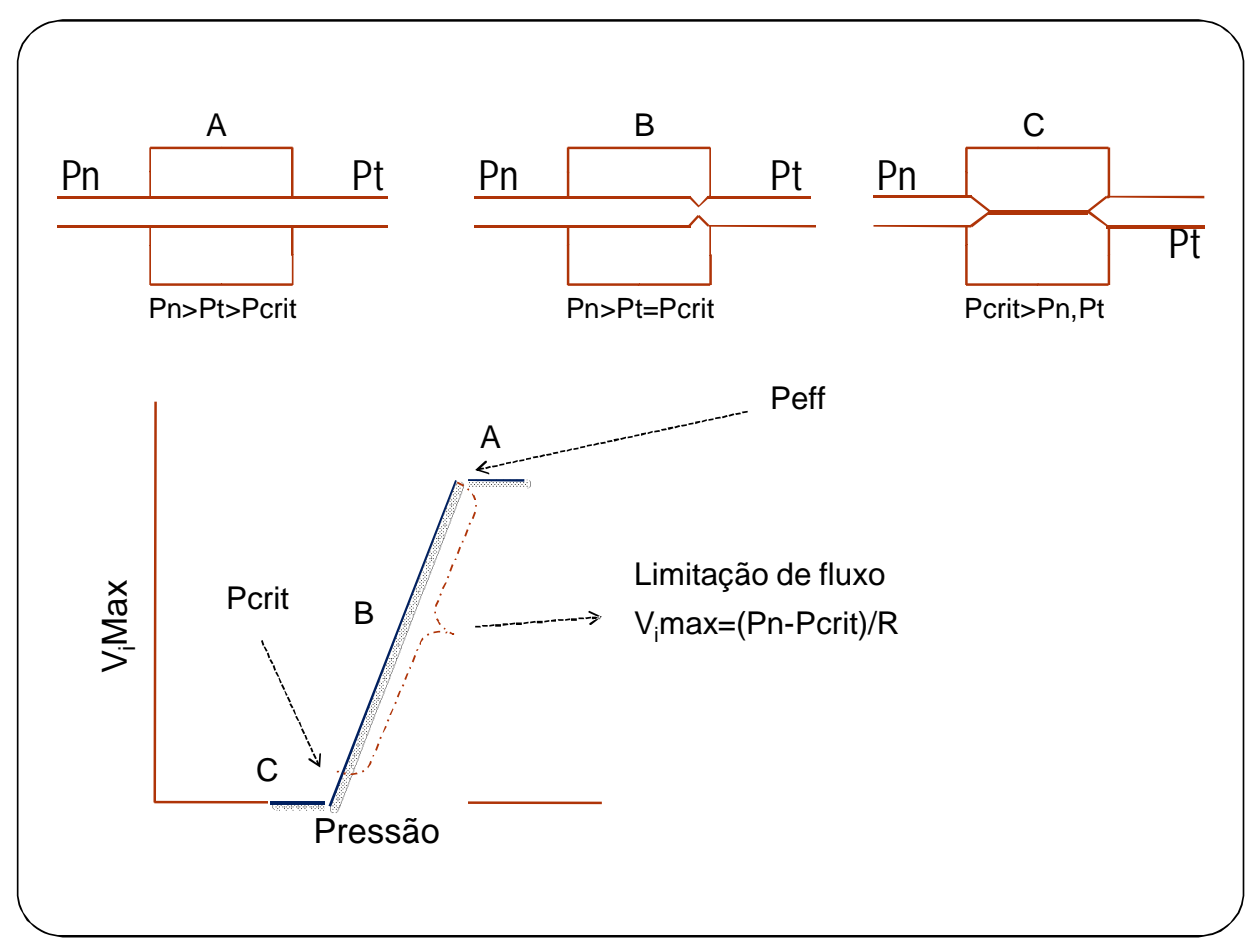

FONTE: Am Rev Respir Dis 1991; 143: 1300-1303

Figura 10 - Comportamento da curva fluxo vs. pressão na vigência de limitação de fluxo e colapso parcial da faringe. $A$, sem restrição de fluxo e faringe totalmente patente; $B$, com limitação ao fluxo e colapso parcial da faringe; $C$, colapso total da faringe. $\mathrm{Na}$ condição $B$, existe um gradiente de pressão decrescente em direção à extremidade traqueal devido à resistência à montante, sendo que a pressão traqueal é próxima à Pcrit. Nesta condição, a faringe está parcialmente colabada e $V_{i} \max$ não depende da variação de pressão traqueal. Assim, existe relação linear de $V_{i} \max$ vs. Pressão Nasal (condição (B)).

Definição das abreviaturas: Pn, pressão nasal; Pt, pressão traqueal; Pcrit, pressão crítica de fechamento; $V_{i} \max$, fluxo inspiratório máximo; $R$, resistência; Peff, pressão efetiva. 
Operacionalmente, é possível determinar a Pcrit através da redução progressiva da pressão nasal até que o fluxo cesse. A Pcrit avalia as propriedades mecânicas das vias aéreas superiores e os seus tecidos circundantes e é considerada uma medida da contribuição do componente anatômico na gênese da AOS. No entanto, a Pcrit varia conforme as condições em que é medida, o que reflete o tônus muscular. A Pcrit do indivíduo acordado é mais negativa que durante 0 sono.$^{66} \mathrm{Em}$ situação de anestesia e paralisia muscular a Pcrit é mais positiva que durante o sono. ${ }^{67}$ Assim, dependendo da situação em que a Pcrit é determinada, além da contribuição das estruturas anatômicas ao redor da via aérea, há também contribuição do tônus dilatador. A fim de se minimizar a influência do tônus dilatador da faringe, titula-se a CPAP até que não haja limitação de fluxo antes de se iniciar o protocolo de determinação da Pcrit. Esta pressão de CPAP é chamada pressão de manutenção ou "holding pressure". A partir da pressão de manutenção reduz-se a pressão de CPAP por 5 respirações a fim de se determinar limitação ao fluxo aéreo sem que haja tempo para recrutamento da musculatura dilatadora. Este método de determinação da Pcrit denomina-se Pcrit passiva. A fim de se determinar a contribuição do recrutamento da musculatura dilatadora da via aérea, tem-se utilizado outro método de determinação da Pcrit (Pcrit ativa). Nesta modalidade, induz-se limitação ao fluxo por tempo maior (3 a 5 minutos), permitindose ativação da musculatura. ${ }^{68}$

Foi descrito um espectro da Pcrit progressivamente positivo em indivíduos normais, com ronco, hipopnéias e apnéias ${ }^{63}$ (Figura 11), o que evidencia que a Pcrit 
pode diferenciar todo espectro da AOS. A determinação da Pcrit permite o estudo da fisiopatologia da AOS em diversas situações como: diferenças entre gêneros, diferenças entre indivíduos jovens e idosos, diferenças entre posições do corpo, diferenças entre fases do sono. A medida da Pcrit tem sido proposta também para a avaliação de diversos tipos de tratamento da AOS. ${ }^{63}$ Como indivíduos normais tem Pcrit ao redor de $8 \mathrm{cmH2O}$, é possível estimar que seja necessário uma diferença entre a pressão nasal e a Pcrit de pelo menos $8 \mathrm{cmH}_{2} \mathrm{O}$ a fim de se abolir a $\mathrm{AOS}^{63}$ Indivíduos com hipopnéias e com apnéias têm Pcrit entre $-4 \mathrm{cmH} 2 \mathrm{O}$ e $+4 \mathrm{cmH} 2 \mathrm{O}$. Desta forma, é possível tratar a AOS através do aumento da pressão nasal com a aplicação de CPAP entre $+4 \mathrm{cmH}_{2} \mathrm{O}$ e $+12 \mathrm{cmH}_{2} \mathrm{O}$ em geral. Por outro lado, tratamentos da AOS que permitam a redução da Pcrit (p.ex. avanço mandibular, posição lateral, cirurgia) podem também alargar o gradiente (pressão nasal - Pcrit), protegendo a faringe do colapso. A redução da Pcrit a valores inferiores a $-4 \mathrm{CmH}_{2} \mathrm{O}$ permitiria um controle razoável da AOS. Desta forma, a determinação da Pcrit poderia ser útil no planejamento do tratamento do portador de AOS. Cada modalidade de tratamento (avanço mandibular, cirurgia) deve ter um efeito máximo de redução da Pcrit que, no entanto, ainda não foi bem estudado. Assim, a magnitude de efeito na Pcrit permitiria escolher o tratamento ideal de acordo com a Pcrit basal do paciente. ${ }^{63}$ 


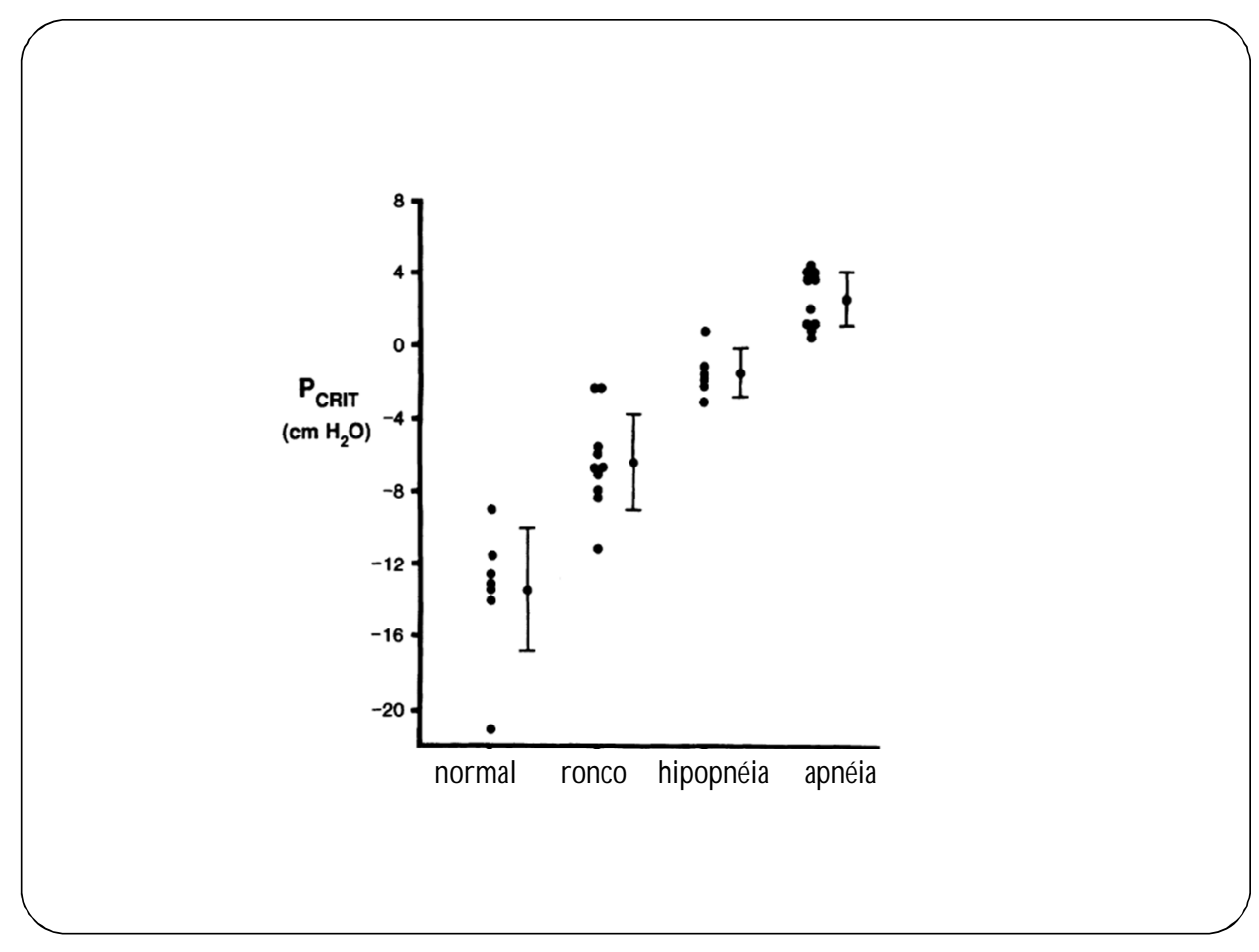

FONTE: Am Rev Respir Dis 1991; 143: 1300-1303

Figura 11 - Pressão crítica de fechamento entre indivíduos normais, roncadores, portadores de hipopnéia e apnéia. Note 0 aumento progressivo da Pcrit desde indivíduos normais até portadores de apnéia obstrutiva.

Definição da abreviatura: Pcrit, pressão crítica de fechamento

Para que ocorra obstrução da via aérea, no entanto, há a interação entre predisposição anatômica (Pcrit) e distúrbio no mecanismo neuromuscular que controla a patência da faringe. Assim, indivíduos obesos, com Pcrit elevada, se tiverem compensação neuromuscular adequada, podem não desenvolver AOS. Por outro lado, indivíduos magros, com Pcrit pouco alterada podem desenvolver AOS significativa caso 
tenham compensação neuromuscular deficiente. ${ }^{68}$ (Figura 12)

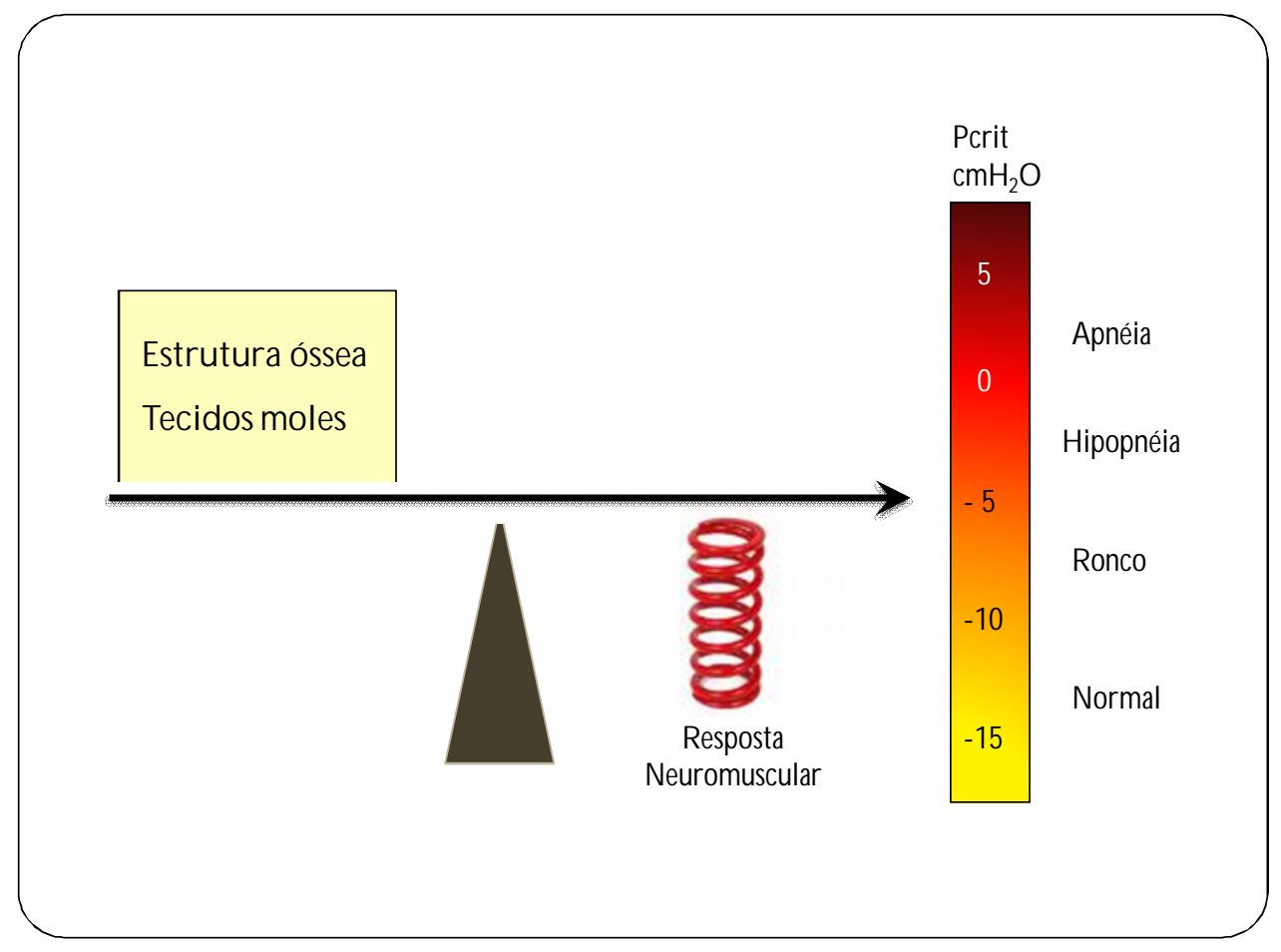

FONTE: J Appl Physiol 2007; 102: 547-557

Figura 12 - Interação entre anatomia e resposta neuromuscular. Indivíduos com obesidade ou alterações crânio-faciais tem predisposição ao desenvolvimento da AOS. Porém, o recrutamento da musculatura dilatadora da faringe pode compensar a anatomia desfavorável. Desta forma, o desenvolvimento de AOS depende de dois fenômenos simultâneos: Anatomia desfavorável e deficiência no sistema de controle neuromuscular.

Definição da abreviatura: Pcrit, pressão crítica de fechamento 


\subsubsection{Pcrit e anatomia da via aérea superior}

Apesar da Pcrit ser considerada uma medida da contribuição anatômica na patogênese da AOS, poucos estudos associaram a Pcrit às características anatômicas. ${ }^{41,69}$ Nenhum estudo avaliou a Pcrit e variáveis anatômicas utilizando tomografia computadorizada da via aérea superior, a qual permite avaliar a via aérea em duas dimensões.

\subsection{Indução do sono}

A determinação da Pcrit é cercada por diversos desafios técnicos que incluem a aplicação de dispositivo de CPAP, controle de vazamento da máscara, titulação da pressão de CPAP, reconhecimento dos estágios do sono e dos padrões de limitação ao fluxo de ar. A necessidade, durante a noite, de pesquisadores treinados nestas técnicas limita a determinação da Pcrit, realizada em apenas alguns centros no mundo. A avaliação da Pcrit foi feita previamente durante sedação ou anestesia geral. ${ }^{66,67,70-76}$ No entanto, o uso de sedativos poderia aumentar a colapsabilidade das vias aéreas superiores e o risco de depressão respiratória e poderia ainda interferir na arquitetura do sono. Por outro lado, a indução do sono com midazolam e propofol têm sido utilizados para permitir a realização de polissonografia e sono-endoscopia da faringe

durante o dia. ${ }^{77-79}$ Deste modo, a indução do sono poderia representar uma alternativa 
para a determinação da Pcrit. No entanto, não existem dados comparando a Pcrit obtida durante o dia após a indução do sono e durante o sono natural.

\subsubsection{Midazolam}

0 midazolam é um sedativo benzodiazepínico com meia vida de 3 horas ${ }^{80} \mathrm{e}$ amplamente utilizado como hipnótico por via oral ou para sedação em procedimentos ambulatoriais como endoscopia digestiva e broncoscopia. É utilizado para indução do sono e endoscopia da faringe (sonoendoscopia) a fim de se determinar os locais de obstrução. ${ }^{77,78} 0$ midazolam já foi utilizado ainda para a indução do sono e polissonografia diurna. ${ }^{79,81} \mathrm{Em} 5$ estudos prévios, o midazolam foi utilizado para sedação e a realização da Pcrit. ${ }^{71-75}$

Não há estudos publicados que tenham avaliado a arquitetura do sono após indução do sono com midazolam endovenoso. Estudos que avaliaram benzodiazepínicos via oral como hipnóticos mostraram aumento de fusos, redução do estágio 3 e REM e aumento do estágio $2{ }^{82}$ 
A determinação da colapsabilidade da via aérea superior é um método de estudo da fisiopatologia da via aérea superior e pode ter implicações futuras no manejo dos pacientes portadores da doença. No entanto, poucos centros no mundo utilizam a técnica devido às dificuldades decorrentes da necessidade de investigadores com experiência no reconhecimento polissonográfico dos estágios do sono e dos padrões de limitação ao fluxo aéreo durante a noite.

Nesse contexto, a indução do sono com midazolam poderia representar uma alternativa para a determinação da Pcrit. Fizemos então a hipótese de que a Pcrit determinada durante o sono natural é igual à Pcrit determinada após a indução do sono com dose baixa de midazolam. 
Objetivos 
Primário:

Validar a determinação da Pcrit durante o dia após a indução do sono com midazolam através da comparação com o padrão ouro que consiste na determinação durante o sono natural noturno.

Secundários:

1. Avaliar a arquitetura do sono após a indução do sono com midazolam endovenoso, bem como a segurança do procedimento

2. Comparar a Pcrit com a anatomia da via aérea superior

3. Determinar se a Pcrit pode discriminar um grupo de pacientes com AOS mais grave (com predomínio de apnéias) de outro mais leve (hipopnéias). 


\section{Métodos}




\subsection{Sujeitos}

Indivíduos do sexo masculino sob investigação ou com diagnóstico recente de AOS do ambulatório de distúrbios do sono da Disciplina de Pneumologia do Hospital das Clínicas da Faculdade de M edicina da Universidade de São Paulo, com idade entre 18 e 70 anos foram convidados a participar. Indivíduos com IMC> 40 $\mathrm{kg} / \mathrm{m} 2$, obstrução nasal significativa e anomalias craniofaciais foram excluídos. Todos os participantes assinaram termo de consentimento livre e esclarecido antes da entrada no estudo, que foi aprovado pelo Comitê de Ética em Pesquisa do Hospital das Clínicas da Faculdade de Medicina da Universidade de São Paulo (Anexo 1).

\subsection{Avaliações}

Os indivíduos foram submetidos a uma avaliação clínica detalhada, que incluiu idade, peso, altura e medidas da circunferência do pescoço e circunferência abdominal, questionário de sonolência de Epworth, doenças concomitantes, diagnóstico prévio de AOS, utilização atual de CPAP, medicação em uso. 0 índice de massa corpórea (IMC) foi calculado como peso/altura². Este estudo é parte de um projeto de pesquisa que pretende comparar aspectos anatômicos e funcionais relacionados à fisiopatologia da AOS entre descendentes de Japoneses e Brancos.

Todos os sujeitos foram submetidos a uma polissonografia diagnóstica, seguida pela determinação da Pcrit após indução do sono pela manhã, bem como a 
determinação da Pcrit durante o sono natural em um exame separado e dentro de um mês. A tomografia computadorizada da cabeça e pescoço foi realizada no período da tarde, imediatamente antes da PSG basal. (Figura 13) As avaliações clínicas, polissonografias e exames para determinação da Pcrit foram realizados no Laboratório do Sono do Instituto do Coração (InCor). Os exames de tomografia de cabeça e pescoço foram realizados no Instituto de Radiologia (InRad).

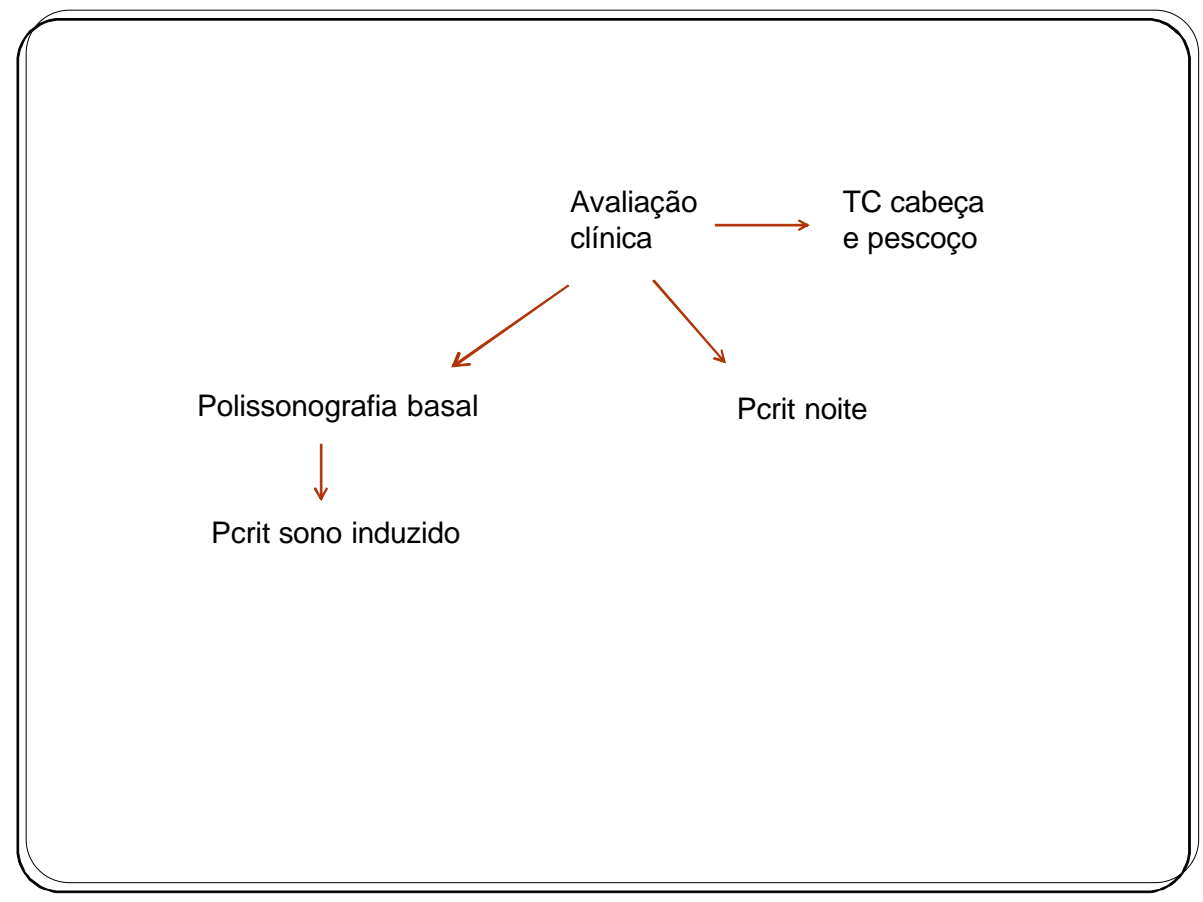

Figura 13 - Desenho experimental

\subsubsection{Avaliação tomográfica vias aéreas superiores}

Todos os indivíduos foram submetidos à tomografia computadorizada de cabeça e pescoço para avaliar índices cefalométricos e áreas transversais das vias 
Métodos 38

aéreas ao nível da velofaringe e hipofaringe. (CT Brilliance 16, Philips, Best, Holanda). Os exames foram realizados na posição supina com a cabeça em posição neutra. As imagens foram obtidas durante a respiração tranqüila. As medidas cefalométricas foram feitas após a reconstrução multiplanar sagital, utilizando os pontos de referências ósseos e de partes moles. As definições destas medições são mostradas na Figura 14. As imagens axiais foram usadas para medir as áreas seccionais das vias aéreas superiores, ao nível da velofaringe e hipofaringe, Também foram medidos os diâmetros da parede lateral da faringe e da gordura parafaríngea. Todas as medições foram feitas com paquímetro eletrônico por um único investigador. 


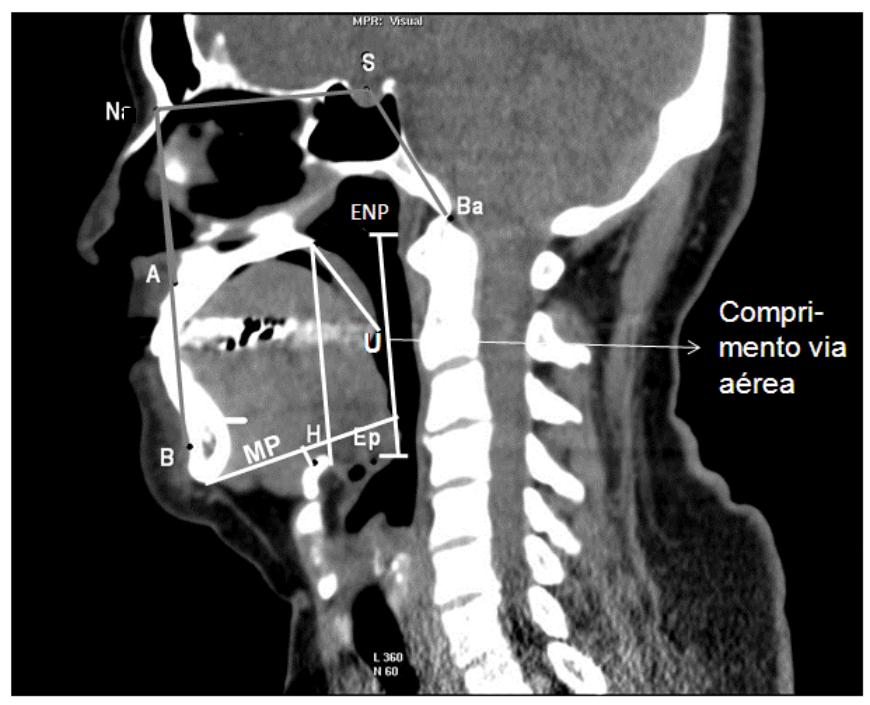

Figura 14a - Variáveis analisadas em corte sagital de tomografia computadorizada

Definição das abreviaturas: A, ponto mais profundo na curva da maxila entre a espinha nasal anterior e 0 alvéolo dentário; $B$, ponto mais profundo da curva anterior da sínfise mandibular; Ba, base do crânio; S, sela túrcica; N, nasion; SNA, posição da maxila; ENP, espinha nasal posterior; $U$, extremidade inferior da úvula; Ep, base da epiglote, $\mathrm{H}$, hióide; MP, plano mandibular; SNB, posição da mandíbula; NSBa, ângulo da base do crânio; MPH, distância do hióide ao plano mandibular; HENP, distância do hióide à espinha nasal posterior; 


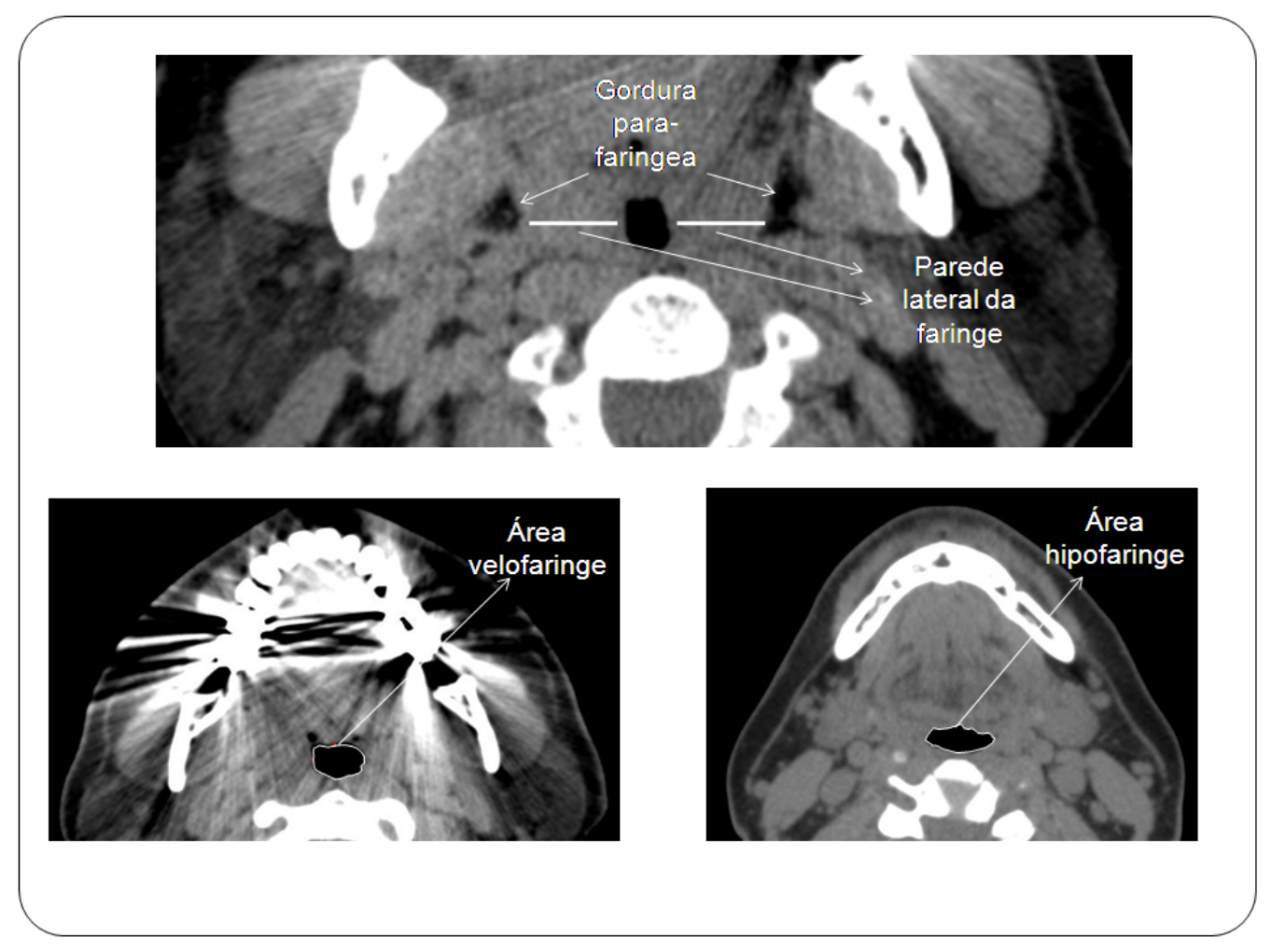

Figura 14 b - Variáveis analisadas em corte axial de tomografia computadorizada

\subsubsection{Polissonografia}

Todos os participantes foram submetidos a uma polissonografia basal durante a noite (Alice 5, Philips Respironics, M urrysville, PA). M esmo pacientes com diagnóstico recente de OSA foram submetidos a esta polissonografia, a fim de padronizar os procedimentos. A monitorização incluiu eletroencefalografia, eletrocardiografia, eletromiografia submentoniana e tibial, oximetria de pulso, fluxo de ar (termístor oronasal e cânula de pressão), e movimentação da caixa torácica e abdominal através de cintas. Apnéia foi definida como a cessação completa do fluxo 
de ar por pelo menos 10 segundos. Hipopnéia foi definida como uma redução significativa ( $>50 \%$ ) do fluxo por pelo menos 10 segundos associada à dessaturação de oxigênio de pelo menos 3\% ou despertar. 0 índice de apnéia-hipopnéia foi calculado como o número total de eventos respiratórios (apnéias mais hipopnéias) por hora de sono.

\subsubsection{Indução do sono}

A indução do sono foi realizada no laboratório do sono, a partir das 08:00hs a seguir da PSG basal. Durante a indução do sono, todos os canais de PSG foram utilizados, com exceção da pressão nasal e do termístor. 0 midazolam foi diluído em uma solução salina com concentração de $1 \mathrm{mg} / 10 \mathrm{ml}$ e infundido em uma veia periférica gota a gota até ser observado o início do sono pela PSG. Se o paciente acordasse e não fosse capaz de adormecer novamente após 10 minutos, a infusão de midazolam era iniciada novamente.

\subsubsection{Determinação da Pcrit}

As medidas da Pcrit foram realizadas em decúbito dorsal. Os indivíduos usaram uma máscara nasal conectada a um pneumotacógrafo aquecido (modelo 3700A, Hans Rudolf, Kansas City, M0) e um transdutor de pressão diferencial (Validyne, Northbridge, CA) para a medição do fluxo inspiratório. A pressão da máscara foi medida continuamente e foi simultaneamente gravada em um canal separado do equipamento de polissonografia para o estadiamento do sono durante 
as quedas de pressão necessárias. A pressão da máscara e o fluxo foram gravados em um computador pessoal usando um conversor analógico-digital (National Instruments, Austin, TX) e um software de aquisição de dados (LabVIEW, National Instruments, Austin, TX). Um dispositivo de CPAP modificado (Philips Respironics, Murrysville, PA) capaz de gerar pressões positivas e negativas foi conectado à máscara.(Figura 15)

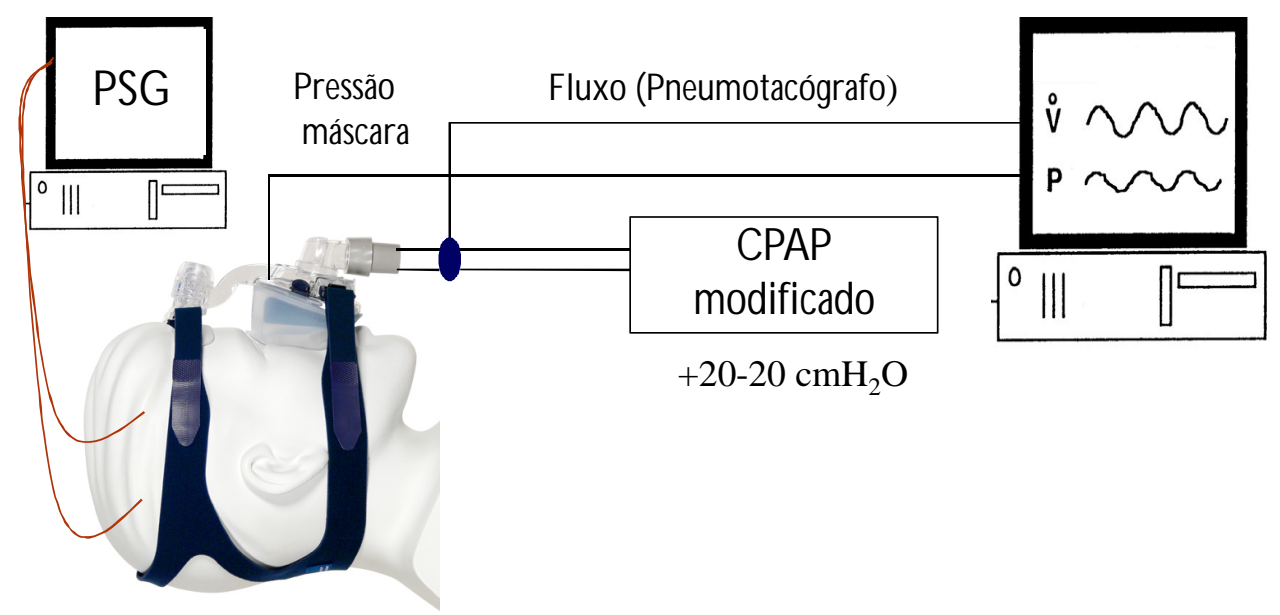

Figura 15 - Representação do equipamento utilizado na determinação da Pcrit

Definição das abreviaturas: PSG, polissonografia; CPAP $+20-20 \mathrm{cmH}_{2} \mathrm{O}$, dispositivo de CPAP (continuous positive airway pressure) modificado capaz de gerar pressões positivas e negativas; $V$, fluxo respiratório; $P$, pressão da máscara. 
Após o início do sono, a pressão de CPAP foi aumentada a fim de suprimir a limitação ao fluxo aéreo. Esse nível de pressão de CPAP foi usado como a pressão de manutenção de CPAP para cada paciente. Uma vez que pelo menos 2 minutos dos estágios 2 ou 3 tivessem sido alcançados, a pressão de CPAP era abruptamente reduzida em 1-2 cmH20 durante a expiração, por cinco respirações.(Figura 16) A pressão de CPAP era então retornada à pressão de manutenção por um minuto antes de ser reduzida em mais 1-2 cmH20, por mais cinco respirações (Figura 17).

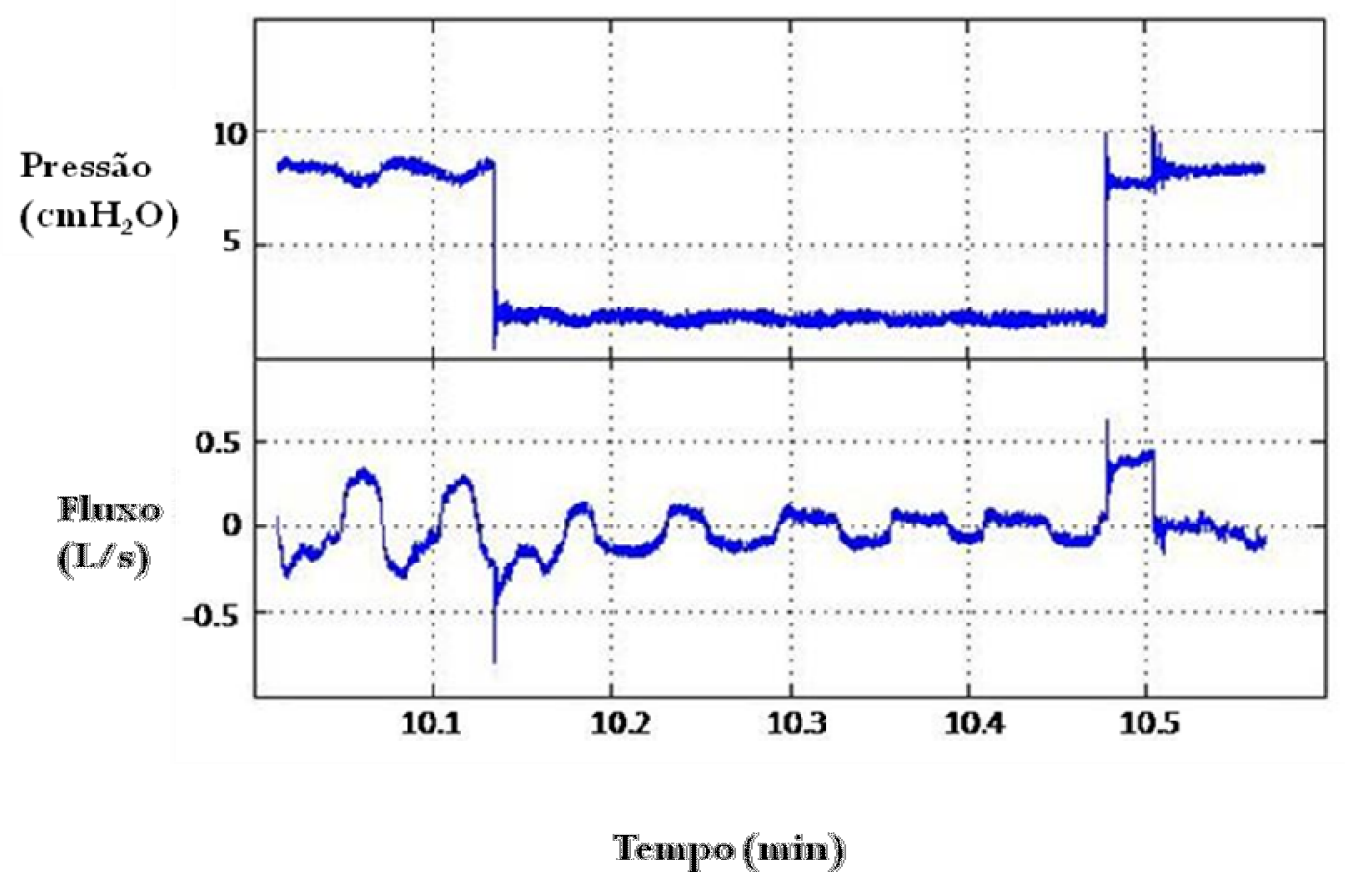

Figura 16 - Detalhe de uma redução de pressão da máscara e surgimento de padrão de limitação de fluxo. 0 fluxo inspiratório máximo e pressão da máscara concomitante das 3ạ. a 5ạ. respirações são utilizados desde que haja padrão de limitação ao fluxo aéreo 


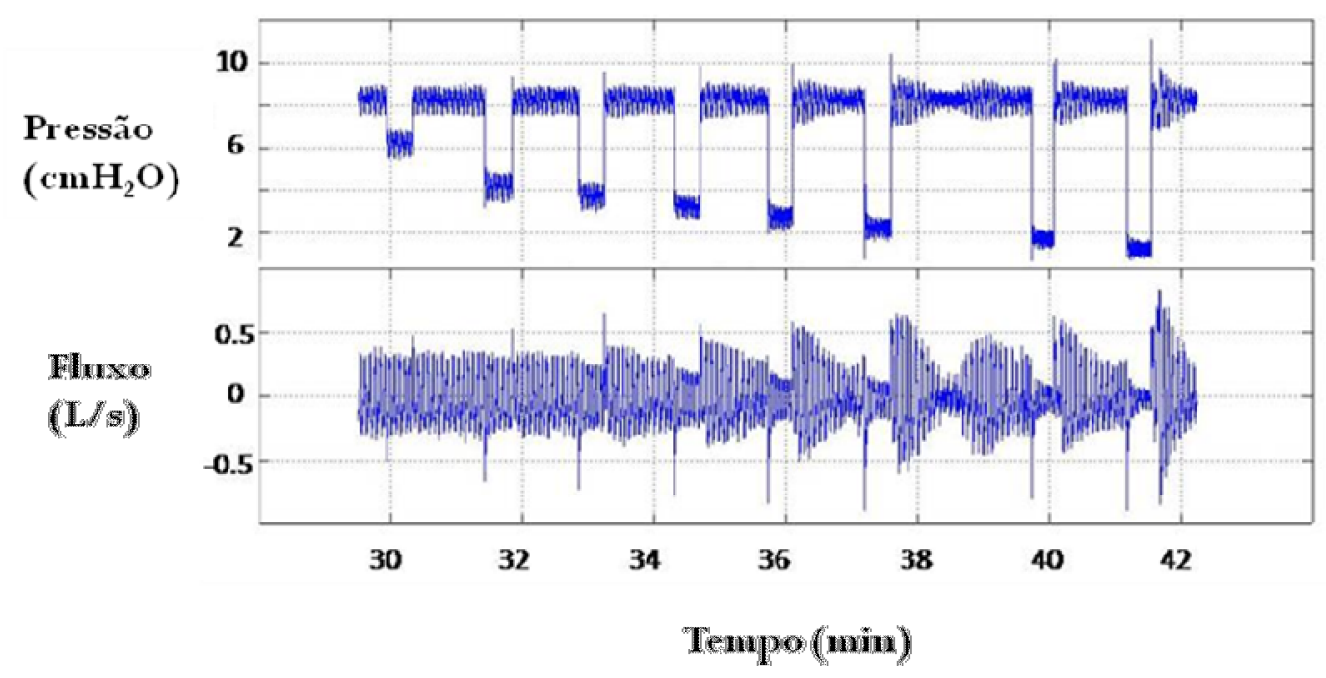

Figura 17- Seqüência de reduções da pressão da máscara e registro concomitante do fluxo aéreo. A pressão da máscara é reduzida progressivamente até que ocorra apnéia obstrutiva.

Este processo de queda progressiva da CPAP prosseguia até que uma apnéia obstrutiva ocorresse. Se houvesse despertar durante a queda de pressão, a CPAP era retornada à pressão de manutenção até que o paciente voltasse a atingir os estágios 2 ou 3. Todo o processo de queda progressiva de CPAP até que houvesse obstrução foi repetido 3-5 vezes em cada paciente. Os dados foram analisados usando um software escrito em Matlab (The MathWorks, Inc., Natick, MA) para determinar o pico de fluxo inspiratório ( $\mathrm{V}_{i} \mathrm{max}$ ) nas respirações 3 a-5 durante a queda de pressão (Figura 16). 0 software foi especialmente desenvolvido para este protocolo, pelo Engenheiro Henrique Takachi M oriya através de colaboração com 0 
Laboratório de Bioengenharia da Escola Politécnica da Universidade de São Paulo. A pressão nasal foi, então, plotada contra $V_{i}$ max. A Pcrit foi determinada como a interceptação do fluxo zero a partir da regressão linear de $V_{i} \max$ versus pressão nasal.(Figura 18) Pcrit foi determinada tanto durante o sono natural, durante uma PSG completa durante a noite como durante o dia durante 0 sono induzido.

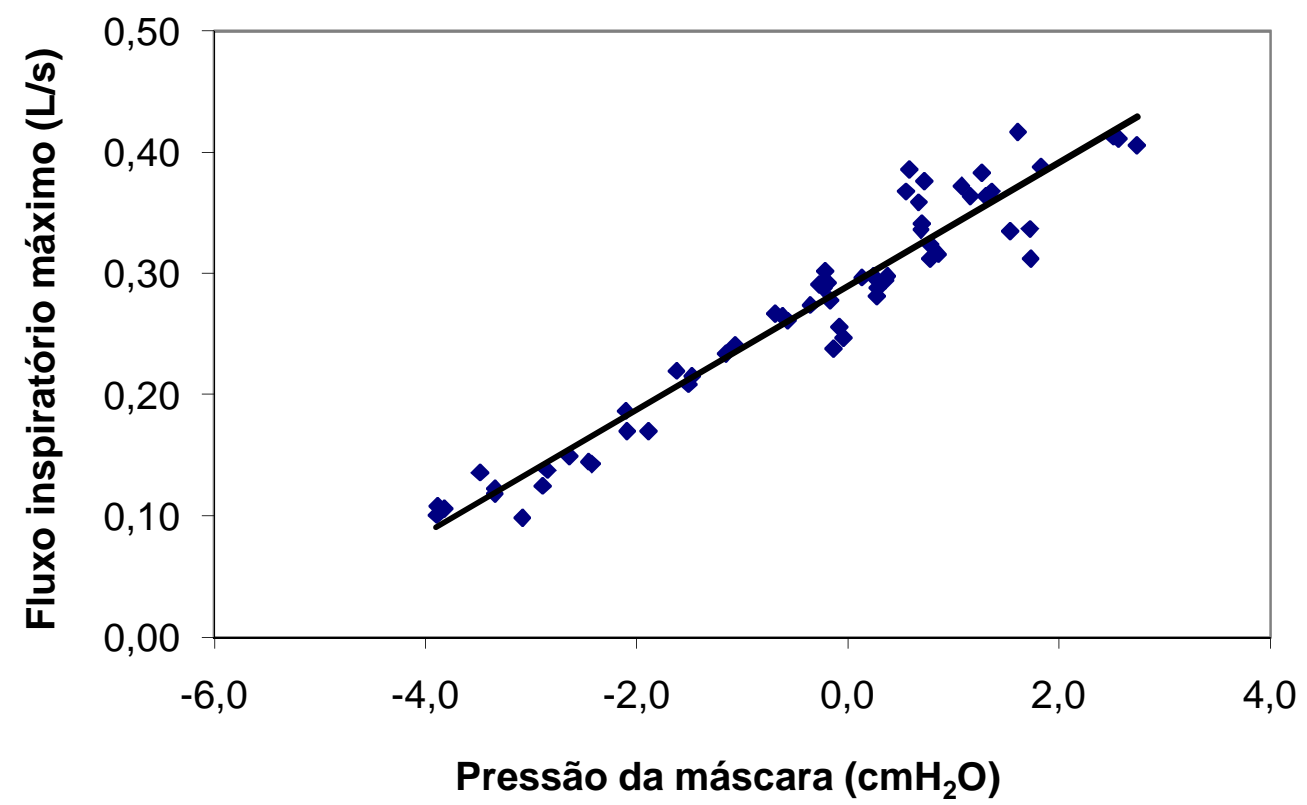

Figura 18- Dispersão dos dados de fluxo inspiratório máximo e pressão da máscara de um exame para determinação da Pcrit e reta de regressão linear. A Pcrit é determinada pela extrapolação da reta ao fluxo zero. 


\subsection{Cálculo amostral}

Os dados para o cálculo amostral foram derivados de um estudo piloto que revelou que o desvio padrão da diferença de Pcrit entre sono natural e sono induzido foi igual a $1,2 \mathrm{cmH}_{2} 0 .{ }^{83}$ Considerando-se uma diferença da Pcrit a partir de $1 \mathrm{cmH}_{2} \mathrm{O}$ como clinicamente relevante e utilizando-se um poder de $80 \%$ e alfa de 0,5\% e teste t de Student para amostras pareadas bi-caudal, obtivemos um número de 14 pacientes.

\subsection{Análise estatística}

Todas as variáveis foram testadas para avaliar se apresentavam distribuição normal (teste de Kolgmorov-Smirnov). Os dados são expressos em média \pm DP ou mediana [intervalo interquartil] quando necessário (distribuição não normal). A Pcrit durante sono normal e sono induzido foram comparadas com o gráfico de Bland-Altman e teste t de Student para amostras pareadas. As características do sono durante a determinação da Pcrit no sono normal e durante 0 sono induzido foram também comparadas com teste t pareado ou teste de Wilcoxon. Uma vez que a Pcrit pode discriminar pacientes conforme o predomínio de eventos (apnéias ou hipopnéias), ${ }^{64}$ os pacientes foram divididos conforme a predominância ( $>50 \%$ ) dos eventos respiratórios (apnéias ou hipopnéias) e comparado utilizando-se um teste t de Student para amostras não pareadas. 0 coeficiente de correlação intraclasse foi utilizado para avaliar a concordância entre as duas medidas da Pcrit no 
mesmo paciente. A análise de correlação de Pearson foi utilizada para avaliar as variáveis antropométricas, anatômicas e da PSG associadas com a Pcrit. Um modelo de regressão linear múltiplo foi utilizado para avaliar as variáveis associadas com a variabilidade do IAH. Para este fim, foram consideradas as variáveis que apresentaram correlação $(\mathrm{P} \varangle, 1)$ com o IAH. 


\section{Resultados}


As características clínicas, antropométricas e da polissonografia basal dos pacientes estudados estão descritas nas Tabela 1 e 2. Dos 15 pacientes, 13 eram descendentes de Japoneses e 2 brancos. 0 sono pôde ser induzido em todos os pacientes com uma dose de $1 \mathrm{mg}^{4}$. A dose total de midazolam durante todo 0 procedimento foi de 2,4 [2,0-4,4mg]. 0 número de doses de midazolam necessárias durante todo o procedimento foi de 3 [ 2-8]. Não houve qualquer intercorrência durante os exames com sono induzido. Não foi necessária a utilização de flumazenil para reversão da ação do midazolam. Todos os pacientes foram dispensados entre 12:00 e 13:00hs.

Tabela 1 - Características clínicas e antropométricas

$$
N=15
$$

Idade, anos

IMC, $\mathrm{Kg} / \mathrm{m}^{2}$

Circunferência abdominal, cm

Circunferência cervical, cm

Escala de sonolência de Epworth

Hipertensão, \%

Diabetes, \%

Dislipidemia, \%

Doença arterial coronariana, \%

Antihipertensivos \%

Antidepressivos, \%

Hipoglicemiantes e insulina,\%

Estatinas, \%

IMC, índice de massa corpórea. Resultados apresentados como média £DP (mínimo e máximo). 
Tabela 2- Polissonografia basal

\begin{tabular}{lc}
\hline Latência para sono, min & $8,7 \pm 3,1$ \\
Eficiência do sono, \% & $79,8 \pm 11,6$ \\
Tempo total do sono, min & $345 \pm 87$ \\
$\mathrm{~S} 1, \%$ & $8,4 \pm 3,1$ \\
$\mathrm{~S} 2, \%$ & $59,3 \pm 8,0$ \\
$\mathrm{~S} 3, \%$ & $12,8 \pm 6,8$ \\
$\mathrm{REM}, \%$ & $16,2 \pm 7,0$ \\
& $38,2 \pm 21,9(8,7-82,8)$ \\
IAH, eventos/h & $69,0 \pm 16,8(10,1-111,9)$ \\
IAH sup, eventos/h & $18,6 \pm 5,9(0-72,9)$ \\
IA, eventos/h & $19,2 \pm 10,9(8,7-46,2)$ \\
IH, eventos/h & $16,3 \pm 12,7(0-37,3)$ \\
Tempo médio de apnéia, seg & $77,8 \pm 11,3(60-92,3)$ \\
Sat $\mathrm{O}_{2}$ M in, (\%) & Resultados apresentados como média \pm DP (mínimo e máximo). IAH, índice de \\
\hline apnéia e hipopnéia; IAH sup , índice de apnéia e hipopnéia na posição supina; IA, \\
índice de apnéia; IH, índice de hipopnéia; Sat $\mathrm{O}_{2}$ M in, saturação mínima de oxigênio.
\end{tabular}

Uma vez que foram utilizadas doses mínimas de midazolam e de forma intermitente e quando necessária, a indução do sono permitiu reproduzir todas as fases do sono observadas durante o sono normal. O hipnograma de um dos pacientes obtido durante o protocolo de determinação da Pcrit em sono natural e sono induzido é representado nas Figuras 19 a e b. 
Figura 19a - Hipnograma de um paciente submetido à determinação da Pcrit após indução do sono

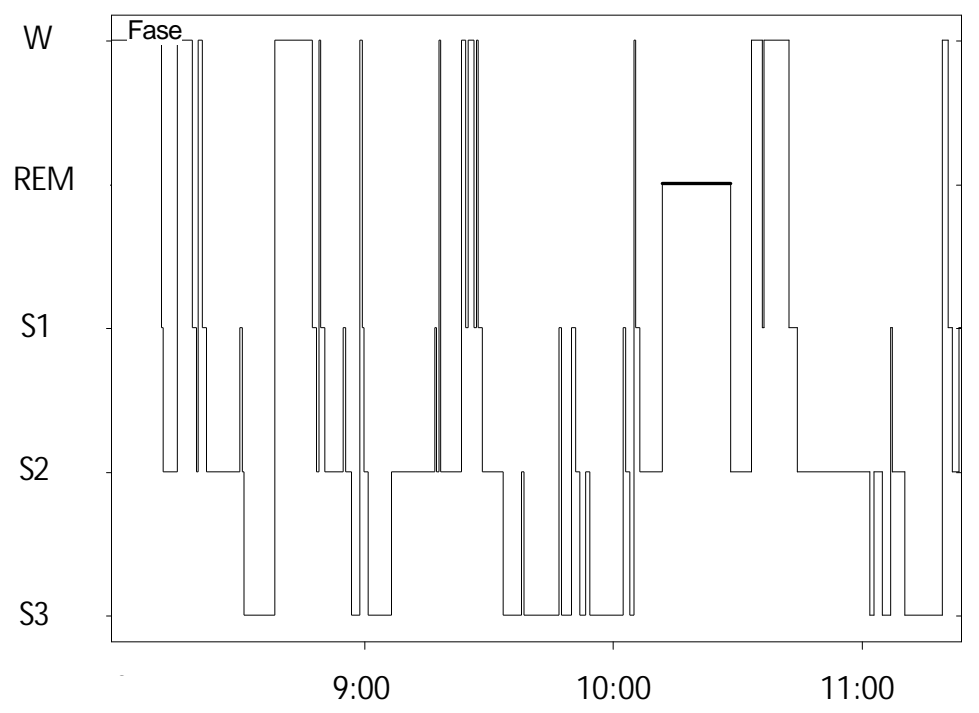

Figura 19b - Hipnograma do mesmo paciente da figura 18a submetido à determinação da Pcrit durante o sono natural à noite

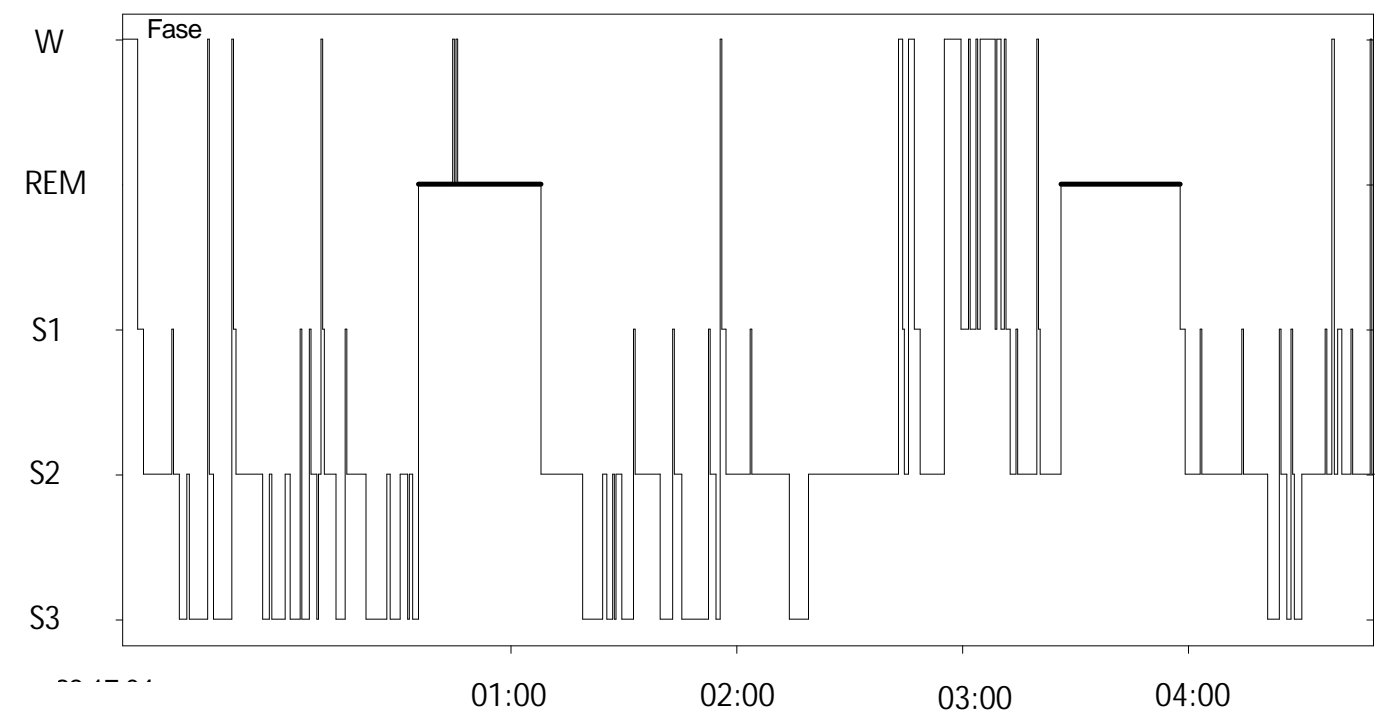


As características do sono durante os estudos para determinação da Pcrit no sono normal e sono induzido são demonstradas na tabela 3.

Tabela 3 - Arquitetura do sono dos estudos de Pcrit com sono natural e induzido

\begin{tabular}{lccc} 
& Sono natural & Sono induzido & $P$ \\
\hline \hline Latência para sono, min & $6,0[4,0-14,5]$ & $8,5[3,5-10,5]$ & 0,502 \\
Eficiência do sono, \% & $78,3 \pm 10,0$ & $77,6 \pm 11,6$ & 0,844 \\
Tempo total do sono, min & $204 \pm 67$ & $139 \pm 38$ & 0,004 \\
S1, \% & $10,5 \pm 5,1$ & $20,6 \pm 8,1$ & 0,001 \\
S2,\% & $61,9 \pm 13,3$ & $55,7 \pm 9,8$ & 0,112 \\
S3, \% & $20,3 \pm 10,5$ & $15,5 \pm 14,0$ & 0,245 \\
REM , \% & $9,4 \pm 8,0$ & $8,2 \pm 8,0$ & 0,712
\end{tabular}

CPAP, pressão positiva contínua na via aérea para abolir a limitação de fluxo; Pcrit, pressão crítica de fechamento

A Pcrit e a pressão de manutenção de CPAP ("holding pressure") de ambos os estudos (sono natural e induzido) são demonstradas na tabela 4. A Pcrit e a pressão de manutenção de CPAP foram similares (tabela 4).

Tabela 4 - Pressão de manutenção de CPAP e Pcrit

\begin{tabular}{lccc} 
& Sono natural & Sono induzido & $P$ \\
\hline CPAP, $\mathrm{CmH}_{2} \mathrm{O}$ & $9,1 \pm 2,6$ & $9,9 \pm 2,0$ & 0,350 \\
Pcrit, $\mathrm{CmH}_{2} \mathrm{O}$ & $-0,82 \pm 3,44$ & $-0,97 \pm 3,21$ & 0,663 \\
\hline
\end{tabular}

CPAP, pressão positiva contínua na via aérea para abolir a limitação de fluxo; Pcrit, pressão crítica de fechamento 
A análise gráfica de Bland-Altman (Figura 20) revela boa concordância entre as medidas (diferença média $0,15 \pm 1,32 \mathrm{cmH}_{2} \mathrm{O}$ ) em toda a faixa de valores de Pcrit. $\mathrm{O}$ coeficiente de correlação intraclasse foi de 0,92 (95\%Cl 0,78-0,97), $\mathrm{P} \varangle, 001$.

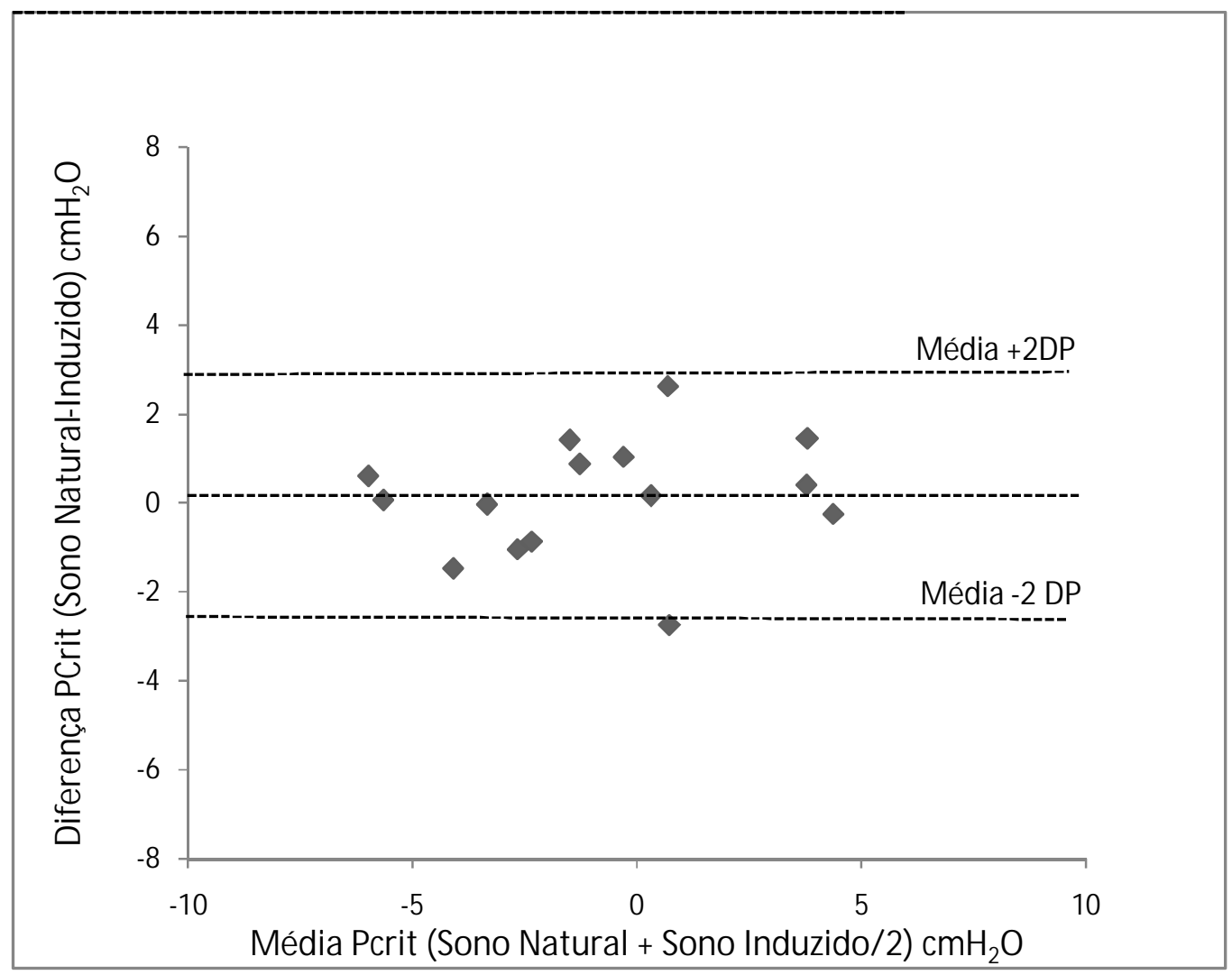

Figura 20 - Gráfico de Bland-Altman

As características dos pacientes classificados conforme a predominância de hiopnéias ou apnéias são mostradas na Tabela 5. Quando comparado com o grupo apnéia, o grupo hipopnéia tinha uma menor circunferência cervical e tenderam a apresentar menor circunferência abdominal. A Pcrit durante sono induzido e sono 
Resultados 54

natural foram menores no grupo hipopnéia, assim com a pressão de manutenção de CPAP.

Tabela 5- Características dos sujeitos conforme a predominância dos eventos respiratórios (hipopnéia vs. apnéia)

\begin{tabular}{|c|c|c|c|}
\hline $\begin{array}{l}\text { Predomínio dos eventos } \\
\text { respiratórios }\end{array}$ & $\begin{array}{l}\text { Hipopnéia } \\
\qquad(\mathrm{n}=9)\end{array}$ & $\begin{array}{c}\text { Apnéia } \\
(n=6)\end{array}$ & $P$ \\
\hline \multicolumn{4}{|l|}{ Variáveis antropométricas } \\
\hline & $52 \pm 10$ & $57 \pm 10$ & 0,381 \\
\hline \multicolumn{4}{|l|}{ Idade, anos } \\
\hline $\mathrm{IMC}, \mathrm{Kg} / \mathrm{m}^{2}$ & $28,8 \pm 3,5$ & $31,6 \pm 4,2$ & 0,210 \\
\hline Circunferência abdominal, cm & $98,8 \pm 6,9$ & $109,5 \pm 9,9$ & 0,051 \\
\hline Circunferência cervical, cm & $40,3 \pm 2,8$ & $45,5 \pm 2,8$ & 0,005 \\
\hline \multicolumn{4}{|l|}{ Polissonografia } \\
\hline $\mathrm{IAH}$, eventos/h & $25,7 \pm 14,7$ & $56,8 \pm 17,2$ & 0,006 \\
\hline $\mathrm{IA}$, eventos $/ \mathrm{h}$ & $3,3 \pm 5,3$ & $41,6 \pm 19,2$ & 0,005 \\
\hline $\mathrm{H}$, eventos/h & $22,4 \pm 13,1$ & $14,5 \pm 3,8$ & 0,122 \\
\hline $\mathrm{IAH}_{\text {sup, }}$ eventos/h & $46,2 \pm 36,8$ & $69,0 \pm 16,8$ & 0,181 \\
\hline Tempo médio de apnéia, seg & $8,2 \pm 8,3$ & 28,5 & $\varangle 0,001$ \\
\hline Sat $\mathrm{O}_{2} \mathrm{Min}$. (\%) & $84,5 \pm 5,7$ & $67,7 \pm 10$ & 0,007 \\
\hline $\mathrm{CPAP}, \mathrm{CmH}_{2} \mathrm{O}$ & $7,7 \pm 1,4$ & $11,2 \pm 2,6$ & 0,022 \\
\hline \multicolumn{4}{|l|}{ Pcrit } \\
\hline Pcrit sono natural, $\mathrm{CmH}_{2} \mathrm{O}$ & $-2,43 \pm 2,75$ & $1,59 \pm 3,09$ & 0,030 \\
\hline Pcrit sono induzido, $\mathrm{CmH}_{2} \mathrm{O}$ & $-2,48 \pm 2,59$ & $1,29 \pm 2,80$ & 0,025 \\
\hline Dose M idazolam, m & $3,1[2,4-4,4]$ & $2,2[1,7-3,4]$ & 0,195 \\
\hline Número de doses de midazolam & $4[2-5,5]$ & $3[2,3-5,3]$ & 1 \\
\hline \multicolumn{4}{|l|}{ Variáveis tomográficas } \\
\hline $\mathrm{MPH}, \mathrm{mm}$ & $14,3 \pm 5,9$ & $21,1 \pm 10,4$ & 0,189 \\
\hline H-ENP, mm & $67,6 \pm 6,7$ & $78,8 \pm 10,1$ & 0,048 \\
\hline Comprimento da via aérea, $\mathrm{mm}$ & $66,9 \pm 5,9$ & $74,9 \pm 7,2$ & 0,051 \\
\hline $\mathrm{NSBa},{ }^{0}$ & $123,3 \pm 3,2$ & $119,8 \pm 8,2$ & 0,465 \\
\hline Comprimento da língua, $\mathrm{mm}$ & $64,9 \pm 6,9$ & $75,1 \pm 10,9$ & 0,079 \\
\hline SNA, ${ }^{\circ}$ & $90,1 \pm 3,6$ & $88,9 \pm 4,6$ & 0,678 \\
\hline
\end{tabular}




\begin{tabular}{lccc}
$\mathrm{SNB}^{\circ}{ }^{\circ}$ & $86,4 \pm 4,6$ & $85,9 \pm 2,9$ & 0,833 \\
$\mathrm{ANB}^{\circ}{ }^{\circ}$ & $3,7 \pm 3,5$ & $3,0 \pm 4,2$ & 0,785 \\
$\mathrm{PMU}, \mathrm{mm}$ & $37,9 \pm 5,4$ & $42,0 \pm 4,1$ & 0,122 \\
$\mathrm{Max}-\mathrm{SP}, \mathrm{mm}$ & $9,8 \pm 1,8$ & $8,9 \pm 1,4$ & 0,296 \\
${\text { Área da velofaringe, } \mathrm{mm}^{2}}^{2}$ & $95,8 \pm 37,9$ & $57,4 \pm 31,4$ & 0,054 \\
Área da hipofaringe, $\mathrm{mm}^{2}$ & $293 \pm 149$ & $337 \pm 130$ & 0,560 \\
Parede lateral da faringe, $\mathrm{mm}$ & $14,5 \pm 4,1$ & $16,6 \pm 4,2$ & 0,354 \\
Gordura para-faríngea, $\mathrm{mm}$ & $8,3 \pm 3,3$ & $8,4 \pm 3,8$ & 0,962 \\
\hline
\end{tabular}

IMC, índice de massa corpórea; IAH,índice de apnéia e hipopnéia, IA, índice de apnéia, IH, índice de hipopnéia; Sat $\mathrm{O}_{2} \mathrm{M}$ in, saturação mínima de oxigênio ; CPAP, pressão positiva contínua na via aérea para abolir a limitação de fluxo; Pcrit, pressão crítica de fechamento; SNA, posição da maxila; SNB, posição da mandíbula; ANB, diferença SNA-ANB; NSBa, ângulo da base do crânio; M PH, distância do hióide ao plano mandibular; H-ENP, distância do hióide à espinha nasal posterior; PMU,comprimento do palato mole, Max-SP, espessura máxima do palato mole perpendicular à PMU.

A tabela 6 demonstra os coeficientes de correlação entre IAH, variáveis antropométricas e polissonográficas e Pcrit (sono natural e sono induzido). A Pcrit durante sono natural e sono induzido se correlacionaram com o IAH (figuras 21 a e b). Os coeficientes de correlação entre ambas as medidas de Pcrit (sono natural e sono induzido) e o índice de apnéias em posição supina ( $\left(A_{\text {sup }}\right)$ (Figura 22)tenderam a ser maiores do que os coeficientes de correlação entre Pcrit e IAH (Figura 21). Ambas as medidas de Pcrit (sono natural e sono induzido) também se correlacionaram com a saturação mínima de oxigênio (Figura 23) e o tempo médio em apnéia (Figura 24). Houve ainda correlação significativa entre IAH e circunferência abdominal (Figura 25). 
Tabela 6 - Coeficientes de correlação de Pearson entre IAH, Pcrit no sono natural e induzido e varáveis antropométricas e polissonográficas.

\begin{tabular}{|c|c|c|c|c|c|c|}
\hline & \multicolumn{2}{|c|}{$\begin{array}{l}\text { IAH } \\
\text { eventos/h }\end{array}$} & \multicolumn{2}{|c|}{$\begin{array}{l}\text { Pcrit sono natural } \\
\qquad \mathrm{cmH}_{2} \mathrm{O}\end{array}$} & \multicolumn{2}{|c|}{$\begin{array}{c}\text { Pcrit sono } \\
\text { induzido } \mathrm{CmH}_{2} \mathrm{O}\end{array}$} \\
\hline & $r$ & $P$ & $r$ & $P$ & $\mathrm{R}$ & $P$ \\
\hline Idade, anos & 0,481 & 0,069 & $-0,126$ & 0,654 & $-0,052$ & 0,853 \\
\hline $\mathrm{IMC}, \mathrm{Kg} / \mathrm{m}^{2}$ & 0,420 & 0,119 & 0,469 & 0,078 & 0,329 & 0,231 \\
\hline $\begin{array}{l}\text { Circunferência abdominal, } \\
\text { cm }\end{array}$ & 0,420 & 0,010 & 0,470 & 0,077 & 0,361 & 0,187 \\
\hline Circunferência cervical, cm & 0,499 & 0,058 & 0,501 & 0,057 & 0,426 & 0,114 \\
\hline $\mathrm{IAH}$, eventos/h & - & - & 0,592 & 0,020 & 0,576 & 0,025 \\
\hline IA, eventos/h & 0,881 & $\varangle, 001$ & 0,664 & 0,007 & 0,715 & 0,003 \\
\hline $\mathrm{IH}$, eventos/h & 0,134 & 0,634 & $-0,256$ & 0,356 & $-0,384$ & 0,157 \\
\hline $\mathrm{IAH}_{\text {Sup, }}$ eventos/h & 0,774 & 0,001 & 0,518 & 0,048 & 0,452 & 0,090 \\
\hline IA $A_{\text {sup }}$, eventos/h & 0,782 & 0,001 & 0,752 & 0,001 & 0,787 & 0,001 \\
\hline $\mathrm{IH}_{\text {sup, }}$ eventos/h & 0,047 & 0,868 & $-0,235$ & 0,399 & $-0,357$ & 0,191 \\
\hline $\begin{array}{l}\text { Tempo médio de apnéia, } \\
\text { seg }\end{array}$ & 0,688 & 0,005 & 0,719 & 0,003 & 0,695 & 0,004 \\
\hline Sat $\mathrm{O}_{2} \mathrm{M}$ in. (\%) & $-0,485$ & 0,067 & $-0,810$ & $<0,001$ & $-0,757$ & $\varangle 0,001$ \\
\hline Pcrit sono natural, $\mathrm{CmH}_{2} \mathrm{O}$ & 0,592 & 0,020 & - & - & 0,923 & $\varangle 0,001$ \\
\hline Pcrit sono induzido $\mathrm{CmH}_{2} \mathrm{O}$ & 0,576 & 0,025 & 0,923 & $<0,001$ & - & - \\
\hline
\end{tabular}

IMC, índice de massa corpórea; IAH, índice de apnéia hipopnéia; IA, índice de apnéia; $\mathrm{IH}$, índice de hipopnéia; Sat $\mathrm{O}_{2} \mathrm{M}$ in, saturação de oxigênio mínima; Pcrit, pressão crítica de fechamento 
Figura 21a - Correlação entre IAH e Pcrit (sono natural)

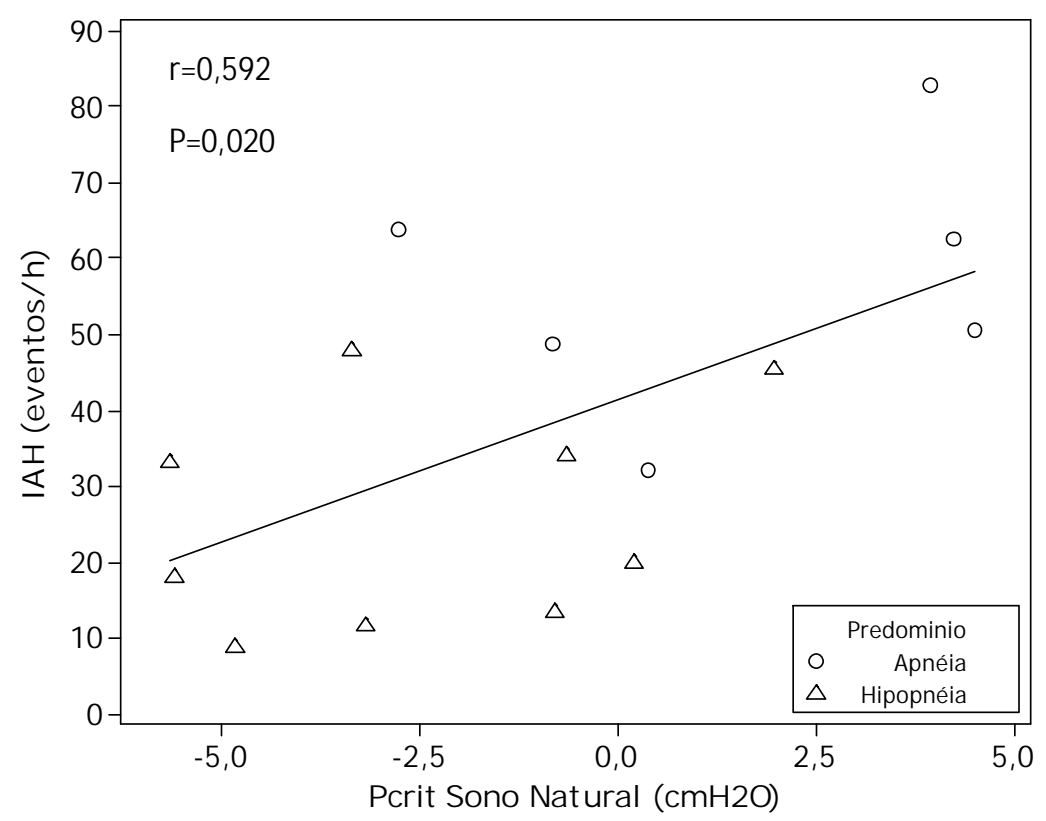

Figura 21b - Correlação entre IAH e Pcrit (sono induzido)

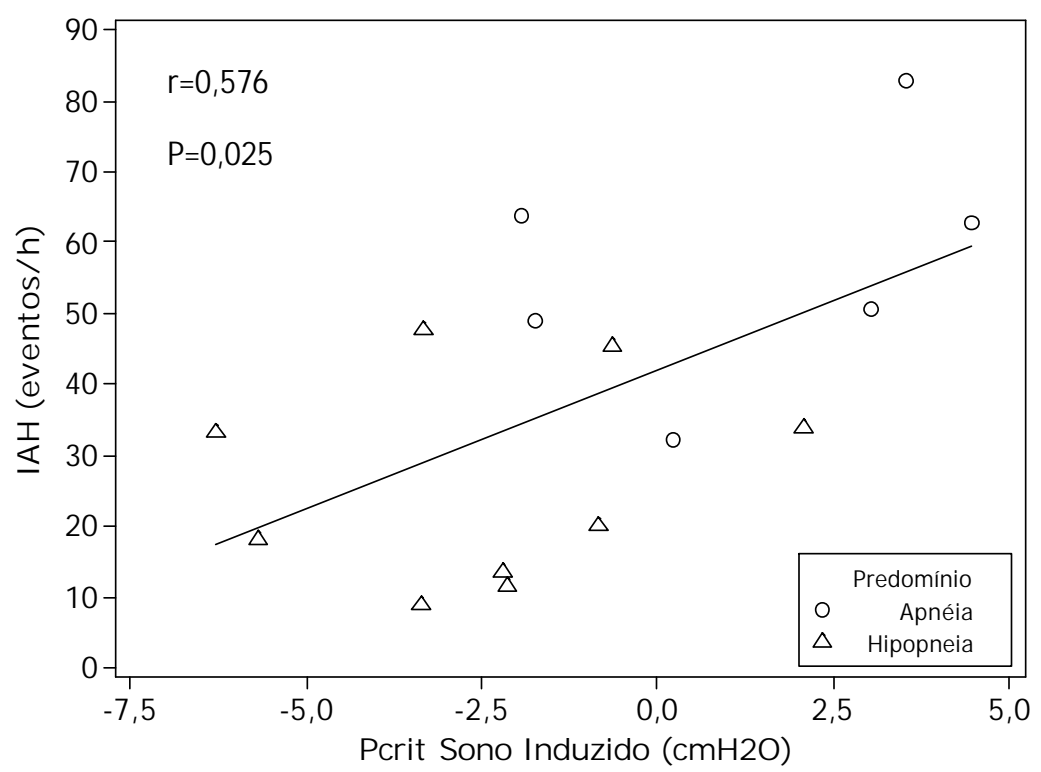


Figura 22- Correlação entre IA $A_{\text {sup }}$ e Pcrit

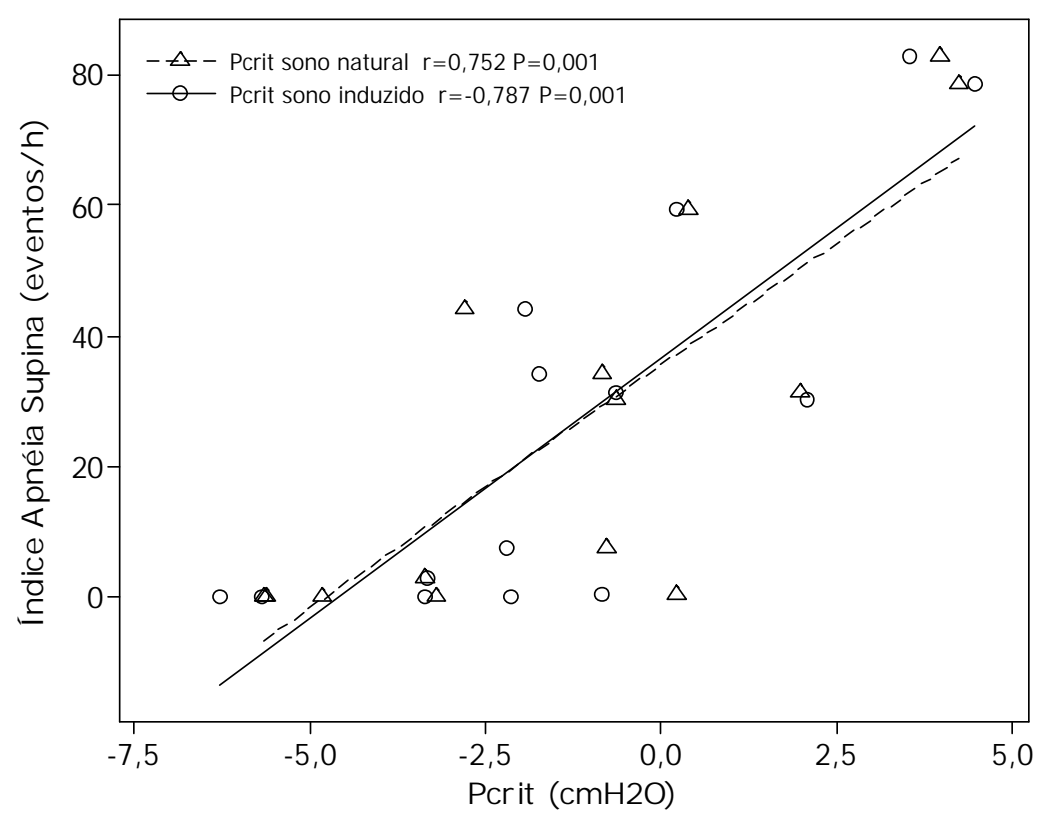

Figura 23- Correlação entre saturação mínima de oxigênio e Pcrit

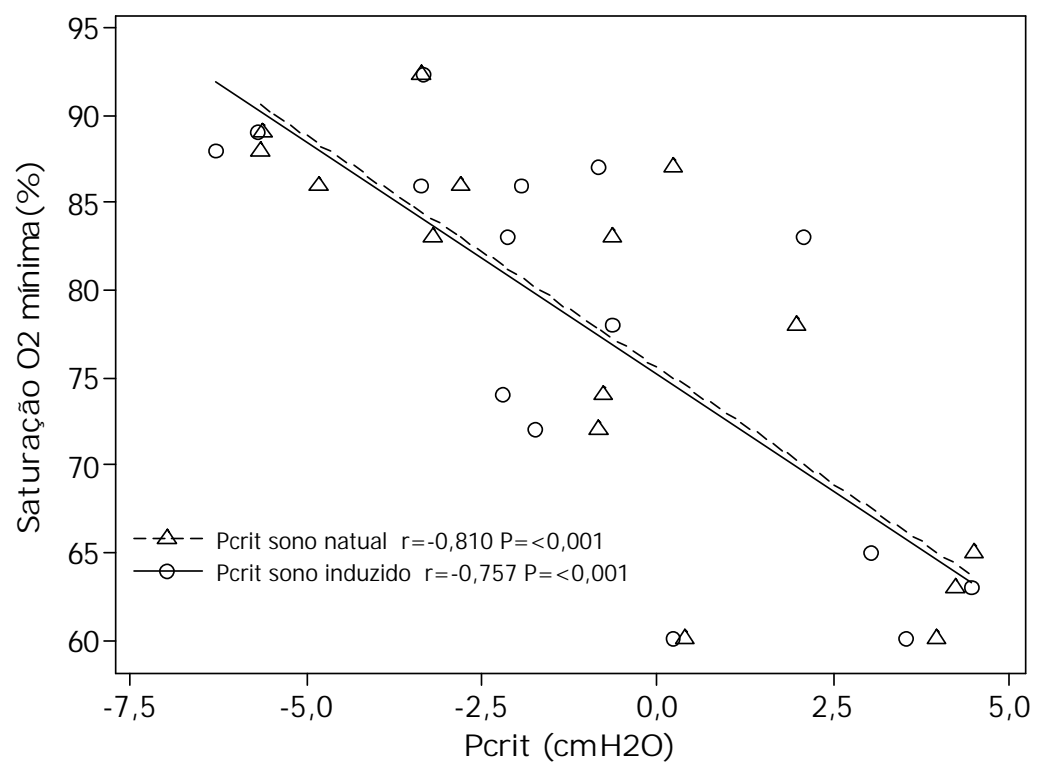


Figura 24- Correlação entre tempo médio de apnéia e Pcrit

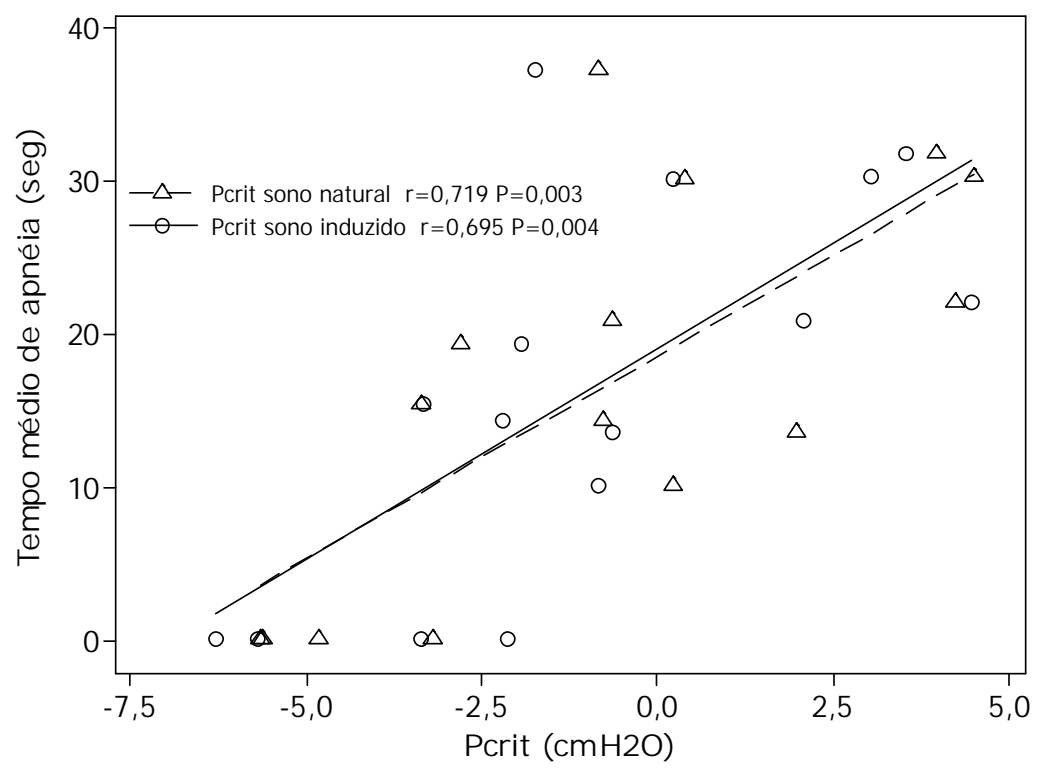

Figura 25- Correlação entre IAH e circunferência abdominal

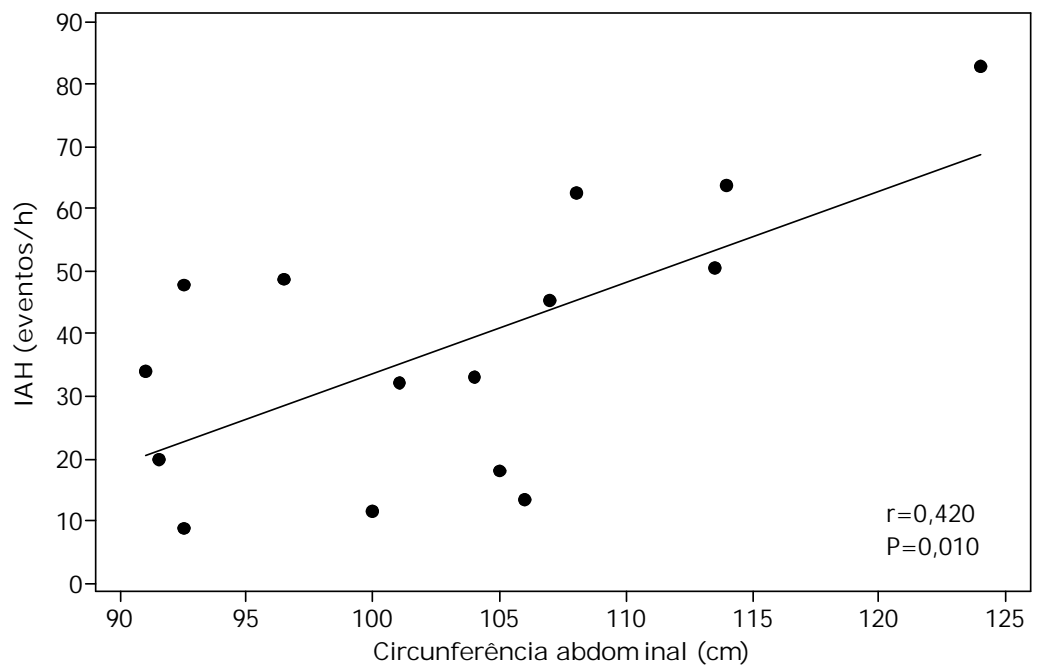


Na tabela 7, estão descritas as associações entre IAH, Pcrit (sono natural e sono induzido) e variáveis tomográficas. Houve correlação significativa do IAH e comprimento da língua (Figura 26), distância MPH (Figura 27), distância H-ENP (Figura 28), comprimento da via aérea (Figura 29) e ângulo NSBa (Figura 30). A Pcrit durante o sono natural e induzido se correlacionaram com a distância M PH (Figura 31), ângulo NSBa (Figura 32) e área da velofaringe (Figura 33). Já a Pcrit durante 0 sono natural se correlacionou com a distância H-ENP (Figura 34), comprimento da via aérea (Figura 35) e parede lateral da faringe (Figura 36). 
Tabela 7 - Coeficientes de correlação de Pearson entre IAH, Pcrit no sono natural e induzido e varáveis tomográficas

\begin{tabular}{|c|c|c|c|c|c|c|}
\hline \multirow[b]{2}{*}{$\begin{array}{l}\text { Comprimento da língua, } \\
\mathrm{mm}\end{array}$} & \multicolumn{2}{|c|}{$\begin{array}{c}\mathrm{IAH} \\
\text { eventos/h }\end{array}$} & \multicolumn{2}{|c|}{$\begin{array}{l}\text { Pcrit sono natural } \\
\qquad \mathrm{CmH}_{2} \mathrm{O}\end{array}$} & \multicolumn{2}{|c|}{$\begin{array}{c}\text { Pcrit sono } \\
\text { induzido } \mathrm{CmH}_{2} \mathrm{O}\end{array}$} \\
\hline & 0,671 & 0,006 & 0,449 & 0,093 & 0,468 & 0,079 \\
\hline Área da língua, mm² & 0,209 & 0,454 & 0,211 & 0,451 & 0,128 & 0,648 \\
\hline $\mathrm{MPH}, \mathrm{mm}$ & 0,594 & 0,020 & 0,602 & 0,018 & 0,577 & 0,024 \\
\hline $\mathrm{H}$-ENP, mm & 0,690 & 0,004 & 0,563 & 0,029 & 0,468 & 0,079 \\
\hline $\begin{array}{l}\text { Comprimento da via } \\
\text { aérea, } \mathrm{mm}\end{array}$ & 0,565 & 0,028 & 0,534 & 0,040 & 0,423 & 0,116 \\
\hline NSBa, ${ }^{0}$ & $-0,622$ & 0,031 & $-0,636$ & 0,026 & $-0,686$ & 0,014 \\
\hline SNA $^{0}$ & 0,052 & 0,873 & 0,116 & 0,720 & 0,309 & 0,329 \\
\hline SNB, ${ }^{\circ}$ & 0,099 & 0,760 & 0,311 & 0,324 & 0,307 & 0,332 \\
\hline ANB, ${ }^{0}$ & $-0,055$ & 0,865 & $-0,224$ & 0,484 & $-0,016$ & 0,962 \\
\hline PMU, mm & 0,274 & 0,324 & 0,311 & 0,260 & 0,118 & 0,675 \\
\hline Max-SP, mm & $-0,134$ & 0,634 & $-0,208$ & 0,457 & $-0,173$ & 0,537 \\
\hline Área da velofaringe, $\mathrm{mm}^{2}$ & $-0,217$ & 0,437 & $-0,603$ & 0,017 & $-0,591$ & 0,020 \\
\hline Área da hipofaringe, $\mathrm{mm}^{2}$ & 0,509 & 0,053 & 0,193 & 0,492 & 0,274 & 0,323 \\
\hline $\begin{array}{l}\text { Parede lateral da faringe, } \\
\mathrm{mm}\end{array}$ & 0,169 & 0,548 & 0,583 & 0,023 & 0,447 & 0,095 \\
\hline $\begin{array}{l}\text { Gordura para-faríngea, } \\
\mathrm{mm}\end{array}$ & 0,047 & 0,868 & $-0,513$ & 0,051 & $-0,429$ & 0,111 \\
\hline
\end{tabular}

IAH, índice de apnéia hipopnéia; Pcrit, pressão crítica de fechamento; SNA, posição da maxila; SNB, posição da mandíbula; ANB, diferença entre SNA e SNB; NSBa, ângulo da base do crânio; M PH, distância plano mandibular-hióide; H-ENP, distância hióide-espinha nasal posterior, PMU, comprimento do pálato mole, Max-SP, espessura máxima do pálato mole perpendicular à PMU. 
Figura 26- Correlação entre IAH e comprimento de língua

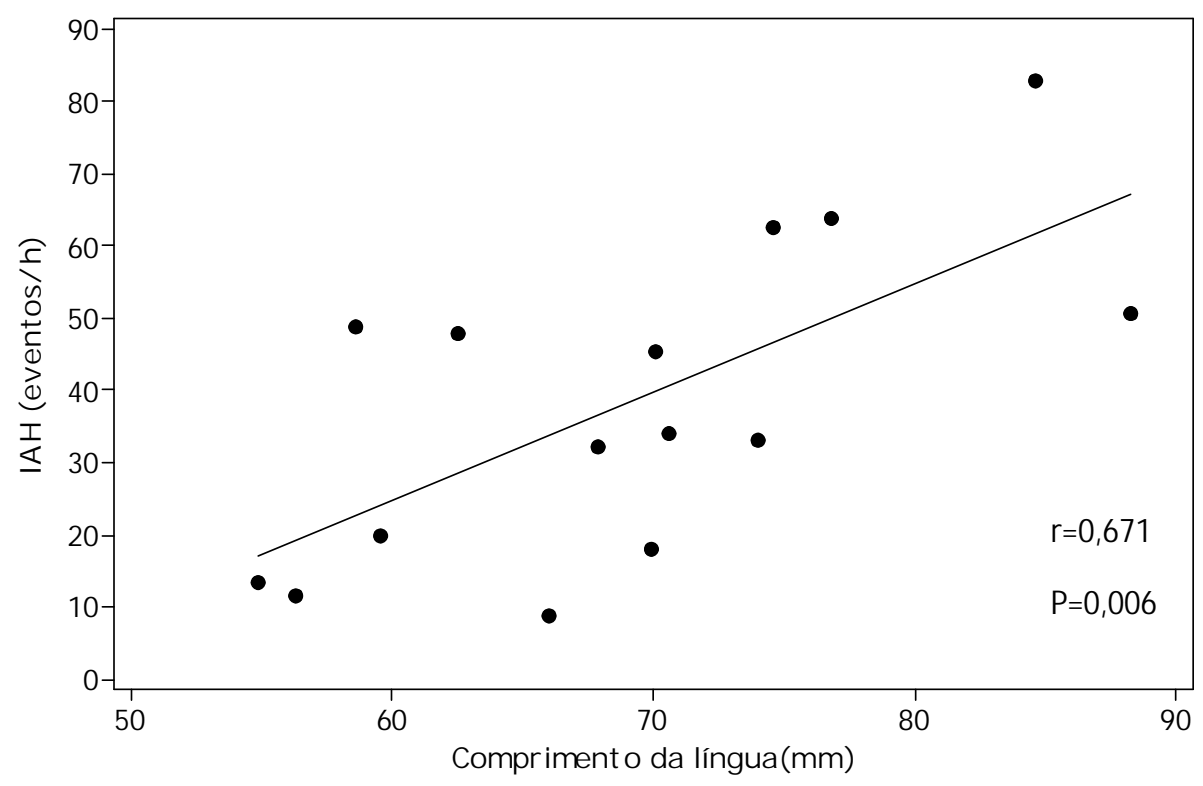

Figura 27- Correlação entre IAH e distância M PH

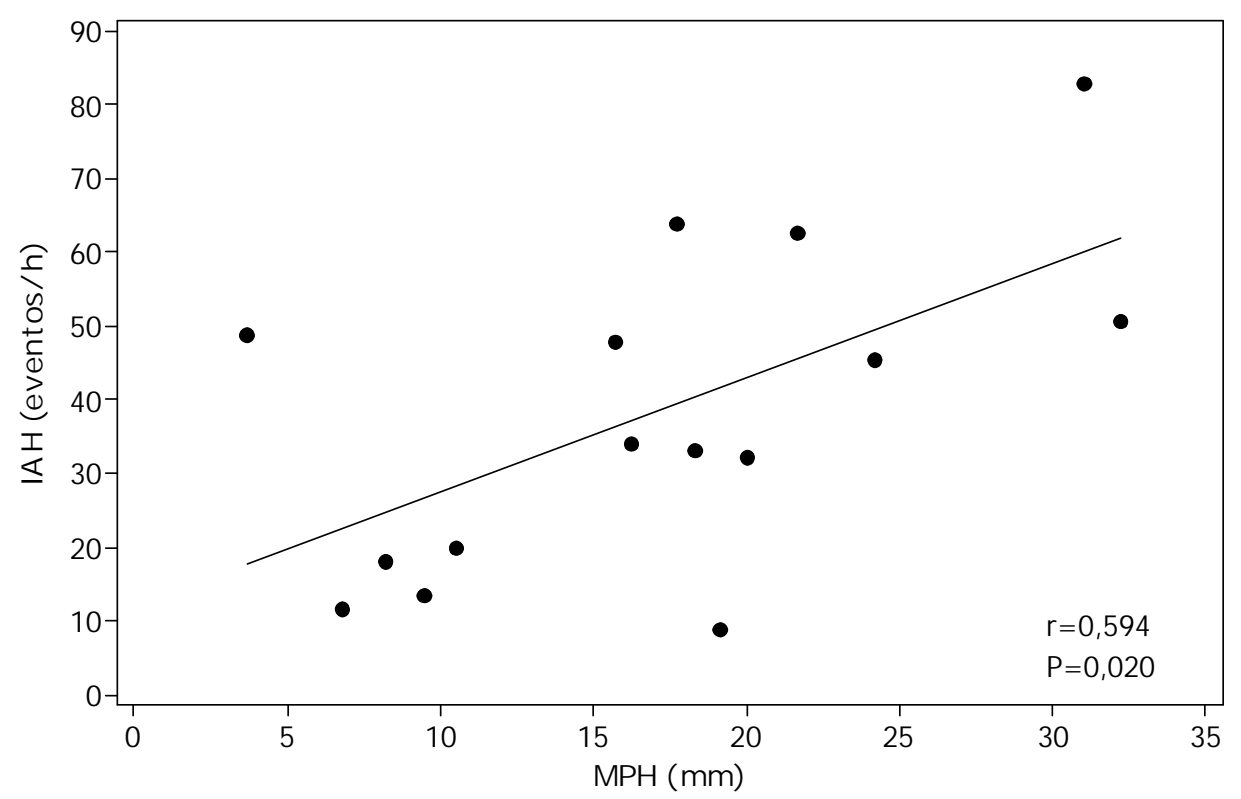


Figura 28- Correlação entre IAH e distância H-ENP

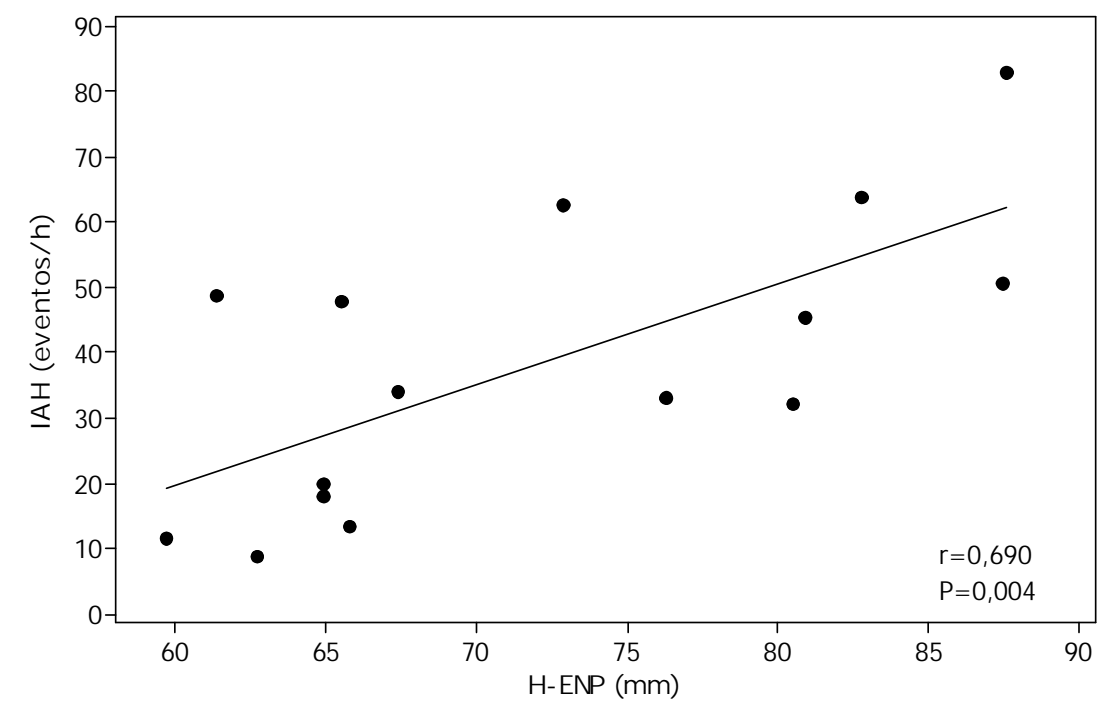

Figura 29- Correlação entre IAH e comprimento da via aérea

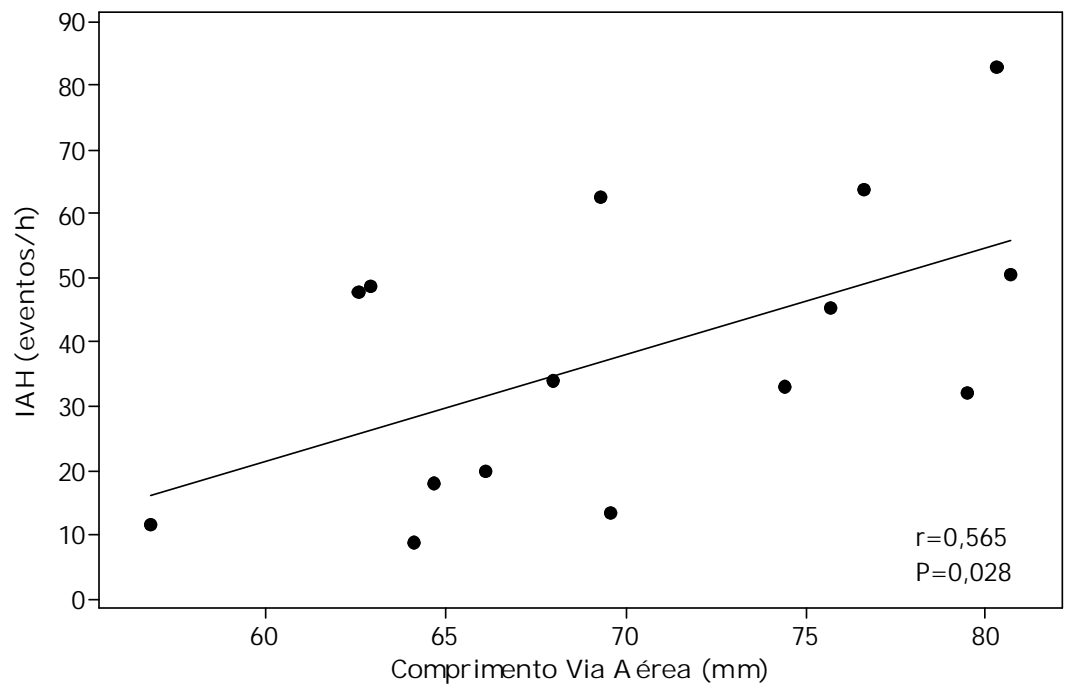


Figura 30 - Correlação entre IAH e ângulo NSBa

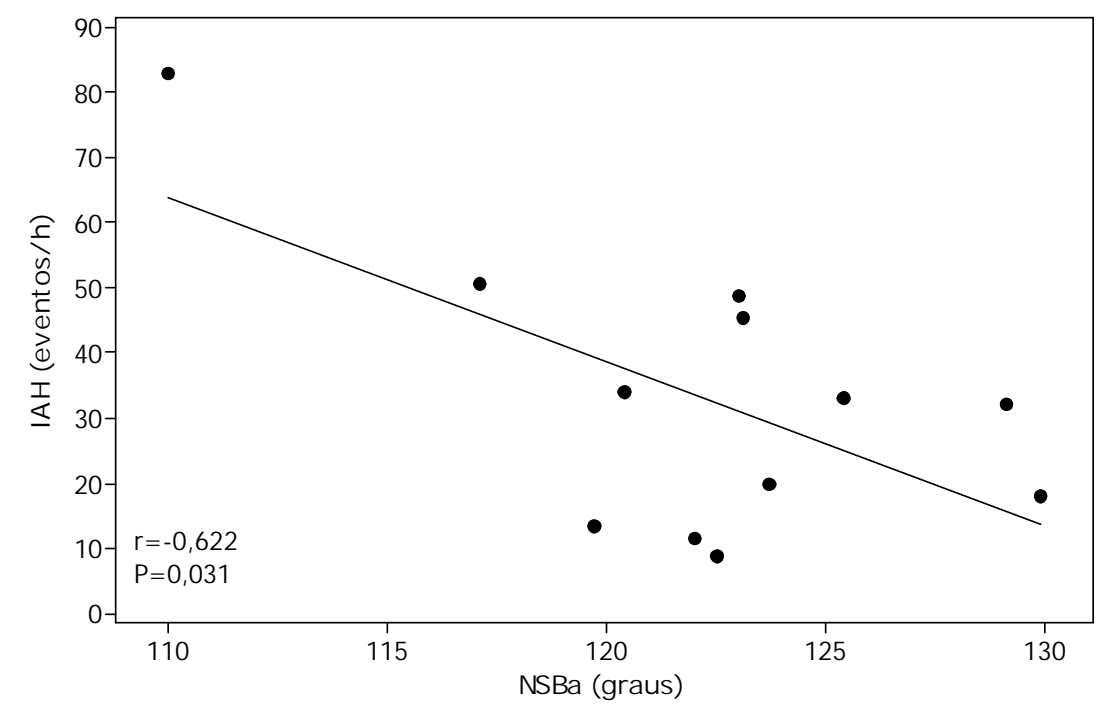

Figura 31 - Correlação entre Pcrit e distância M PH

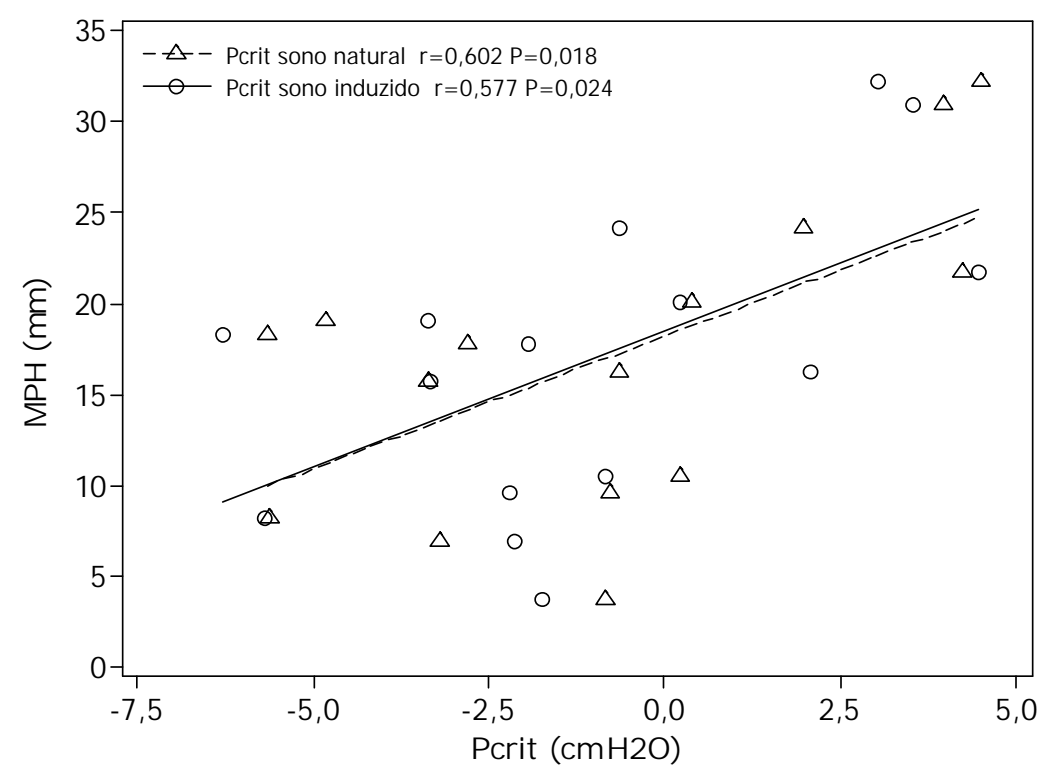


Figura 32 - Correlação entre Pcrit e ângulo NSBa

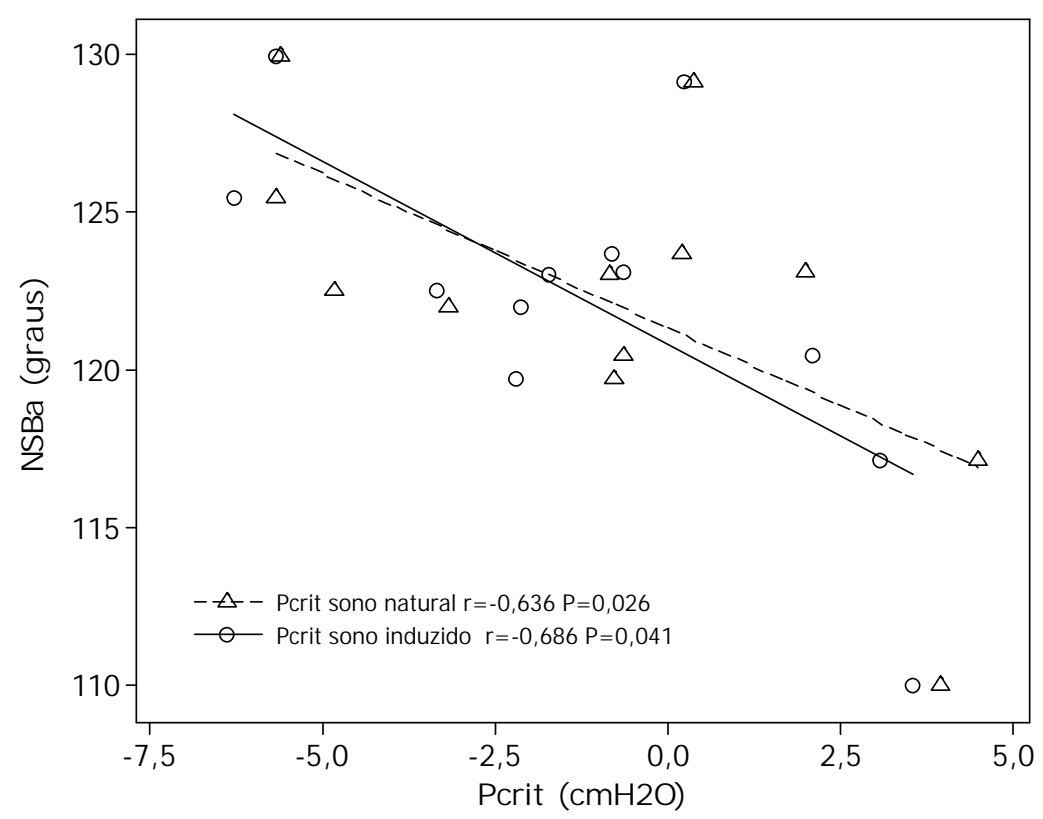

Figura 33 - Correlação entre Pcrit e área da velofaringe

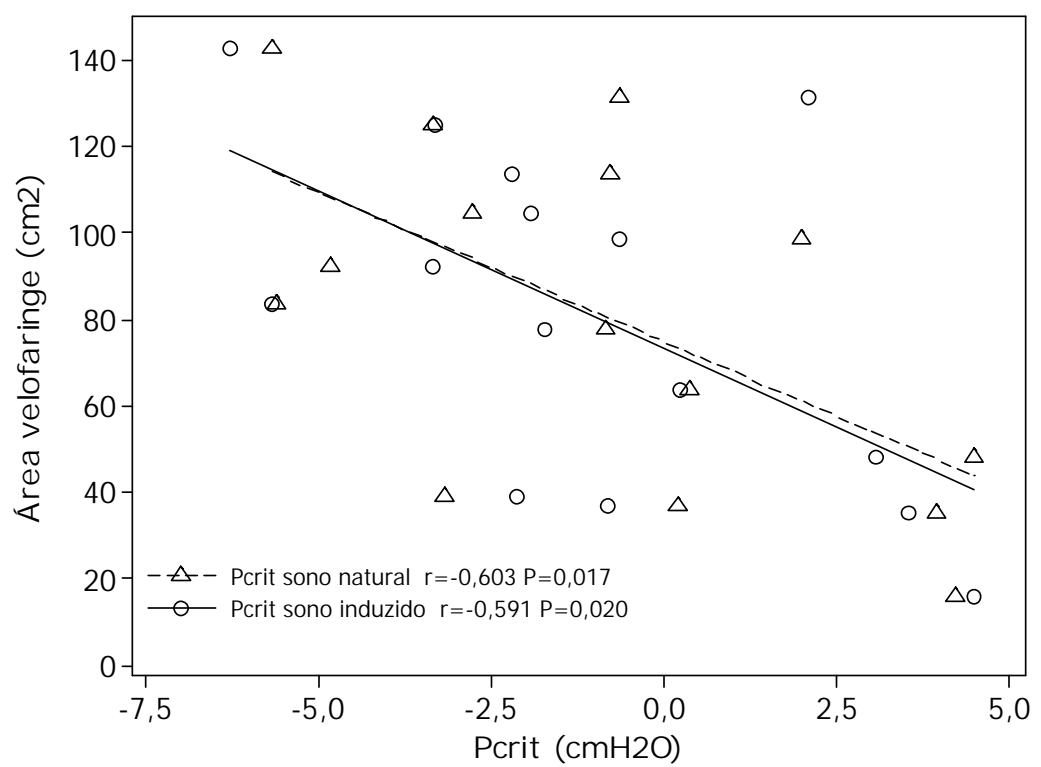


Figura 34 - Correlação entre Pcrit (sono natural) e distância H-ENP

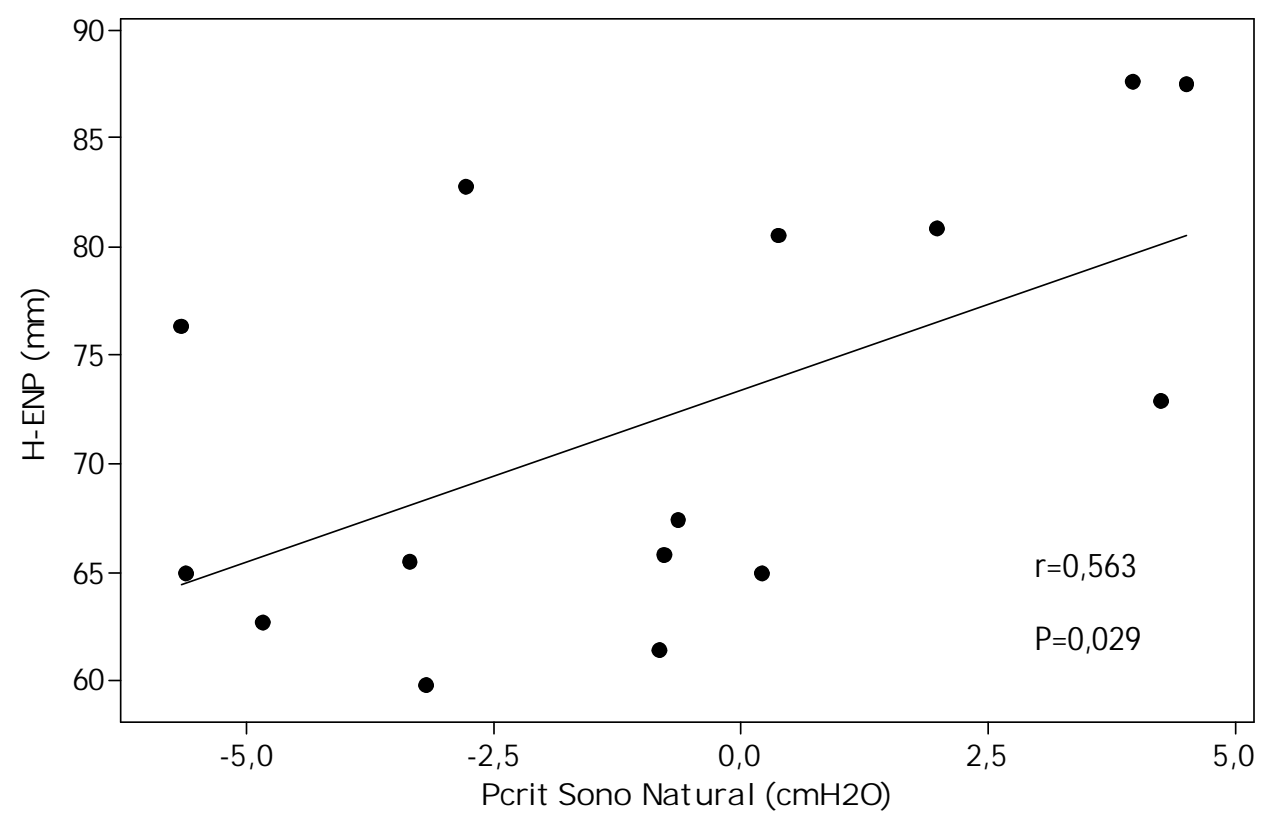

Figura 35 - Correlação entre Pcrit (sono natural) e comprimento da via aérea

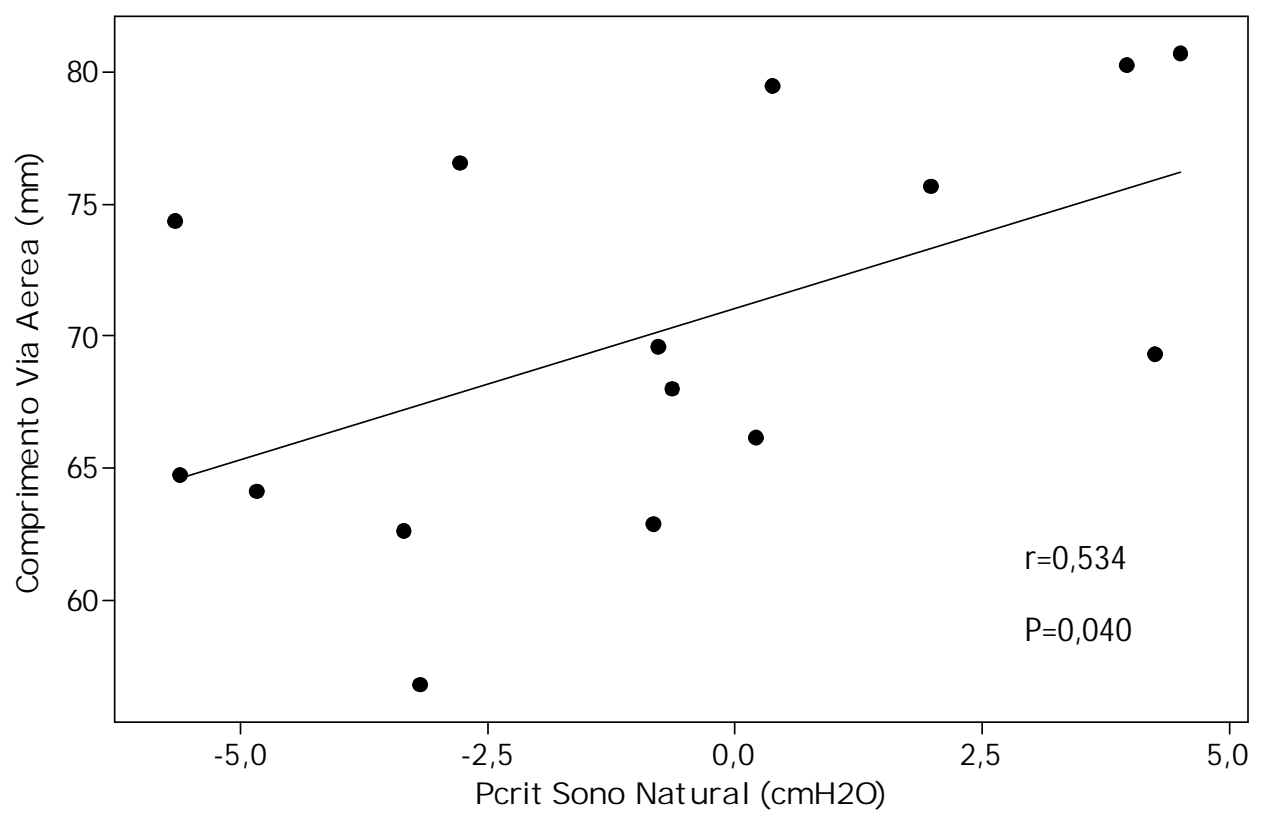


Figura 36- Correlação entre Pcrit (sono natural) e parede lateral da faringe

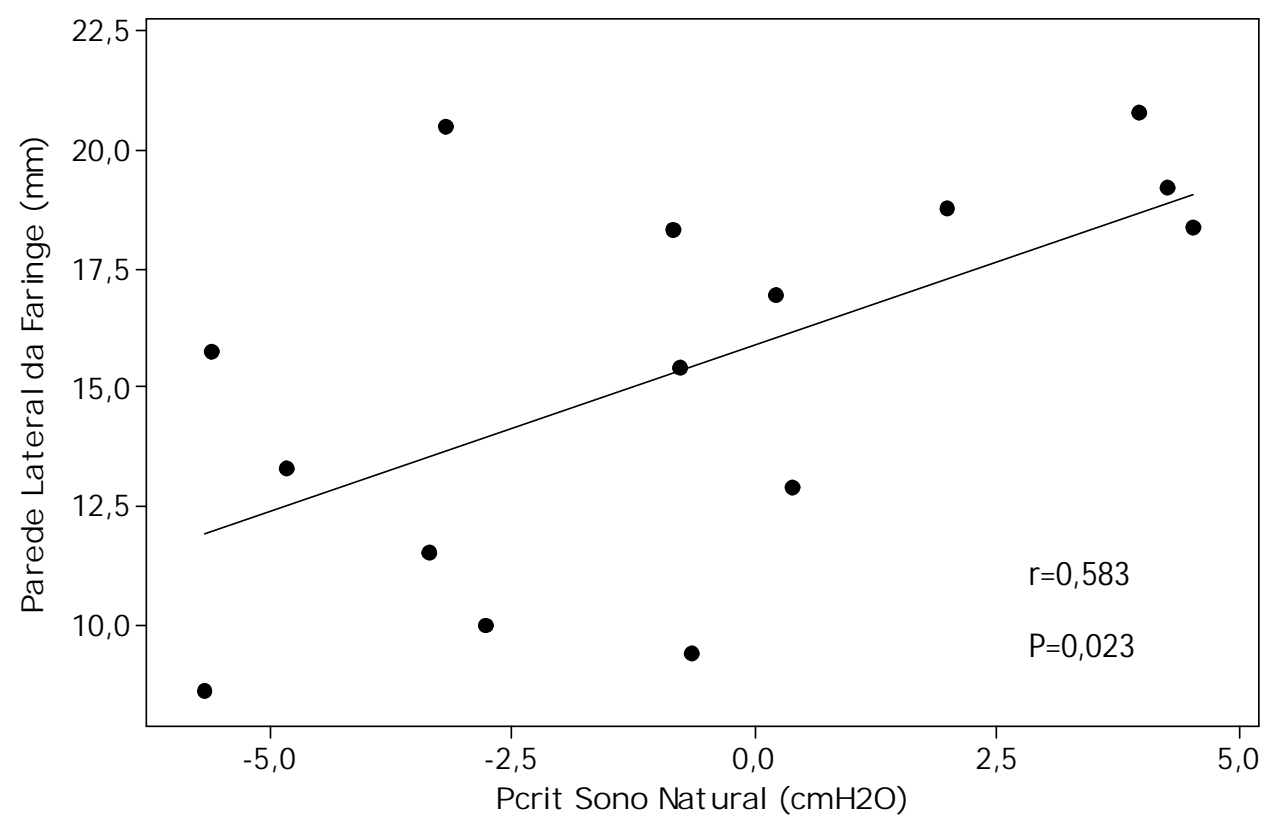

A análise de regressão linear múltipla revelou que a Pcrit durante sono induzido, a circunferência abdominal e a idade foram variáveis independentemente associadas ao IAH (Tabela 8).

Tabela 8 - Análise de regressão linear múltipla das variáveis associadas à variabilidade do IAH

\begin{tabular}{cccc} 
& B coeff & $\mathrm{r}^{2}$ & $\mathrm{P}$ \\
\hline Pcrit sono induzido, $\mathrm{CmH}_{2} \mathrm{O}$ & 2,95 & 0,332 & 0,015 \\
Circunferência abdominal, $\mathrm{cm}$ & 1,07 & 0,216 & 0,010 \\
Idade, anos & 1,04 & 0,237 & 0,008 \\
Modelo & & $\mathbf{0 , 7 8 5}$ & $\mathbf{0 , 0 0 1}$ \\
\hline
\end{tabular}

IAH, índice de apnéia-hipopnéia; Pcrit, pressão crítica de fechamento 
Discussão 
Este estudo traz novas informações relacionadas à metodologia da determinação da Pcrit, à indução do sono com midazolam e às associações da Pcrit com variáveis anatômicas. Inicialmente, pequenas doses de midazolam foram suficientes e seguras para induzir o sono, com características similares ao sono natural. Além disso, a Pcrit determinada durante o sono induzido foi similar à Pcrit durante o sono natural. Finalmente, a Pcrit obtida durante o sono induzido e natural foram fortemente correlacionadas a variáveis anatômicas e polissonográficas e pôde distinguir um grupo de pacientes com predomínio de apnéias de outro com predomínio de hipopnéias. A discussão que se segue foi dividida em alguns tópicos que destacam a relevância do estudo.

\subsection{População estudada}

Cinco estudos prévios advindos de um mesmo grupo de pesquisa utilizaram sedação com midazolam com a finalidade de permitir a determinação da Pcrit. Estes estudos incluíram apenas indivíduos normais ou com AOS leve, sendo que a maioria dos indivíduos incluídos tinham Pcrit negativa. ${ }^{71-75}$

No presente estudo, avaliamos uma amostra representativa do espectro de gravidade da Pcrit (Pcrit negativas e positivas) e da AOS (leve, moderada e grave). Isto permitiu a comparação da Pcrit durante o sono natural e após a indução do sono numa gama ampla de gravidade da AOS e da Pcrit, aumentando o significado e aplicação dos resultados obtidos. 
Outro fato relevante é que fatores raciais podem influenciar na relação das medidas craniofaciais e sua relação com a AOS. Com o intuito de diminuir essa variabilidade, estudamos uma população predominantemente de descendentes de japoneses.

\subsection{Protocolo de sedação e determinação da Pcrit sob sedação}

A maioria dos estudos que avaliaram Pcrit após sedação com midazolam, utilizou um protocolo de sedação padronizado que envolveu a infusão de $1 \mathrm{mg}$ de midazolam a cada 2 minutos até que 0 indivíduo não respondesse a um comando em tom de voz normal. Após atingir este objetivo, $0,5 \mathrm{mg}$ de midazolam era infundido a cada 30 minutos. $^{71,72,74,75}$ Litman avaliou 10 indivíduos saudáveis e determinou a Pcrit após a indução do sono com midazolam. ${ }^{75}$ A Pcrit foi em média de $-8,2 \mathrm{cmH}_{2} \mathrm{O}$. No entanto, não foi descrita a dose total de midazolam. Este estudo demonstrou que a Pcrit pôde ser determinada após sedação e revelou uma correlação inversa entre $I M C$ e Pcrit $(r=0,6, P=0,005)^{75}$. Esse resultado é na realidade contra intuitivo e inesperado, pois outros estudos demonstraram correlação direta entre IMC e Pcrit. ${ }^{55,56}$ Ayuse e colaboradores avaliaram 9 indivíduos do sexo masculino com ronco primário e AOS leve. ${ }^{72}$ Os indivíduos foram submetidos à indução do sono com midazolam a fim de avaliar a Pcrit sem e com a aplicação de dispositivo de avanço mandibular. A aplicação do dispositivo de avanço promoveu a redução da Pcrit de $-1,9$ para $-7,3 \mathrm{cmH}_{2} \mathrm{O}$, mas não é descrita a dose total de midazolam utilizada. ${ }^{72}$ Em outro estudo, Ayuse e colaboradores avaliaram a 
Pcrit após sedação com midazolam de 13 indivíduos saudáveis em 3 condições: boca fechada, com abertura moderada e abertura total. ${ }^{71} \mathrm{~A}$ dose média de midazolam foi de 4,4 $\pm 1,2 \mathrm{mg}$ e a duração do exame foi de $43 \pm 5$ min. A Pcrit foi em média -8,7, 7,2 e $-3,6 \mathrm{cmH}_{2} \mathrm{O}$ nas situações de boca fechada, com abertura parcial e total, respectivamente. ${ }^{71}$ Inazawa e colaboradores também avaliaram o efeito do avanço mandibular de 9 indivíduos saudáveis em 4 posições até 75\% da protrusão máxima na Pcrit após indução do sono com midazolam. ${ }^{74}$ A Pcrit foi em média de $-4,2$ (posição neutra) a -13,3 cmH 20 (75\% da protrusão máxima). Não foram descritas as doses de midazolam e a duração do exame. ${ }^{74}$ Ayuse e colaboradores determinaram a Pcrit após sedação com midazolam de 32 indivíduos saudáveis. ${ }^{73} 0$ protocolo de sedação exigia sedação mais profunda na qual deveria haver resposta a estímulo tátil à glabela, mas não ao comando de voz (escore de Ramsay $=5$ ). A dose total de midazolam foi de $6,2 \pm 0,7 \mathrm{mg}$. A duração do protocolo foi de $53 \pm 7$ minutos. ${ }^{73}$ Neste estudo, a Pcrit ativa (ou seja, a Pcrit determinada após alguns minutos de limitação de fluxo parcial para permitir o recrutamento muscular dos dilatadores das vias aéreas superiores) foi inferior à Pcrit passiva (ou seja, o mesmo método usado no presente protocolo). ${ }^{73}$ Este achado é semelhante ao que é observado durante 0 sono natural ${ }^{68} 0$ que sugere que a compensação neuromuscular à obstrução da via aérea esteja preservada, pelo menos parcialmente, durante a sedação com midazolam.

0 protocolo de sedação utilizado em nosso estudo foi diferente dos estudos descritos anteriormente, resultando em doses médias de midazolam menores 
(2,4mg) que nos estudos prévios (4,4 a 6,2mg). Nos estudos descritos anteriormente a sedação mais profunda pode ter sido induzida já que exigia um ausência de resposta a estímulo verbal ou à estímulo tátil, independentemente da atividade

eletroencefalográfica e estágio do sono. ${ }^{71-75}$ É possível que doses mais elevadas de midazolam possam também fornecer informações fisiológicas importantes das vias aéreas superiores. A Pcrit determinada durante anestesia geral em indivíduos normais é significativamente mais positiva que a determinada durante 0 sono natural ou sedação. ${ }^{76}$ Esta observação sugere uma redução significativa ou eliminação dos mecanismos neuromusculares envolvidos na manutenção da patência das vias aéreas superiores durante a anestesia geral. Portanto, a Pcrit determinada durante anestesia geral teria um significado diferente pois não consideraria o tônus muscular. Deste modo, a Pcrit sob sedação mais profunda pode ser mais negativa que com sedação mais superficial. Através da utilização de doses mínimas de midazolam, pudemos minimizar qualquer efeito na redução do tônus muscular pelo midazolam e, portanto, nos valores da Pcrit.

\subsection{Método de determinação da Pcrit}

Os trabalhos descritos realizaram a determinação da Pcrit com metodologia diferente daquela utilizada no presente estudo As reduções de pressão necessárias para induzir a limitação do fluxo aéreo em nosso estudo foram realizadas apenas após 2 minutos de sono estável e nas fases 2 e 3. Por outro lado, nos estudos prévios os estágios do sono não foram considerados para que fossem feitas as 
reduções da pressão. Desta forma, pode ter havido, nos estudos descritos, reduções de pressão durante o sono REM, onde 0 tônus da musculatura dilatadora da faringe é mínimo, e logo após microdespertares, quando há aumento do tônus. ${ }^{50}$ Além disso, através da monitorização da polissonografia em tempo real, pudemos padronizar as reduções de pressão nos estágios 2 e 3 estáveis. Isto permitiu maior homogeneidade dos dados de Pcrit obtidos e, sobretudo, uma forma padronizada de compará-los à Pcrit obtida durante o sono natural.

\subsection{Validação da Pcrit após indução do sono com midazolam}

Neste trabalho determinamos a Pcrit sob sono natural e induzido com midazolam e observamos valores similares nos dois métodos. A análise gráfica de Bland-Altman (Figura 20) revelou boa concordância entre as medidas em toda a gama de valores de Pcrit. 0 alto coeficiente de correlação intraclasse $(0,92)$ também reforça a associação entre as duas abordagens de mensuração da Pcrit. A falta de efeito significativo do midazolam na Pcrit, encontrados no presente estudo (Tabela

4) reforça a segurança da sedação leve freqüentemente utilizada na prática clínica. ${ }^{84}$ Finalmente, nenhum estudo validou a Pcrit após a indução do sono com midazolam e a comparou com a Pcrit determinada durante o sono natural. 


\subsection{Efeitos da sedação na arquitetura do sono}

Nos estudos prévios que avaliaram a Pcrit após sedação com midazolam, os estágios do sono não foram descritos. ${ }^{71-75}$ Desta forma, 0 exato efeito de doses mais elevadas de midazolam sobre a arquitetura do sono não é conhecido. No presente estudo, induzimos o sono com doses mínimas de midazolam e detectamos o início do sono em tempo real pela polissonografia. Após o início do sono, pudemos observar uma seqüência normal dos estágios do sono na maioria dos pacientes, sem a necessidade de infusão contínua da droga. $\mathrm{Na}$ realidade, doses mínimas de midazolam (media $=2,4 \mathrm{mg}$ ) foram necessárias para induzir o sono. A maioria dos pacientes tiveram fase 3 e REM ( $n=13,80 \%$ ) após a indução do sono e a Pcrit foi obtida de forma relativamente rápida. 0 midazolam pode influenciar o sono de várias formas tais como: aumento de fusos do sono, diminuição dos estágios 1 e 3 e aumento do estágio $2 .{ }^{85}$ Além disso, o uso dos critérios padrão de estadiamento do sono após sedação com midazolam tem sido questionada. ${ }^{86}$ Tendo essas potenciais limitações em mente, nossos pacientes apresentaram um maior percentual de estágio 1 do sono, porém, uma distribuição de fases do sono em geral semelhantes aos exames realizados durante 0 sono natural à noite (Tabela 3). 0 aumento do estágio 1 após a indução do sono em nosso estudo pode ter ocorrido devido ao aumento da densidade de fusos e atividade alfa, sobretudo nos primeiros minutos após a infusão do midazolam. Pode também ter ocorrido por maior dificuldade de consolidação do sono relacionado ao período diurno do ciclo sono-vigília. Em um estudo de sono-endoscopia, no qual se utilizou uma dose relativamente elevada de 
diazepam para a indução do sono (média $=10,3 \mathrm{mg}$ ), os autores encontraram curtos períodos de estágio ${ }^{75} 3$ e REM em apenas $34 \%$ dos 50 pacientes avaliados. ${ }^{87} \mathrm{Um}$ estudo recente avaliou a arquitetura do sono durante o sono induzido com propofol e a comparou com o sono natural durante o dia. Os autores relataram maior duração do estágio 3 e supressão total do sono REM durante o sono induzido com propofol.$^{88} 0$ protocolo para determinar a dose adequada de propofol neste estudo foi baseado na capacidade de despertar aos comandos verbais e na depressão do reflexo córneo-palpebral. ${ }^{88}$ Embora as diferenças relatadas na arquitetura do sono possam ser atribuídas ao uso do propofol, neste estudo a sedação pode ter sido induzida além de simples indução do sono. Outras limitações importantes do propofol são a necessidade de infusão continua em ambiente do centro cirúrgico ou terapia intensiva e o risco de depressão respiratória. ${ }^{89} \mathrm{Um}$ aspecto importante do nosso estudo é que avaliamos pacientes com AOS que freqüentemente apresentam sintomas de sonolência diurna excessiva. Os pacientes dormiram com CPAP nasal a fim de se determinar a Pcrit, ajudando a proteger as vias aéreas e facilitando 0 sono.

\subsection{Significado fisiológico da Pcrit}

Reforçando o significado fisiológico da determinação da Pcrit obtida durante o sono induzido, nós mostramos uma forte correlação entre a Pcrit e IAH, IA, I $\mathrm{A}_{\text {sup }}$, tempo médio de apnéia e saturação de oxigênio mínima (Tabela 6). Estas associações foram muito semelhantes para ambas determinações de Pcrit (sono 
natural e sono induzido) e estão em linha com estudos anteriores que avaliaram apenas a Pcrit durante sono natural..$^{56,90,91} \mathrm{Em}$ nosso estudo, a Pcrit durante o sono induzido, circunferência abdominal e idade foram preditores independentes do IAH em um modelo de regressão linear múltipla e pôde explicar 79\% da variabilidade do IAH (Tabela 8). Resultados muito semelhantes foram obtidos quando a Pcrit durante o sono natural foi usada no modelo. Este achado é importante visto que os dados antropométricos isoladamente explicam apenas cerca de 30 a $40 \%$ da variabilidade do IAH. ${ }^{18,38,92,93}$ Desta forma, a determinação da Pcrit poderia ter um papel adicional na avaliação de risco para AOS além de fatores como sexo, idade, IMC, circunferência abdominal e cervical. Oliven e colaboradores avaliaram a Pcrit durante anestesia geral em 227 indivíduos. Os autores encontraram uma contribuição estatisticamente significativa, porém baixa, da Pcrit na estimativa de risco para AOS. Entretanto, a medida da Pcrit sob anestesia geral reduz significativamente a contribuição neuromuscular da musculatura dilatadora da faringe, reduzindo o seu significado fisiológico. Além disso, AOS foi apenas estimada pelo questionário de Berlin. ${ }^{67}$ Kirkness e colaboradores avaliaram um grupo de 164 sujeitos e mostraram que a Pcrit acima de $-5 \mathrm{CmH}_{2} \mathrm{O}$ teve sensibilidade de $96,5 \%$ para detecção de AOS. No entanto, a especificidade foi de $30,6 \%{ }^{56}$ Desta forma, uma parcela dos indivíduos com Pcrit acima de $-5 \mathrm{cmH}_{2} \mathrm{O}$ não tinha $\mathrm{AOS}$, o que pode sugerir que a atividade neuromuscular dilatadora da faringe pode contrabalançar uma situação anatômica desfavorável (Pcrit elevada) (Figura 11) Gleadhill e colaboradores demonstraram que a colapsibilidade das vias aéreas superiores determinada pela Pcrit durante o sono natural foi capaz de discriminar o espectro 
da AOS, diferenciando-se pacientes com ronco, hipopnéias e apnéias. ${ }^{64}$ No presente estudo, também observamos que a Pcrit (sono natural e sono induzido) é significativamente mais alta entre pacientes nos quais predominam apnéias obstrutivas quando comparados com pacientes nos quais predominam hipopnéias. Esta classificação pôde diferenciar um grupo de pacientes mais graves de outro com doença mais leve, como pode ser visto pela comparação do número de apnéias, nível de CPAP e saturação de oxigênio mínima entre os dois grupos (Tabela 5). Estes resultados reforçam o papel independente da colapsibilidade da faringe determinada pela Pcrit durante o sono natural ou induzido na gênese da AOS e fornece suporte para a validade da determinação da Pcrit durante o sono induzido.

\subsection{Anatomia das vias aéreas superiores e Pcrit}

Encontramos no presente estudo correlações significativas entre IAH, variáveis antropométricas, cefalométricas e Pcrit (Tabela 7). As relações entre variáveis cefalométricas e IAH foram descritas em diversos estudos. A associação mais consistente é do IAH com a posição do hióide (distância M PH). ${ }^{41,94-96}$ Houve ainda correlação do comprimento da língua com IAH. Watanabe e colaboradores sugeriram que a base do crânio limita a expansão das partes moles relacionada, por exemplo, à obesidade. Porém, como a região submandibular não tem estruturação óssea, o aumento de partes moles, incluindo a língua, poderia se expandir em direção caudal, deslocando o hióide. ${ }^{41}$ Da mesma forma, a distância H-ENP e 0 comprimento da via aérea, ambos dependentes da posição do hióide, também poderiam aumentar. De fato, em um estudo de autópsia, o peso, o volume e 
quantidade de gordura da língua se correlacionaram com o IM C. ${ }^{40}$ Também já foi descrita a associação inversa entre IAH e ângulo da base do crânio, refletindo maior gravidade da AOS relacionada ao ângulo da base do crânio mais estreito, e portanto, restrição óssea à expansão de partes moles. ${ }^{94,95}$ No entanto, as associações entre Pcrit e ângulo da base do crânio (NSBa), área da velofaringe e parede lateral da faringe nunca haviam sido demonstradas anteriormente. Tais achados refletem que a colapsabilidade da faringe está intimamente relacionada à interação entre anatomia óssea e partes moles representada na Figura $4 .{ }^{41}$ Poucos estudos avaliaram as associações da Pcrit com variáveis anatômicas. Em um estudo, a Pcrit foi determinada somente nos casos em que ela era acima de zero, não considerando, portanto, aqueles indivíduos com Pcrit negativa. ${ }^{69} \mathrm{~A}$ Pcrit se associou ao IMC, circunferência cervical, à distância do hióide à parede posterior da faringe (H-Ph), ao comprimento do pálato mole, à altura do hióide em relação ao plano mandibular (MP-H) e à distância do hióide à espinha nasal posterior (H-ENP). ${ }^{69}$ Outro estudo avaliou a colapsabilidade segmentar em dois níveis (velo e orofaringe) durante anestesia geral e paralisia e a correlacionou com variáveis cefalométricas. ${ }^{41}$ Neste estudo, a pressão de fechamento da orofaringe se correlacionou com a distância M P-H, os comprimentos médio-facial e da mandíbula. ${ }^{41}$ Em outro estudo, no qual a Pcrit foi determinada durante anestesia geral, houve correlação entre Pcrit e idade entre todos os pacientes e entre Pcrit e IMC e circunferência cervical entre os homens. ${ }^{67}$ As associações entre variáveis antropométricas, tomográficas e Pcrit reforçam o conceito que a Pcrit representa a contribuição anatômica na fisiopatologia da AOS. 


\subsection{Limitações}

Nosso estudo tem diversas limitações. Em primeiro lugar, a utilização dos critérios padrão para o estadiamento do sono após indução do sono com midazolam pode não ser precisa. Porém, usamos baixas doses de midazolam, minimizando os artefatos de EEG previamente relatados durante a sedação com midazolam em terapia intensiva ${ }^{86} \mathrm{Em}$ segundo lugar, o número de pacientes estudados é relativamente pequeno. Por outro lado, as fortes correlações observadas apontam para a consistência dos nossos resultados. Em terceiro lugar, estudamos apenas homens e apenas alguns tinham apnéia do sono leve. Assim, nossas conclusões são limitadas à população estudada. Por fim, estudamos predominantemente descendentes de Japoneses, fazendo com que estes resultados não sejam necessariamente aplicáveis a outras etnias. Por outro lado, esta abordagem permitiu-nos reduzir a variabilidade que poderia ser introduzida por diferentes etnias. Outros estudos envolvendo mulheres e outras etnias serão úteis para que nossos resultados sejam generalizados.

\subsection{Considerações Finais}

A medida da Pcrit tem sido utilizada com alguma freqüência em estudos experimentais que visam entender aspectos fisiopatológicos da AOS. No entanto, a técnica ainda não é difundida, conforme já discutido. A aplicação clínica da Pcrit parece ser uma questão de tempo. Para isso, a comprovação da sua utilidade na detecção da AOS e na seleção do tratamento (desde procedimentos cirúrgicos a dispositivo de avanço mandibular) será necessária em estudos futuros. Portanto, o 
presente trabalho tem 0 intuito de contribuir para a difusão da técnica da determinação da Pcrit por torná-la aplicável durante o dia, após a indução do sono com midazolam. 


\section{Conclusão}


1. A Pcrit determinada durante o dia após a indução do sono com midazolam é válida e similar a Pcrit obtida com o protocolo considerado padrão ouro durante o sono natural.

2. A arquitetura do sono após a indução do sono com baixas doses de midazolam é semelhante ao sono natural.

3. A Pcrit determinada tanto durante 0 sono induzido e sono natural se correlacionou coma anatomia da via aérea superior, reforçando o seu significado.

4. A Pcrit foi preditor independente do IAH e pôde discriminar um grupo de pacientes mais graves (com predomínio de apnéias) de outro mais leve (hipopnéias). 
Anexos 
Anexo A - Termo de consentimento livre e esclarecido

HOSPITAL DAS CĹNICAS DA FACULDADE DE MEDICINA DA UNIVERSIDADE DE SÃO PAULO-HCFMUSP

TERMO DE CONSENTIMENTO LVRE E ESCLARECIDO

\section{DADOS DE IDENTIFICAÇÃO DO SUJEITO DA PESQUISA OU RESPONSÁVEL LEGAL}

1. NOME: :

DOCUMENTO DE IDENTIDADE № : SEXO:.$M \cdot F \cdot$ DATA NASCIM ENTO: .......................

ENDEREÇO № APTO:

BAIRRO: CIDADE

CEP: TELEFONE: DDD ( ..)

\section{RESPONSÁVEL LEGAL}

NATUREZA (grau de parentesco, tutor, curador etc.)

DOCUMENTO DE IDENTIDADE : SEXO: $M \cdot F \cdot$

DATA NASCIM ENTO.: ......./.............

ENDEREÇO: № APTO:

BAIRRO: CIDADE:

CEP: TELEFONE: DDD ( 


\section{DADOS SOBRE A PESQUISA}

1. TÍTULO DO PROTOCOLO DE PESQUISA: Fatores de Risco Anatômicos e Funcionais na Apnéia Obstrutiva do Sono: Comparação entre Descendentes de Japoneses e Indivíduos Brancos

PESQUISADOR : Dr. Geraldo Lorenzi Filho

CARGO/FUNÇÃO: Prof. Livre-docente / Diretor do Laboratório do Sono InCor.. ................ INSCRIÇÃO CONSELHO REGIONAL № ..52063

UNIDADE DO HCFMUSP: Serviço de

Pneumologia..

3. AVALIAÇÃO DO RISCO DA PESQUISA:

$\begin{array}{llr}\text { RISCO MÍNIMO } & X & \text { RISCO MÉDIO • } \\ \text { RISCO BAIXO } & & \text { RISCO MAIOR }\end{array}$

4.DURAÇÃO DA PESQUISA : Dezembro 2008 a Dezembro 2009 (12 meses) 
Anexos 86

Essas informações estão sendo fornecidas para sua participação voluntária neste estudo, que visa avaliar os fatores de risco para apnéia obstrutiva do sono entre descendentes de Japoneses e Brancos do sexo masculino. A apnéia obstrutiva do sono caracteriza-se pelo colapso repetido da garganta durante o sono. Esta doença pode acarretar diversos problemas para a saúde como, por exemplo, cansaço, sonolência e doenças cardiovasculares. Os motivos que levam uma pessoa a desenvolver apnéia obstrutiva do sono ainda não são totalmente definidos. Uma das dúvidas que persiste é se há diferenças entre raças no desenvolvimento da doença. Sabe-se que a obesidade é um fator de risco para apnéia do sono e que os descendentes de Japoneses com apnéia do sono tem peso menor que pacientes da raça branca. Em nosso estudo pretendemos comparar os fatores de risco para apnéia do sono entre descendentes de Japoneses e Brancos. Caso concorde em participar do estudo, você responderá algumas perguntas sobre problemas de saúde passados e/ou atuais, medicamentos que usa normalmente e sobre o risco de cochilar durante o dia. Você fará uma série de exames para avaliar o seu sono e sua composição corporal. Os exames são os seguintes: 1. Polissonografia - você será submetido a dois exames que vão monitorizar o seu sono, através de eletrodos colados na cabeça, e sua respiração, através de um cateter por fora do nariz e cintas no tórax e abdome. 0 primeiro exame vai ser feito durante uma noite em que você dormirá no laboratório do sono do Instituto do Coração. Este exame é realizado em ambiente confortável e não prejudica o seu sono. 0 segundo exame será realizado no mesmo local e com equipamento similar, mas você utilizará uma máscara ao redor do nariz para respirar. No início do exame, após você adormecer, será 
Anexos 87

realizado um exame para medir com qual facilidade sua garganta obstrui. Este exame simula o que ocorre durante uma apnéia obstrutiva durante o sono. Este exame é específico para este estudo, e portanto, experimental. Pode haver pequeno desconforto, pois será reduzida a pressão em sua garganta, o que pode fazer com que você desperte. Se você despertar, poderá respirar sem qualquer desconforto. 0 risco para sua saúde é mínimo porque o teste é curto, realizado com monitorização contínua de seu eletrocardiograma, de sua respiração e da oxigenação do sangue. Indivíduos normais podem ter apnéias durante o sono isoladas (até um número de 5 vezes por hora) sem que isto represente qualquer risco para sua saúde. 2. Tomografia de crânio e abdome - Se você concordar em participar do estudo, você também fará uma tomografia de crânio e pescoço, o qual é feito deitado num aparelho de tomografia e dura cerca de 15 minutos. Este exame servirá para determinar as estruturas do crânio e da face que estão relacionadas com 0 desenvolvimento da apnéia obstrutiva do sono. No mesmo exame de tomografia, será avaliada a quantidade de gordura visceral. A gordura visceral está relacionada ao desenvolvimento de apnéia do sono, mas também de doenças cardiovasculares. Este dado será útil a você para alertá-lo sobre este importante fator de risco para o desenvolvimento de doenças cardiovasculares. 0 risco para este exame é mínimo e envolve apenas a quantidade de radiação normal de um exame de tomografia. 3. Densitometria - os participantes deste estudo também serão submetidos à densitometria do corpo. Este exame avalia a composição do corpo e define a quantidade de gordura que temos no corpo. Ele é feito deitado e dura cerca de 20 minutos. A gordura corporal também é fator de risco para apnéia 
Anexos 88

do sono e para doenças cardiovasculares. Neste exame também será definida a densidade dos ossos, o que permitirá saber se você tem ou tem maior risco para desenvolver osteoporose, uma doença na qual o osso enfraquece e fica predisposto a fraturas. 0 risco deste exame é mínimo, pois envolve pequena quantidade de radiação. 4. Avaliação endoscópica: o seu nariz e sua garganta também serão examinados por um aparelho fino e flexível que permite o médico olhar diretamente o nariz e a garganta. Esse aparelho é parecido com o aparelho de endoscopia que é usado para quem tem problemas de estômago. A diferença é que esse aparelho é muito fino, é colocado diretamente pelo nariz com aplicação de anestésico local (tipo spray) no nariz e na garganta. Durante o exame também será feita uma punção venosa para aplicação de soro com sedativo que vai fazer você dormir por aproximadamente 30 minutos. Esse exame é chamado de sono induzido e permitirá avaliar se sua garganta "fecha" durante o sono e em qual local. Esse exame será feito com um sedativo leve e sob supervisão de médico com experiência no exame. Todo o exame será registrado em um computador e com fotos. 0 risco do exame é baixo, você estará sob contínua vigilância médica e em caso de necessidade será administrado oxigênio pelo nariz. Não será realizado nenhum corte ou biópsia, ou até mesmo cirurgia durante o exame. 0 exame envolve apenas um desconforto (incômodo) à passagem do aparelho pelo nariz. Após o exame, será necessário um breve repouso de aproximadamente 30 minutos, no laboratório do sono até passar o efeito da medicação por completo. De forma semelhante a um exame de endoscopia do estômago, você precisará de um acompanhante para ir 
Anexos 89

para casa após o exame. Você não deverá dirigir qualquer tipo de automóvel, operarar máquinas ou nem mesmo exercer atividades que exijam muita atenção.

Em qualquer etapa do estudo, você terá acesso aos profissionais responsáveis pela pesquisa para pode esclarecimento de eventuais dúvidas. 0 principal investigador é o Dr. Geraldo Lorenzi Filho que pode ser encontrado no endereço Av. Dr. Enéas de Carvalho Aguiar, 44 - 7‥ Andar (laboratório do sono) Telefone(s) 3069-5486 tiver alguma consideração ou dúvida sobre a ética da pesquisa, entre em contato com 0 Comitê de Ética em Pesquisa (CEP) - Rua Ovídio Pires de Campos, 225 - 5o andar tel: 3069-6442 ramais 16, 17, 18 ou 20, FAX: $3069-6442$ ramal 26 - E-mail: cappesq@hcnet.usp.br

É garantida a liberdade da retirada de consentimento a qualquer momento e deixar de participar do estudo, sem qualquer prejuízo à continuidade de seu tratamento na Instituição;

As informações obtidas neste estudo serão analisadas em conjunto com outros pacientes, não sendo divulgado a identificação de nenhum paciente; Você terá o direito de ser mantido atualizado sobre os resultados parciais e finais do estudo.

Não há despesas pessoais para o participante em qualquer fase do estudo, incluindo exames e consultas. Também não há compensação financeira relacionada à sua participação. Se existir qualquer despesa adicional, ela será absorvida pelo orçamento da pesquisa. 
Anexos 90

Em caso de dano pessoal, diretamente causado pelos procedimentos ou tratamentos propostos neste estudo (nexo causal comprovado), o participante tem direito a tratamento médico na Instituição, bem como às indenizações legalmente estabelecidas.

O pesquisador se compromete a utilizar os dados e o material coletado somente para esta pesquisa.

Acredito ter sido suficientemente informado a respeito das informações que li ou que foram lidas para mim, descrevendo o estudo "Fatores de Risco Anatômicos e Funcionais na Apnéia Obstrutiva do Sono: Comparação entre Descendentes de Japoneses e Indivíduos Brancos".

Eu discuti com o Dr. Geraldo Lorenzi Filho sobre a minha decisão em participar nesse estudo. Ficaram claros para mim quais são os propósitos do estudo, os procedimentos a serem realizados, seus desconfortos e riscos, as garantias de confidencialidade e de esclarecimentos permanentes. Ficou claro também que minha participação é isenta de despesas e que tenho garantia do acesso a tratamento hospitalar quando necessário. Concordo voluntariamente em participar deste estudo e poderei retirar o meu consentimento a qualquer momento, antes ou durante o mesmo, sem penalidades ou prejuízo ou perda de qualquer benefício que eu possa ter adquirido, ou no meu atendimento neste Serviço. 
para casos de pacientes menores de 18 anos, analfabetos, semi-analfabetos ou portadores de deficiência auditiva ou visual.

(Somente para o responsável do projeto)

Declaro que obtive de forma apropriada e voluntária o Consentimento Livre e Esclarecido deste paciente ou representante legal para a participação neste estudo.

Assinatura do responsável pelo estudo Data 
Anexo B - Escala de sonolência de Epworth

\begin{tabular}{|l|l|l|l|l|}
\hline SITUAÇÃO & 0 & 1 & 2 & 3 \\
\hline Sentado e lendo. & 0 & 1 & 2 & 3 \\
\hline Assistindo TV. & 0 & 1 & 2 & 3 \\
\hline Sentado em um lugar público (cinema, igreja, sala de espera). & 0 & 1 & 2 & 3 \\
\hline Como passageiro de trem, carro ou ônibus, andando uma hora sem & & & & \\
parar. & & & & \\
\hline Deitando-se para descansar à tarde, quando as circunstâncias & 0 & 1 & 2 & 3 \\
permitem. & & & & \\
\hline Sentado e conversando com alguém. & 0 & 1 & 2 & 3 \\
\hline Sentado calmamente após o almoço (sem álcool). & 0 & 1 & 2 & 3 \\
\hline Dirigindo um carro, enquanto pára por alguns minutos ao pegar um & 0 & 1 & 2 & 3 \\
trânsito intenso. & & & & \\
\hline
\end{tabular}

\section{Legendas: 0 - nenhuma chance de cochilar; 1 - pequena chance de cochilar; 2 -} moderada chance de cochilar; 3 - alta chance de cochilar.

Valores maiores que 10 pontos identificam indivíduos com significativa sonolência diurna. 
Referências 
1. Sleep-related breathing disorders in adults: Recommendations for syndrome definition and measurement techniques in clinical research. The report of an american academy of sleep medicine task force. Sleep 1999;22:667-689.

2. Parish JM, Lyng PJ. Quality of life in bed partners of patients with obstructive sleep apnea or hypopnea after treatment with continuous positive airway pressure. Chest 2003;124:942-947.

3. Marin J, Carrizo S, Vicente E, Agusti A. Long-term cardiovascular outcomes in men with obstructive sleep apnoea-hypopnoea with or without treatment with continuous positive airway pressure: An observational study. Lancet 2005;365:1046-1053.

4. Drager L, Bortolotto L, Figueiredo A, Krieger E, Lorenzi G. Effects of continuous positive airway pressure on early signs of atherosclerosis in obstructive sleep apnea. Am J Respir Crit Care Med 2007;176:706-712.

5. Young T, Finn L, Peppard P, Szklo-Coxe M, Austin D, Nieto J, Stubbs R, Hla K. Sleep disordered breathing and mortality: Eighteen-year follow-up of the wisconsin sleep cohort. Sleep 2008;31:1071-1078.

6. Punjabi N, Caffo B, Goodwin J, Gottlieb D, Newman A, O'Connor G, Rapoport D, Redline S, Resnick H, Robbins J, Shahar E, Unruh M, Samet J. Sleepdisordered breathing and mortality: A prospective cohort study. PLOS Med 2009;6:e1000132.

7. American Academy of Sleep Disorders. International classification of sleep disorders, second edition. Westchester, IL; 2005. 
8. Tufik S, Santos-Silva R, Taddei J, Bittencourt L. Obstructive sleep apnea syndrome in the sao paulo epidemiologic sleep study. Sleep M ed 2010;11:441446.

9. Young T, Palta M, Dempsey J, Skatrud J, Weber S, Badr S. The occurrence of sleep-disordered breathing among middle-aged adults. N Engl J Med 1993;328:1230-1235.

10. Young T, Shahar E, Nieto F, Redline S, Newman A, Gottlieb D, Walsleben J, Finn L, Enright P, Samet J. Predictors of sleep-disordered breathing in communitydwelling adults - the sleep heart health study. Arch Intern M ed 2002;162:893900.

11. Pesquisa de orçamentos familiares 2008-2009- antropometria e estado nutricional de crianças, adolescentes e adultos no brasil. Instituto Brasileiro de Geografia e Estatística; 2010.

12. Prentice A. The emerging epidemic of obesity in developing countries. Int J Epidemiol 2006;35:93-99.

13. Redline S, Tishler P, Hans M, Tosteson T, Strohl K, Spry K. Racial differences in sleep-disordered breathing in african-americans and caucasian. Am J Respir Crit Care M ed 1997;155:186-192.

14. Li K, Kushida C, Powell N, Riley R, Guilleminault C. Obstructive sleep apnea syndrome: A comparison between far-east asian and white men. Laryngoscope 2000;110:1689-1693. 
15. Ong K, Clerk A. Comparison of the severity of sleep-disordered breathing in asian and caucasian patients seen at a sleep disorders center. Respir Med 1998;92:843-848.

16. Yoon K, Lee J, Kim J, Cho J, Choi Y, Ko S, Zimmet P, Son H. Epidemic obesity and type 2 diabetes in asia. Lancet 2006;368:1681-1688.

17. World Health Organization. The asia-pacific perspective: Redefining obesity and its treatment. Australia: Health Communications; 2000. p. 1-56.

18. Genta PR, M arcondes B, Danzi N, Lorenzi-Filho G. Ethnicity as a risk factor for obstructive sleep apnea: Comparison of japanese descendants and white males in São Paulo, Brazil. Braz J Med Biol Res 2008;41:728-733.

19. Ip M, Lam B, Lauder I, Tsang K, Chung K, M ok Y, Lam W. A community study of sleep-disordered breathing in middle-aged chinese men in hong kong. Chest 2001;119:62-69.

20. Kim J, In K, Kim J, You S, Kang K, Shim J, Lee S, Lee J, Park C, Shin C. Prevalence of sleep-disordered breathing in middle-aged korean men and women. Am J Respir Crit Care 2004;170:1108-1113.

21. Tuomilehto HP, Seppä JM, Partinen M M, Peltonen M, Gylling H, Tuomilehto JO, Vanninen EJ, Kokkarinen J, Sahlman JK, Martikainen T, Soini EJ, Randell J, Tukiainen H, Uusitupa M, Group KSA. Lifestyle intervention with weight reduction: First-line treatment in mild obstructive sleep apnea. Am J Respir Crit Care Med 2009;179:320-327. 
22. Cuccia AM, Caradonna C. Mandibular advancement devices: Indications and predictors of treatment outcome. A review. Minerva Stomatol 2007;56:427443.

23. Aurora RN, Casey KR, Kristo D, Auerbach S, Bista SR, Chowdhuri S, Karippot A, Lamm C, Ramar K, Zak R, M orgenthaler TI. Practice parameters for the surgical modifications of the upper airway for obstructive sleep apnea in adults. Sleep 2010;33:1408-1413.

24. Guimarães K, Drager L, Genta PR, Marcondes B, Lorenzi-Filho G. Effects of oropharyngeal exercises on patients with moderate obstructive sleep apnea syndrome. Am J Respir Crit Care M ed 2009;179:962-966.

25. Kushida CA, Littner M R, Hirshkowitz M, M orgenthaler TI, Alessi CA, Bailey D, Boehlecke B, Brown TM, Coleman J, Friedman L, Kapen S, Kapur VK, Kramer M, Lee-Chiong T, Owens J, Pancer JP, Swick TJ, Wise MS, American Academy of Sleep Medicine. Practice parameters for the use of continuous and bilevel positive airway pressure devices to treat adult patients with sleep-related breathing disorders. Sleep 2006;29:375-380.

26. Pepperell JC, Ramdassingh-Dow S, Crosthwaite N, Mullins R, Jenkinson C, Stradling JR, Davies RJ. Ambulatory blood pressure after therapeutic and subtherapeutic nasal continuous positive airway pressure for obstructive sleep apnoea: A randomised parallel trial. Lancet 2002;359:204-210.

27. Kaneko Y, Floras J, Usui K, Plante J, Tkacova R, Kubo T, Ando S, Bradley T. Cardiovascular effects of continuous positive airway pressure in patients with heart failure and obstructive sleep apnea. N Engl J M ed 2003;348:1233-1241. 
28. Eckert D, Malhotra A, Jordan A. Mechanisms of apnea. Prog Cardiovasc Dis 2009;51:313-323.

29. Patil S, Schneider H, Schwartz A, Smith P. Adult obstructive sleep apnea pathophysiology and diagnosis. Chest 2007;132:325-337.

30. Morgan TD, Remmers JE. Phylogeny and animal models: An uninhibited survey. In: Kushida CA, editor. Obstructive sleep apnea. New York, NY: Informa Healthcare; 2007.

31. Verin E, Tardif C, Buffet X, Marie JP, Lacoume $Y$, Andrieu-Guitrancourt J, Pasquis P. Comparison between anatomy and resistance of upper airway in normal subjects, snorers and osas patients. Respir Physiol 2002;129:335-343.

32. Bacon W, Krieger J, Turlot J, Stierle J. Craniofacial characteristics in patients with obstructive sleep apneas syndrome. Cleft Palate J 1988;25:374-378.

33. Lam B, Ooi C, Peh W, Lauder I, Tsang K, Lam W, Ip M. Computed tomographic evaluation of the role of craniofacial and upper airway morphology in obstructive sleep apnea in chinese. Respir M ed 2004;98:301-307.

34. Rivlin J, Hoffstein V, Kalbfleisch J, McNicholas W, Zamel N, Bryan A. Upper airway morphology in patients with idiopathic obstructive sleep apnea. Am Rev Respir Dis 1984;129:355-360.

35. Riha R, Brander P, Vennelle M, Douglas N. A cephalometric comparison of patients with the sleep apnea/hypopnea syndrome and their siblings. Sleep 2005;28:315-320. 
36. Fregosi R, Quan S, Kaemingk K, Morgan W, Goodwin J, Cabrera R, Gmitro A. Sleep-disordered breathing, pharyngeal size and soft tissue anatomy in children. J Appl Physiol 2003;95:2030-2038.

37. M ortimore I, Marshall I, Wraith P, Sellar R, Douglas N. Neck and total body fat deposition in nonobese and obese patients with sleep apnea compared with that in control subjects. Am J Respir Crit Care Med 1998;157:280-283.

38. Simpson L, Mukherjee S, Cooper MN, Ward KL, Lee JD, Fedson AC, Potter J, Hillman DR, Hillman Fanzca DR, Eastwood P, Palmer LJ, Kirkness J. Sex differences in the association of regional fat distribution with the severity of obstructive sleep apnea. Sleep 2010;33:467-474.

39. Brennick M, Pack A, Ko K, Kim E, Pickup S, M aislin G, Schwab R. Altered upper airway and soft tissue structures in the new zealand obese mouse. Am J Respir Crit Care M ed 2009;179:158-169.

40. Nashi N, Kang S, Barkdull GC, Lucas J, Davidson TM. Lingual fat at autopsy. Laryngoscope 2007;117:1467-1473.

41. Watanabe T, Isono S, Tanaka A, Tanzawa H, Nishino T. Contribution of body habitus and craniofacial characteristics to segmental closing pressures of the passive pharynx in patients with sleep-disordered breathing. Am J Respir Crit Care Med 2002;165:260-265.

42. Su MC, Chiu KL, Ruttanaumpawan P, Shiota S, Yumino D, Redolfi S, Haight JS, Yau B, Lam J, Bradley TD. Difference in upper airway collapsibility during wakefulness between men and women in response to lower-body positive pressure. Clin Sci (Lond) 2009;116:713-720. 
Referências 100

43. Shiota S, Ryan CM, Chiu KL, Ruttanaumpawan P, Haight J, Arzt M, Floras JS, Chan C, Bradley TD. Alterations in upper airway cross-sectional area in response to lower body positive pressure in healthy subjects. Thorax $2007 ; 62: 868-872$.

44. Redolfi S, Yumino D, Ruttanaumpawan P, Yau B, Su M C, Lam J, Bradley TD. Relationship between overnight rostral fluid shift and obstructive sleep apnea in nonobese men. Am J Respir Crit Care M ed 2009;179:241-246.

45. Stuck B, Maurer J. Airway evaluation in obstructive sleep apnea. Sleep Med Rev 2008;12:411-436.

46. Dempsey J, Veasey S, M organ B, O'Donnell C. Pathophysiology of sleep apnea. Physiol Rev 2010;90:47-112.

47. Owens RL, Malhotra A, Eckert DJ, White DP, Jordan AS. The influence of endexpiratory lung volume on measurements of pharyngeal collapsibility. J Appl Physiol 2010;108:445-451.

48. Suratt $\mathrm{P}, \mathrm{M}$ cTier $\mathrm{R}$, Wilhoit $\mathrm{S}$. Upper airway muscle activation is augmented in patients with obstructive sleep apnea compared with that in normal subjects. Am Rev Respir Dis 1988;137:889-894.

49. Mezzanotte $W$, Tangel D, White D. Waking genioglossal electromyogram in sleep-apnea patients versus normal controls (a neuromuscular compensatory mechanism). J Clin Invest 1992;89:1571-1579.

50. Eckert $D$, Malhotra $A, L O Y$, White $D$, Jordan $A$. The influence of obstructive sleep apnea and gender on genioglossus activity during rapid eye movement sleep. Chest 2009;135:957-964. 
Referências 101

51. Lindman R, Stal P. Abnormal palatopharyngeal muscle morphology in sleepdisordered breathing. J Neurol Sci 2002;195:11-23.

52. Wellman A, Malhotra A, Jordan A, Stevenson K, Gautam S, White D. Effect of oxygen in obstructive sleep apnea: Role of loop gain. Respir Physiol Neurobiol 2008;162:144-151.

53. Badr MS, Toiber F, Skatrud JB, Dempsey J. Pharyngeal narrowing/occlusion during central sleep apnea. J Appl Physiol 1995;78:1806-1815.

54. Young T, Peppard P, Gottlieb D. Epidemiology of obstructive sleep apnea - a population heal Am J Respir Crit Care M ed 2002;165:1217-1239.

55. Jordan A, Wellman A, Edwards J, Schory K, Dover L, MacDonald M, Patel S, Fogel R, Malhotra A, White D. Respiratory control stability and upper airway collapsibility in men and women with obstructive sleep apnea. J Appl Physiol 2005;99:2020-2027

56. Kirkness J, Schwartz A, Schneider H, Punjabi N, M aly J, Laffan A, M CGinley B, Magnuson T, Schweitzer M, Smith P, Patil S. Contribution of male sex, age, and obesity to mechanical instability of the upper airway during sleep. J Appl Physiol 2008;104:1618-1624.

57. Malhotra A, Huang YQ, Fogel RB, Pillar G, Edwards JK, Kikinis R, Loring SH, White DP. The male predisposition to pharyngeal collapse - importance of airway length. American Journal of Respiratory and Critical Care Medicine 2002;166:1388-1395. 
58. M alhotra A, Huang Y, Fogel R, Lazic S, Pillar G, Jakab M, Kikinis R, White D. Aging influences on pharyngeal anatomy and physiology: The predisposition to pharyngeal collapse. Am J Med 2006;119:72.e79-14.

59. Millman R, Carlisle C, McGarvey S, Eveloff S, Levinson P. Body fat distribution and sleep apnea severity in women. Chest 1995;107:362-366.

60. Whittle A, Marshall I, Mortimore I, Wraith P, Sellar R, Douglas N. Neck soft tissue and fat distribution: Comparison between normal men and women by magnetic resonance imaging. Thorax 1999;54:323-328.

61. Zhou X, Shahabuddin S, Zahn B, Babcock M, Badr M. Effect of gender on the development of hypocapnic apnea/hypopnea during nrem sleep. J Appl Physiol 2000;89:192-199.

62. Eikermann M, Jordan A, Chamberlin N, Gautam S, Wellman A, Lo Y, White D, Malhotra A. The influence of aging on pharyngeal collapsibility during sleep. Chest 2007;131:1702-1709.

63. Gold AR, Schwartz AR. The pharyngeal critical pressure - the whys and hows of using nasal continuous positive airway pressure diagnostically. Chest 1996;110:1077-1088.

64. Gleadhill IC, Schwartz AR, Schubert N, Wise RA, Permutt S, Smith PL. Upper airway collapsibility in snorers and in patients with obstructive hypopnea and apnea. Am Rev Respir Dis 1991;143:1300-1303.

65. Condos R, Norman RG, Krishnasamy I, Peduzzi N, Goldring RM, Rapoport DM. Flow limitation as a noninvasive assessment of residual upper-airway 
Referências 103

resistance during continuous positive airway pressure therapy of obstructive sleep apnea. Am J Respir Crit Care M ed 1994;150:475-480.

66. Hillman D, Walsh J, Maddison K, Platt P, Kirkness J, Noffsinger W, Eastwood P. Evolution of changes in upper airway collapsibility during slow induction of anesthesia with propofol. Anesthesiology 2009;111:63-71.

67. Oliven A, Aspandiarov E, Gankin I, Gaitini L, Tov N. Collapsibility of the relaxed pharynx and risk of sleep apnoea. European Respiratory Journal 2008;32:13091315.

68. Patil S, Schneider H, M arx J, Gladmon E, Schwartz A, Smith P. Neuromechanical control of upper airway patency during sleep. J Appl Physiol 2007;102:547556.

69. Sforza E, Bacon W, Weiss T, Thibault A, Petiau C, Krieger J. Upper airway collapsibility and cephalometric variables in patients with obstructive sleep apnea. Am J Respir Crit Care Med 2000;161:347-352.

70. Isono S, Tanaka A, Nishino T. Lateral position decreases collapsibility of the passive pharynx in patients with obstructive sleep apnea. Anesthesiology 2002;97:780-785.

71. Ayuse $T$, Inazawa $T$, Kurata S, Okayasu I, Sakamoto E, Oi K, Schneider H, Schwartz AR. Mouth-opening increases upper-airway collapsibility without changing resistance during midazolam sedation. J Dent Res 2004;83:718-722.

72. Ayuse T, Hoshino Y, Inazawa T, Oi K, Schneider H, Schwartz AR. A pilot study of quantitative assessment of mandible advancement using pressure-flow relationship during midazolam sedation. J Oral Rehabil 2006;33:813-819. 
73. Ayuse T, Hoshino Y, Kurata S, Schneider H, Kirkness J, Patil S, Schwartz A, Oi K. The effect of gender on compensatory neuromuscular response to upper airway obstruction in normal subjects under midazolam general anesthesia. Anesth Analg 2009;109:1209-1218.

74. Inazawa T, Ayuse T, Kurata S, Okayasu I, Sakamoto E, Oi K, Schneider H, Schwartz AR. Effect of mandibular position on upper airway collapsibility and resistance. J Dent Res 2005;84:554-558.

75. Litman RS, Hayes JL, Basco MG, Schwartz AR, Bailey PL, Ward DS. Use of dynamic negative airway pressure (DNAP) to assess sedative-induced upper airway obstruction. Anesthesiology 2002;96:342-345.

76. Eastwood PR, Szollosi I, Platt PR, Hillman DR. Comparison of upper airway collapse during general anaesthesia and sleep. Lancet 2002;359:1207-1209.

77. Gregorio M G, Jacomelli M, Figueiredo A, Cahali M, Pedreira Junior W, LorenziFilho G. Evaluation of airway obstruction by nasopharyngoscopy: Comparison of the muller maneuver versus induced sleep. Rev Bras Otorrinolaringol; 2007. p. 618-622.

78. Kezirian E, White D, Malhotra A, Ma W, McCulloch C, Goldberg A. Interrater reliability of drug-induced sleep endoscopy. Arch Otolaryngol Head Neck Surg 2010;136:393-397.

79. Miyata S, Noda A, Nakata S, Yagi H, Yanagi E, Honda K, Sugiura T, Nakai S, Nakashima T, Koike Y. Daytime polysomnography for early diagnosis and treatment of patients with suspected sleep-disordered breathing. Sleep Breath 2007;11:109-115. 
Referências 105

80. Amrein R, Hetzel W. Pharmacology of dormicum (midazolam) and anexate (flumazenil). Acta Anaesthesiol Scand Suppl 1990;92:6-15; discussion 47.

81. Gregorio MG. Validação da polissonografia diurna com sono induzido para 0 diagnóstico de apnéia obstrutiva do sono. São Paulo: Tese de Doutorado; 2007

82. Parrino L, Terzano M. Polysomnographic effects of hypnotic drugs. A review. Psychopharmacology (Berl) 1996;126:1-16.

83. Genta PR, Gregorio M, Danzi N, M oriya H, Eckert D, M alhotra A, Lorenzi-Filho G. Determination of the pharyngeal critical closing pressure during induced sleep. Am J Respir Crit Care Med 2010;181: A2214.

84. Lettieri C, Shah A, Holley A, Kelly W, Chang A, Roop S, Trial CPaP-TASAP. Effects of a short course of eszopiclone on continuous positive airway pressure adherence: A randomized trial. Ann Intern M ed 2009;151:696-702.

85. Monti J, Debellis J, Gratadoux E, Alterwain P, Altier H, D'Angelo L. Sleep laboratory study of the effects of midazolam in insomniac patients. Eur J Clin Pharmacol 1982;21:479-484.

86. Ambrogio C, Koebnick J, Quan S, Ranieri M, Parthasarathy S. Assessment of sleep in ventilator-supported critically iii patients. Sleep 2008;31:1559-1568.

87. Sadaoka T, Kakitsuba N, Fujiwara Y, Kanai R, Takahashi H. The value of sleep nasendoscopy in the evaluation of patients with suspected sleep-related breathing disorders. Clin Otolaryngol Allied Sci 1996;21:485-489.

88. Rabelo FAW, Braga A, Kupper DS, De Oliveira JAA, Lopes FM, M attos P, Barreto SG, Sander HH, Fernandes RMF, Valera FCP. Propofol-induced sleep: 
Polysomnographic evaluation of patients with obstructive sleep apnea and controls. Otolaryngol Head Neck Surg 2010;142:218-224.

89. Eikermann M, Malhotra A, Fassbender P, Zaremba S, Jordan AS, Gautam S, White DP, Chamberlin NL. Differential effects of isoflurane and propofol on upper airway dilator muscle activity and breathing. Anesthesiology 2008;108:897-906.

90. Wellman A, Jordan A, Malhotra A, Fogel R, Katz E, Schory K, Edwards J, White D. Ventilatory control and airway anatomy in obstructive sleep apnea. Am J Respir Crit Care Med 2004;170:1225-1232.

91. Sforza E, Petiau C, Weiss T, Thibault A, Krieger J. Pharyngeal critical pressure in patients with obstructive sleep apnea syndrome - clinical implications. Am J Respir Crit Care Med 1999;159:149-157.

92. Santaolalla Montoya F, Iriondo Bedialauneta JR, Aguirre Larracoechea U, Martinez Ibargüen A, Sanchez Del Rey A, Sanchez Fernandez JM. The predictive value of clinical and epidemiological parameters in the identification of patients with obstructive sleep apnoea (OSA): A clinical prediction algorithm in the evaluation of OSA. Eur Arch Otorhinolaryngol 2007;264:637-643.

93. Hoffstein V, Szalai JP. Predictive value of clinical features in diagnosing obstructive sleep apnea. Sleep 1993;16:118-122.

94. Johal A, Patel SI, Battagel JM. The relationship between craniofacial anatomy and obstructive sleep apnoea: A case-controlled study. J Sleep Res 2007;16:319-326. 
95. Battagel JM, Johal A, Kotecha B. A cephalometric comparison of subjects with snoring and obstructive sleep apnoea. Eur J Orthod 2000;22:353-365.

96. Hui DS, Ko FW, Chu AS, Fok JP, Chan MC, Li TS, Choy DK, Lai CK, Ahuja A, Ching AS. Cephalometric assessment of craniofacial morphology in chinese patients with obstructive sleep apnoea. Respir M ed 2003;97:640-646. 